


\section{RECYCLING MATERIALS \\ BASED ON ENVIRONMENTALLY \\ FRIENDLY TECHNIQUES}

Edited by Dimitris S. Achilias 
Recycling Materials Based on Environmentally Friendly Techniques

http://dx.doi.org/10.5772/58503

Edited by Dimitris S. Achilias

\section{Contributors}

Mahsa Sayaf, Azemat Miri, Gity Mir Mohamad Sadeghi, Kazuyuki Hattori, Dimitris S Achilias, Jeffrey Morrell, Toshitaka Funazukuri

\section{(c) The Editor(s) and the Author(s) 2015}

The moral rights of the and the author(s) have been asserted.

All rights to the book as a whole are reserved by INTECH. The book as a whole (compilation) cannot be reproduced, distributed or used for commercial or non-commercial purposes without INTECH's written permission.

Enquiries concerning the use of the book should be directed to INTECH rights and permissions department (permissions@intechopen.com).

Violations are liable to prosecution under the governing Copyright Law.

\section{(c)) BY}

Individual chapters of this publication are distributed under the terms of the Creative Commons Attribution 3.0 Unported License which permits commercial use, distribution and reproduction of the individual chapters, provided the original author(s) and source publication are appropriately acknowledged. If so indicated, certain images may not be included under the Creative Commons license. In such cases users will need to obtain permission from the license holder to reproduce the material. More details and guidelines concerning content reuse and adaptation can be foundat http://www.intechopen.com/copyright-policy.html.

\section{Notice}

Statements and opinions expressed in the chapters are these of the individual contributors and not necessarily those of the editors or publisher. No responsibility is accepted for the accuracy of information contained in the published chapters. The publisher assumes no responsibility for any damage or injury to persons or property arising out of the use of any materials, instructions, methods or ideas contained in the book.

First published in Croatia, 2015 by INTECH d.o.o.

eBook (PDF) Published by IN TECH d.o.o.

Place and year of publication of eBook (PDF): Rijeka, 2019.

IntechOpen is the global imprint of IN TECH d.o.o.

Printed in Croatia

Legal deposit, Croatia: National and University Library in Zagreb

Additional hard and PDF copies can be obtained from orders@intechopen.com

Recycling Materials Based on Environmentally Friendly Techniques

Edited by Dimitris S. Achilias

p. $\mathrm{cm}$.

ISBN 978-953-51-2142-8

eBook (PDF) ISBN 978-953-51-6379-4 


\section{We are IntechOpen, \\ the world's leading publisher of Open Access books}

Built by scientists, for scientists

\section{$3,800+$}

Open access books available

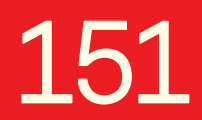

Countries delivered to

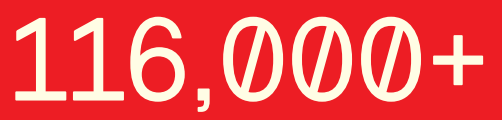

International authors and editors
$120 \mathrm{M}+$

Downloads

Our authors are among the

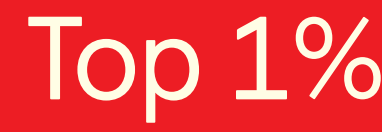

most cited scientists

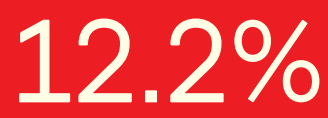

Contributors from top 500 universities

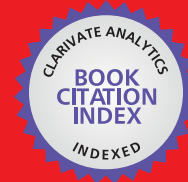

WEB OF SCIENCE ${ }^{\mathrm{TM}}$

Selection of our books indexed in the Book Citation Index in Web of Science ${ }^{\mathrm{TM}}$ Core Collection (BKCI)

Interested in publishing with us?

Contact book.department@intechopen.com

Numbers displayed above are based on latest data collected.

For more information visit www.intechopen.com

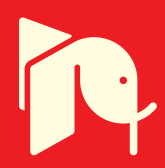





\section{Meet the editor}

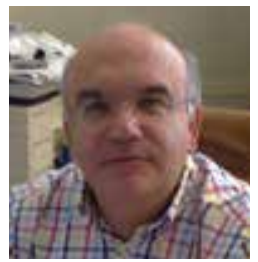

Dimitris S. Achilias occupies the position of Associate Professor in Polymer Chemistry and Technology at the Department of Chemistry, Aristotle University of Thessaloniki, Greece. He obtained his diploma in Chemical Engineering in 1985 and his Ph.D. in 1991 from AUTh. He has published 105 papers in international refereed scientific journals and has received nearly 2800 citations with h-index 29 . He has presented almost 130 research works in conferences and written 7 chapters in international books. Dr. Achilias edited the book Materials Recycling, InTech, with 98000 all chapters downloads. He has supervised 47 graduate, 27 post-graduate and 5 doctorate theses. He has participated in a number of Greek and European research projects. Dr. Achilias research interests include the chemical recycling of polymers and modelling of polymerization kinetics. 



\section{Contents}

Preface XI

Chapter 1 Recycling of Expanded Polystyrene Using Natural Solvents 1 Kazuyuki Hattori

Chapter 2 Hydrothermal Depolymerization of Polyesters and Polycarbonate in the Presence of Ammonia and Amines 17 Toshitaka Funazukuri

Chapter 3 Chemical and Thermochemical Recycling of Polymers from Waste Electrical and Electronic Equipment 37

Dimitris S. Achilias and Eleni V. Antonakou

Chapter 4 Compostable Polymers and Nanocomposites - A Big Chance for Planet Earth 63

Gity Mir Mohamad Sadeghi and Sayaf Mahsa

Chapter 5 Potential for Introduction of Preservative Treated Wood in Wood Waste Recycling Streams and its Prevention 105 Jeffrey J. Morrell 



\section{Preface}

The continuous improvement of the standards of living has lead to a dramatic increase in the production and consumption of materials. Since the life duration of a number of wastes is very small (roughly $40 \%$ have duration of life smaller than one month), there is a vast waste stream that reaches each year to the final recipients creating a serious environmental problem. Presently, most common practice of handling such waste streams is to incinerate them with energy recovery or to use them for land-filling. Disposing of the waste to landfill is becoming undesirable due to legislation pressures, rising costs and the poor biodegradability of commonly used materials. Reducing the amount of solid wastes in landfills is one of the main targets in nowadays wastes' treatment. Therefore, recycling seems to be the best solution. The major driving force in today's recycling project is not only to re-use the materials but also to produce secondary value-added products, reducing the consumption of natural resources and the amount of energy needed, while lowering $\mathrm{CO} 2$ emissions in the environment. One additional goal in a globally successful recycling project is to use environmentally friendly procedures (such as those decreasing energy consumption, or using naturally occurring materials) in order not to surcharge the environment. To this direction, there is a great need in finding of smart recycling techniques which should, as is possible, to be environmentally friendly.

As it is well-known, the word re-cycling comes from the Greek word ' $\kappa v ́ \kappa \lambda o \varsigma^{\prime}$ ' meaning cycle and is usually used to denote the involvement of materials in a continuous cycle from 'cradle' (resources) to 'grave' (disposal of waste) and back to 'cradle' (re-formation of resources).

The intention of this book is to present some recent methods for the recycling of several materials, including plastics and wood, as well as to show the importance of composting of polymers. It targets professionals, recycling companies, researchers, academics and graduate students in the fields of waste management and polymer recycling in addition to chemical engineering, mechanical engineering, chemistry and physics.

This book comprises 5 chapters that have been prepared from the contribution of 7 co-authors from Japan, Greece, I.R. Iran and USA. In the first three chapters, different novel polymer recycling techniques are presented using environmentally friendly procedures, in the forth, the importance of compostable polymers and nanocomposites is discussed, whereas in the fifth, the potential for introduction of preservative treated wood in wood waste recycling streams is illustrated. A brief description of each chapter follows.

Chapter 1. Recycling of Expanded Polystyrene Using Natural Solvents

In this chapter, the selective dissolution of expanded polystyrene (EPS) is illustrated as a way of its recycling. Several naturally-occurring solvents, including terpenes and terpenoids are examined. The solubility of EPS in these solvents is presented together with the dissolving power of these monoterpenes. Certain criteria are set to define whether a specific terpene is suitable to be used as a solvent for PS recycling. PS is finally recovered using steam distillation. Thus, harmful organic solvents are omitted from the recycling procedure. 
Chapter 2. Hydrothermal Depolymerization of Polyesters and Polycarbonate in the Presence of Ammonia and Amines

In this chapter, methods for the chemical recycling of poly(ethylene terephthalate) PET, poly(ethylene naphthalate) PEN and polycarbonate, PC using hydrothermal conversion of the polymers in aqueous ammonia and amine solutions are reviewed. This process is attractive due to highly selective conversion to monomers, easy separation of monomers in resultant aqueous solutions, and relatively mild reaction conditions, i.e., temperature lower than the melting point of polymer and low concentration of ammonia or amines.

Chapter 3. Chemical and Thermo-chemical Recycling of Polymers from Waste Electrical and Electronic Equipment

This chapter provides a critical review on the chemical and thermo-chemical methods proposed and/or applied, during mainly the last decade, on the recycling of polymers from waste electrical and electronic equipment (WEEE). Recycling methods such as the dissolution-reprecipitation and pyrolysis are presented. Special emphasis is given in three different polymers, i.e. polycarbonate (PC), high impact polystyrene (HIPS) and Acrylonitrile-Butadiene-Styrene (ABS) which are commonly found in WEEE. The state-of-the-art of the chemical and thermo-chemical recycling methods of these polymers is illustrated, emphasizing to environmentally friendly techniques, such the use of microwave irradiation instead of conventional heating.

Chapter 4. Compostable Polymers and Nanocomposites - A big chance for the Planet Earth.

In this chapter, the significance of composting composites and nanocomposites based on bio-based polymers used in various applications to reduce the amount of solid waste in landfills is presented. Furthermore, composting methods to produce compostable materials and international standard test methods for evaluation of the above mentioned materials are illustrated.

Chapter 5. Potential for Introduction of Preservative Treated Wood in Wood Waste Recycling Streams and its Prevention

Recycling of woody debris promises to remove a substantial volume from the waste stream, thereby prolonging the useful life of the limited landfill capacity. One potential issue with these recycling programs is the potential for contamination of the recycling stream with treated wood. Treated wood is supposed to be either reused in a similar application or, if that cannot be done, disposed of in a municipal solid waste facility. However, it can sometimes be difficult to distinguish treated wood from other materials and varying amounts of treated wood are entering the waste stream. This chapter outlines methods for assessing volumes of treated wood in the recycling stream, examines the potential risks of this material and then identifies possible methods for excluding these materials.

I want to express my sincere thanks to all the contributors who provided their expertise and enthusiasm to this project and InTech for making this work possible. I would like also to thank my wife Maria and the sons Savvas, Diamantis and Yiannis for their patience and the time deprived them during the preparation of my chapter and the book editing. I dedicate this book to them.

Dimitris S. Achilias

Associate Professor

Department of Chemistry

Aristotle University of Thessaloniki 
Chapter 1

\title{
Recycling of Expanded Polystyrene Using Natural Solvents
}

\author{
Kazuyuki Hattori \\ Additional information is available at the end of the chapter \\ http://dx.doi.org/10.5772/59156
}

\section{Introduction}

The recycling of natural resources and waste products is the most important process in the concept of green chemistry. Recently, the utilization of biomass has been a significant topic, whereas the recycling of petroleum resources must receive similar attention. Expanded polystyrene (EPS) is widely used in packing and building materials and for electrical and thermal insulation owing to the light weight and low thermal and electrical conductivities. The porosity of EPS is very high such as $98 \%$ of the apparent volume is porous. At present, over 2 million tons of EPS are produced in the world per year [1], and the rate of the material recycling is relatively high among commodity plastics [2].

For the recycling of EPS, melting [2,3] or solvent treatment $[4,5]$ is required to reduce the volume and to be reshaped subsequently, as illustrated in Figure 1. The melting process is simple, but brings about some chemical degradation and cannot avoid debasing the quality of the original polystyrene (PS), so the solvent treatment is, in many respects, more desirable for an effective recycling system. Although there are various solvents for PS, for example, hydrocarbons, alkyl halides, aromatics, esters, and ketones, petroleum-based solvents are not favorable to the global environment. Limonene, which is a component of citrous oils, was derived from the above concept, and it is a pioneer of natural solvents for EPS [6-8]. Lately, the recycling of EPS using limonene has been realized in practical use with a semi-industrial scale, however, peel corresponding to approximately 1,000 oranges is necessary to extract 100 $\mathrm{mL}$ of limonene [9]. Except for limonene, there is few report on the natural solvents for EPS. This chapter is mainly focused on the dissolution of PS in naturally abundant monoterpenes including limonene, particularly, the relationship between the chemical structure and dissolving power for PS. In addition, the properties of the PS recycled by using these solvents are also described, compared with those of the original PS. 


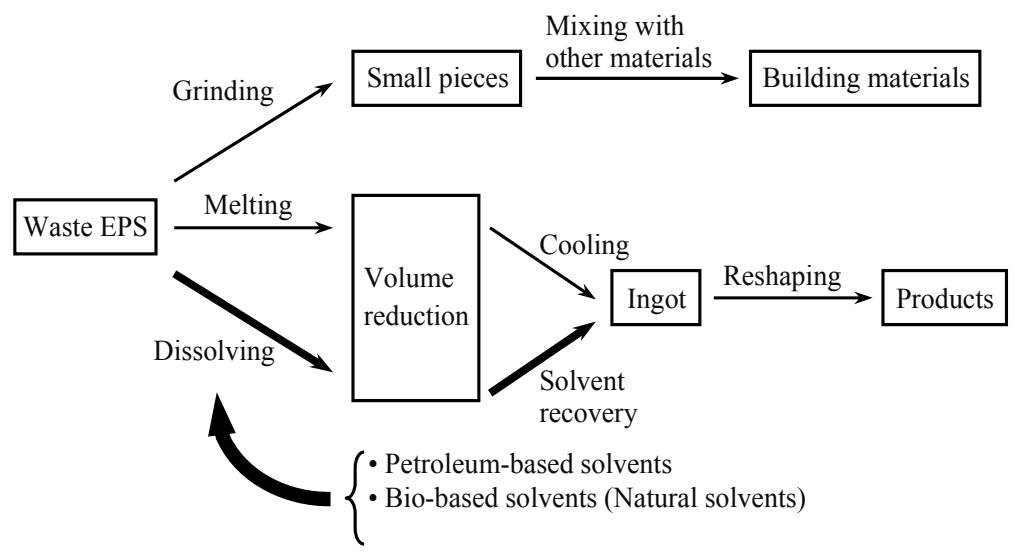

Figure 1. Material recycling system of EPS.

\section{Naturally occurring monoterpenes and their dissolving power for PS}

Hattori et al. [10] paid attention to the fact that, as limonene is one of terpenes, other monoterpenes and terpenoids are expected to dissolve PS as well. Terpene is a biomolecular hydrocarbon whose structural backbone possesses an isoprene unit. Corresponding to the number of an isoprene unit, they are called monoterpene (C10), sesquiterpene (C15), diterpene (C20), sesterterpene (C25), and so forth. Many monoterpenes are liquid at room temperature and main components of essential oils. In particular, the leaf oils of Abies sachalinensis and Eucalyptus species, in which the growth is comparatively fast, may be suitable biomass because they are not utilized effectively at present and contain many monoterpenes. Table 1 summarizes some liquid monoterpenes and terpenoids selected from the viewpoint of content rate in their leaf oils [11-13]. Both are significantly different. $d$-Limonene is much contained in Abies sachalinensis, but a little in Eucalyptus. The largest amount of bornyl acetate in Abies sachalinensis is not contained in Eucalyptus. In contrast, 1,8-cineole occurs abundantly in Eucalyptus, whereas does not occur at all in Abies sachalinensis.

First, some structural isomers and analogues of $d$-limonene, as shown in Figure 2, were studied on the dissolving power for PS [10]. The experimental method is as follows. A known weight of a small piece of commercial PS film with a number-average molecular weight $\left(\bar{M}_{n}\right)$ of $1.2 \times$ $10^{5}$ was put in $0.5 \mathrm{~mL}$ of each terpene at $50{ }^{\circ} \mathrm{C}$, and the behavior of PS was observed by a polarizing microscopy under crossed nicols. The dissolution was judged from the disappearance of birefringence of the PS piece. The additional piece, if necessary, was put after complete dissolution was achieved. In Table 2, the dissolving power of the terpenes is listed as the weight of the PS dissolved per $100 \mathrm{~g}$ of each terpene. All these terpenes are capable of dissolving more than $120 \mathrm{~g}$ of PS per $100 \mathrm{~g}$ of them. The values are greater than that of toluene, which is one of the petroleum-based solvents for PS. These six terpenes except for $p$-cymene are structural isomers with different locations of a $\mathrm{C}=\mathrm{C}$ bond, so they would have similar dissolving power 
Terpene and terpenoid

Content rate $(\%)^{\mathrm{a}}$

\begin{tabular}{lcc}
\cline { 2 - 3 } Terpene and terpenoid & Abies sachalinensis & Eucalyptus \\
\hline Bornyl acetate & 27.0 & 0 \\
\hline$d$-Limonene & 22.6 & 3.1 \\
\hline$\beta$-Phellandrene & 15.6 & 0 \\
\hline$\alpha$-Pinene & 13.3 & 37.9 \\
\hline$\beta$-Pinene & 9.7 & 0.5 \\
\hline Myrcene & 1.9 & 0.4 \\
\hline$p$-Cymene & 0.4 & 2.9 \\
\hline 1,8 -Cineole & 0 & 29.9 \\
\hline
\end{tabular}

a) The percentage in $100 \mathrm{~mL}$ of the leaf oil measured by GC-MS [11-13].

Table 1. Components in the leaf oils of Abies sachalinensis and Eucalyptus.

one another. This result led to a relationship between the structure and dissolving power that the position of a $\mathrm{C}=\mathrm{C}$ bond does not affect the dissolving power greatly. The solubility of PS in $p$-cymene is remarkably higher than that in other terpenes, because $p$-cymene is, as described later, an aromatics that has a similar chemical structure to PS.

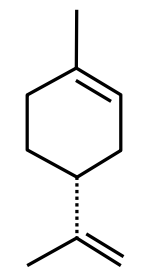

$d$-Limonene

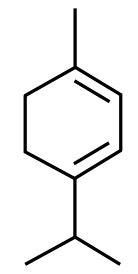

$\alpha$-Terpinene

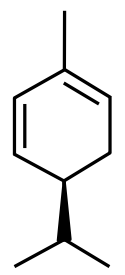

$\alpha$-Phellandrene<smiles>CC1=CCC(C(C)C)=CC1</smiles>

$\gamma$-Terpinene<smiles>C=C1C=C[C@@H](C(C)C)CC1</smiles>

$\beta$-Phellandrene<smiles>Cc1ccc(C(C)C)cc1</smiles>

p-Cymene

Figure 2. Structure of $d$-limonene and its some isomers and analogues. 


\begin{tabular}{lc}
\hline Solvent & ${\text { Solubility }(\mathrm{g} / \mathbf{1 0 0} \mathbf{g} \cdot \mathbf{\text { solvent}})^{\mathrm{a}}}^{\mathrm{a}}$ \\
\hline$\alpha$-Terpinene & 130 \\
\hline$\gamma$-Terpinene & 131 \\
\hline$d$-Limonene & 127 \\
\hline Terpinolene & 125 \\
\hline$\alpha$-Phellandrene & 125 \\
\hline$\beta$-Phellandrene & 122 \\
\hline$p$-Cymene & 212 \\
\hline Toluene & 117 \\
\hline
\end{tabular}
a) Cited from reference [10].
b) One of the petroleum-based solvents was used for comparison.

Table 2. Solubility of PS in several monoterpenes at $50{ }^{\circ} \mathrm{C}$.

As shown in Table 1, there is a considerable amount of 1,8-cineole in Eucalyptus leaf oil. Therefore, the next investigation of the dissolving power of natural solvents for PS went to 1,8cineole and some related oxygen-containing terpenoids [10,14]. Figure 3 and Table 3 represent the chemical structure of the terpenoids and their dissolving power for PS, respectively.

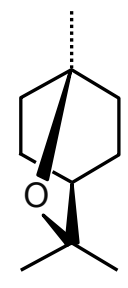

1,8-Cineole

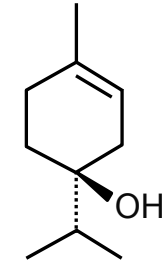

Terpinene-4-ol<smiles>CC1=CC[C@H](C(C)(C)O)CC1</smiles>

$\alpha$-Terpineol<smiles>Cc1ccc(C(C)C)cc1O</smiles>

2-p-Cymenol<smiles>CC(C)=CCCC(C)=CCOC(C)C</smiles>

Geranyl acetate

Figure 3. Structure of 1,8-cineole and some oxygen-containing terpenoids.

Generally, a non-polar molecule such as PS does not interact with a polar solvent. Terpinene-4ol and $\alpha$-terpineol have such a high polar moiety as a hydroxyl group, hence, the solubilities of PS in them (ca. $40 \mathrm{~g} / 100 \mathrm{~g}$ - solvent) are lower than those in the corresponding terpinene and terpinolene without a hydroxyl group (ca. $130 \mathrm{~g} / 100 \mathrm{~g}$ - solvent, Table 2). The oxygen of 1,8cineole is adopted to not a hydroxyl group, but an ether group. It is suggested that the higher solubility of PS in 1,8-cineole (55 g/ $100 \mathrm{~g}$ solvent) than those in terpinene-4-ol and $\alpha$-terpineol is ascribed to the lower polarity of an ether group compared to a hydroxyl group. The high 


\begin{tabular}{lc}
\hline Solvent & ${\text { Solubility }\left(\mathrm{g} / \mathbf{1 0 0} \mathrm{g} \cdot \text { solvent }^{\mathrm{a}}\right.}^{\mathrm{1}, 8 \text {-Cineole }}$ \\
\hline Terpinene-4-ol & 55 \\
\hline$\alpha$-Terpineol & 39 \\
\hline 2-p-Cymenol & 41 \\
\hline Geranyl acetate & 105 \\
\hline
\end{tabular}

a) Cited from refereces [10] and [14].

Table 3. Solubility of PS in several oxygen-containing terpenoids at $50^{\circ} \mathrm{C}$.

dissolving power of 2-p-cymenol (105 g/ $100 \mathrm{~g}$-solvent), in spite of possessing a hydroxyl group, may be due to the presence of an aromatic ring as mentioned above.

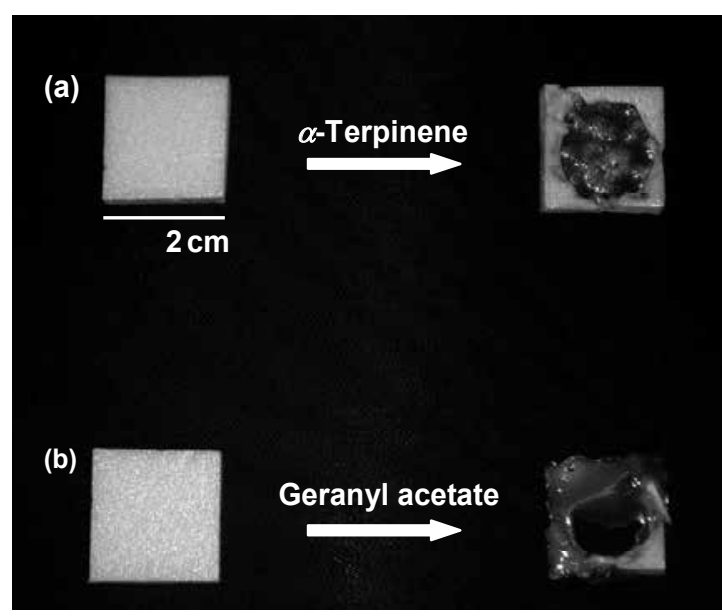

Figure 4. EPS shrunk by $\alpha$-terpinene (a) and geranyl acetate (b) [10].

Geranyl acetate shows highest dissolving power of $174 \mathrm{~g}$ per $100 \mathrm{~g}$ of it. Figure 4 demonstrates the appearance of dissolving EPS by $\alpha$-terpinene (a) and geranyl acetate (b) [10]. Geranyl acetate is apparently more powerful than $\alpha$-terpinene concerning the ability to shrink EPS. It seems that the high dissolving power of geranyl acetate is based on its flexible linear structure, which is more accessible to the inside of bulk PS compared with the cyclic terpenes in Table 2. Therefore, the dissolving power of several acyclic monoterpenes was studied for the confirmation of that. Geranyl acetate, citronellyl acetate, and myrcene are found in the essential oils of Picea genus and others [11], and citral and citronellal are components of citrus oils [15]. As shown in Table 4, geranyl acetone, geranyl formate, and citronellyl acetate have similar dissolving power as high as geranyl acetate has. 


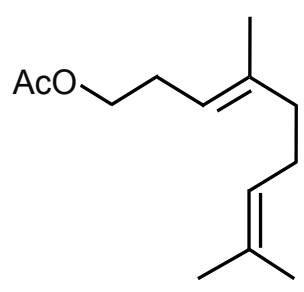

Geranyl acetone<smiles>CC(C)=CCC/C(C)=C/C=O</smiles>

Citral<smiles>CC(C)=CCC/C(C)=C/COC=O</smiles>

Geranyl formate<smiles>CC(C)=CCCC(C)CC=O</smiles>

$d l$-Citronellal<smiles>CC(=O)OCCC(C)CCC=C(C)C</smiles>

$d l$-Citronellyl acetate<smiles>C=CC(=C)CCC=C(C)C</smiles>

Myrcene

Figure 5. Structure of several acyclic terpenes and terpenoids.

\begin{tabular}{|c|c|}
\hline Solvent & Solubility $(\mathrm{g} / 100 \mathrm{~g} \cdot \text { solvent })^{\mathrm{a}}$ \\
\hline Geranyl acetone & 160 \\
\hline Geranyl formate & 175 \\
\hline Citronellyl acetate & 156 \\
\hline Citral & 109 \\
\hline Citronellal & 125 \\
\hline Myrcene & 101 \\
\hline
\end{tabular}

a) Partly cited from reference [10].

Table 4. Solubility of PS in several acyclic terpenoids at $50{ }^{\circ} \mathrm{C}$.

These values are higher than those of typical cyclic monoterpenes in Table 2 . The relatively low dissolving power of citral and citronellal compared with acyclic esters would be due to the occurrence of the terminal aldehyde group of a polar moiety that causes the reduction of accessibility to the hydrophobic matrix of PS. Unexpectedly, myrcene does not show very high dissolving power of $101 \mathrm{~g}$ per $100 \mathrm{~g}$ of it although it is a non-polar hydrocarbon. The structure of the terminal conjugated diene is probably not so flexible as to penetrate it into PS matrix. 
These results indicate clearly that flexible linear terpenes have higher dissolving power for PS than cyclic terpenes have.

A series of these systematic experimental results causes one fundamental question: how much dissolving power do the essential oils themselves have? Abies oil can be easily prepared by refluxing for $6 \mathrm{~h}$ in water and subsequent steam distillation of the leaves of Abies sachalinensis [14]. Eucalyptus oil is commercially available from Tokyo Chemical Industry, Inc., Japan. The solubilities of PS in the Abies and Eucalyptus oils were $85 \mathrm{~g}$ and $96 \mathrm{~g}$ per $100 \mathrm{~g}$ of them [14], respectively, as shown in Table 5. According to the reports of Yatagai et al. [11,12], Abies leaf oil contains $27 \%$ of bornyl acetate and $23 \%$ of pinenes whose structure and dissolving power are as follows.

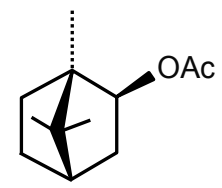

Bornyl acetate

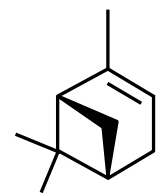

$\alpha$-Pinene

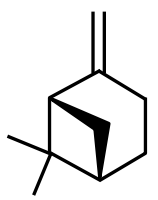

$\beta$-Pinene

Figure 6. Structure of bornyl acetate and pinenes.

Solvent

Abies leaf oil

Eucalyptus oil

Bornyl acetate

$\alpha$-Pinene

$\beta$-Pinene

a) Partly cited from reference [10].
Solubility $\left(\mathrm{g} / 100 \mathrm{~g} \cdot\right.$ solvent$^{\mathrm{a}}$

85

96

67

44

48

Table 5. Solubility of PS in essential oils and several bicyclic terpenes at $50^{\circ} \mathrm{C}$.

The solubilities of PS in bornyl acetate and both pinenes are less than half of those in limonene isomers. Bornyl acetate and the pinenes have a bulky bicyclic structure, which is likely to be disadvantageous to penetrate into PS. As a result, the Abies leaf oil containing approximately $50 \%$ of these three terpenes in total does not have so high dissolving power for PS. Since Eucalyptus oil also contains such bicyclic terpenes as 30\% of 1,8-cineole and 38\% of $\alpha$-pinene, it is not a very strong solvent for PS itself. However, both oils still have dissolving power of nearly $100 \mathrm{~g}$ for PS per $100 \mathrm{~g}$ of them, so that they will be a favorable solvent for PS recycling. 


\section{Relationship between solubility parameter and dissolving power of monoterpenes}

As a general standard for the judgment that a given solute is soluble or insoluble in a solvent, there is a method to compare the "solubility parameter" of the solute with the solvent. Hildebrand first devised the theory of this concept [16], and afterward Hansen [17], Barton [18], and Hoftyzer and Krevelen [19,20] et al. have developed this theory. The solubility parameter $(\delta)$ of a substance is defined as:

$$
\delta=\sqrt{\frac{E_{\mathrm{coh}}}{V}}
$$

where $E_{\text {coh }}$ and $V$ are the cohesive energy (=vaporization energy) and molar volume of the substance, respectively. The $V$ is calculated from the molecular weight and density of the substance. The $E_{\text {coh }}$ can be obtained experimentally for a volatile substance, but is usually derived from theoretical approach. Hansen [17] considered that $E_{\mathrm{coh}}$ is consisting of three types of energies derived from the following interaction forces:

$$
E_{\mathrm{coh}}=E_{\mathrm{d}}+E_{\mathrm{p}}+E_{\mathrm{h}}
$$

where $E_{\mathrm{d}}, E_{\mathrm{p}}$, and $E_{\mathrm{h}}$ are the energy of dispersion forces, polar forces, and hydrogen bonding, respectively. Then, Equation (1) is modified using the corresponding solubility parameter components, $\delta_{\mathrm{d}}, \delta_{\mathrm{p}}$, and $\delta_{\mathrm{h}}$, to each force as follows:

$$
\delta=\sqrt{\delta_{\mathrm{d}}^{2}+\delta_{\mathrm{p}}^{2}+\delta_{\mathrm{h}}^{2}}
$$

Taking account of these intermolecular interactions, Hoftyzer and Krevelen [19] expressed their components such as:

$$
\delta_{\mathrm{d}}=\frac{\sum F_{\mathrm{d}_{i}}}{V}, \delta_{\mathrm{p}}=\frac{\sqrt{\sum F_{\mathrm{p}_{i}}^{2}}}{V} \text {, and } \delta_{\mathrm{h}}=\sqrt{\frac{\sum E_{\mathrm{h}_{i}}}{V}}
$$

where $F_{d_{i}^{\prime}} F_{p_{i}}$ and $E_{h_{i}}$ are the parameter of dispersion forces, polar forces, and hydrogen bonding, respectively, reflecting the contribution of structural groups of the substance. Among 
the group contribution parameters established by Hoftyzer and Krevelen [20], those related to terpenes are shown in Table 6.

\begin{tabular}{|c|c|c|c|}
\hline Structural group & $F_{\mathrm{d}_{\mathrm{i}}}\left(\mathrm{J}^{1 / 2} \mathrm{~m}^{3 / 2} \mathrm{~mol}^{-1}\right)^{\mathrm{a}}$ & $F_{\mathrm{p}_{\mathrm{i}}}\left(\mathrm{J}^{1 / 2} \mathrm{~m}^{3 / 2} \mathrm{~mol}^{-1}\right)^{\mathrm{a}}$ & $E_{\mathrm{h}_{\mathrm{i}}}\left(\mathrm{J} \mathrm{mol}^{-1}\right)^{\mathrm{a}}$ \\
\hline$-\mathrm{CH}_{3}$ & 0.42 & 0 & 0 \\
\hline$-\mathrm{CH}_{2}-$ & 0.27 & 0 & 0 \\
\hline$-{ }_{\mid}^{-\mathrm{CH}-}$ & 0.08 & 0 & 0 \\
\hline$-\mathrm{C}^{-}$ & -0.07 & 0 & 0 \\
\hline$=\mathrm{CH}_{2}$ & 0.40 & 0 & 0 \\
\hline$=\mathrm{CH}^{-}$ & 0.20 & 0 & 0 \\
\hline$=\mathrm{C}-$ & 0.07 & 0 & 0 \\
\hline
\end{tabular}

a) Cited from reference [20].

b) If two identical polar groups are present in a symmetrical position, the value of $\delta_{\mathrm{p}}$ must be multiplied.

Table 6. Group contribution parameters related to terpenes.

\begin{tabular}{|c|c|c|c|}
\hline Structural group & $F_{\mathrm{d}_{\mathrm{i}}}\left(\mathrm{J}^{1 / 2} \mathrm{~m}^{3 / 2} \mathrm{~mol}^{-1}\right)$ & $F_{\mathrm{p}_{\mathrm{i}}}\left(\mathrm{J}^{1 / 2} \mathrm{~m}^{3 / 2} \mathrm{~mol}^{-1}\right)$ & $E_{\mathrm{h}_{\mathrm{i}}}\left(\mathrm{J} \mathrm{mol}^{-1}\right)$ \\
\hline$-\mathrm{CH}_{3} \times 4$ & 1.68 & 0 & 0 \\
\hline$-\mathrm{CH}_{2}-\times 3$ & 0.81 & 0 & 0 \\
\hline$=\mathrm{CH}-\times 2$ & 0.40 & 0 & 0 \\
\hline$=\mathrm{C}-\times 2$ & 0.14 & 0 & 0 \\
\hline$-\mathrm{COO}-$ & 0.39 & 0.49 & 7000 \\
\hline Sum & 3.42 & 0.49 & 7000 \\
\hline
\end{tabular}

Table 7. Group contribution parameters of geranyl acetate.

According to Table 6, the group contribution parameters of geranyl acetate are calculated as shown in Table 7. Since the molecular weight $(M W)$ and density $(d)$ of geranyl acetate are 196.29 $\mathrm{g} / \mathrm{mol}$ and $0.909 \mathrm{~g} / \mathrm{cm}^{3}$, respectively, the molar volume $V$ is estimated to $2.159 \times 10^{-4} \mathrm{~m}^{3} / \mathrm{mol}$. Therefore, the solubility parameter components are: 


$$
\begin{gathered}
\delta_{\mathrm{d}}=\frac{\sum F_{\mathrm{d}_{i}}}{V}=\frac{3.42 \mathrm{~J}^{1 / 2} \cdot \mathrm{m}^{3 / 2} \cdot \mathrm{mol}^{-1}}{2.159 \times 10^{-4} \mathrm{~m}^{3} \cdot \mathrm{mol}^{-1}}=15.8 \mathrm{MPa}^{1 / 2}, \\
\delta_{\mathrm{p}}=\frac{\sqrt{\sum F_{\mathrm{p}_{i}}^{2}}}{V}=\frac{0.490 \mathrm{~J}^{1 / 2} \cdot \mathrm{m}^{3 / 2} \cdot \mathrm{mol}^{-1}}{2.159 \times 10^{-4} \mathrm{~m}^{3} \cdot \mathrm{mol}^{-1}}=2.27 \mathrm{MPa}^{1 / 2}, \text { and } \\
\delta_{\mathrm{h}}=\sqrt{\frac{\sum E_{\mathrm{h}_{i}}}{V}}=\sqrt{\frac{7000 \mathrm{~J} \cdot \mathrm{mol}^{-1}}{2.159 \times 10^{-4} \mathrm{~m}^{3} \cdot \mathrm{mol}^{-1}}}=5.69 \mathrm{MPa}^{1 / 2} .
\end{gathered}
$$

From these components, the solubility parameter of geranyl acetate is found:

$$
\delta=\sqrt{\delta_{\mathrm{d}}^{2}+\delta_{\mathrm{p}}^{2}+\delta_{\mathrm{h}}^{2}}=16.9 \mathrm{MPa}^{1 / 2} .
$$

The calculated $\delta$ values of all the terpenes from Table 1 to Table 5 are shown, together with the MW and $d$, in Table 8 . The $\delta$ of PS is calculated to be $14.5 \mathrm{MPa}^{1 / 2}$ from the structure of a repeating unit. Referring to Table 8 , the $\delta$ values of seven terpenes from $\alpha$-terpinene to $p$ cymene are very close (14.7-15.7 $\left.\mathrm{MPa}^{1 / 2}\right)$, especially the $\delta$ of $p$-cymene is almost the same (14.6 $\mathrm{MPa}^{1 / 2}$ ), to that of PS. This fact is in good agreement with the experimental results in Table 2 that these terpenes, particularly $p$-cymene, dissolve a lot of PS. Although 1,8-cineole and four terpenes from the lower row in Table 8 have similar $\delta$ values to that of PS, their dissolving powers for PS are low. The reason for such low dissolving powers might be attributable to a steric effect as mentioned above. Hence, it is concluded that a solubility parameter is not universal because it cannot reflect the steric effect of a solvent molecule upon the $\delta$. According to the same reason, the $\delta$ value cannot explain the high dissolving powers of three acyclic terpenoids, geranyl acetate, geranyl formate, and citronellyl acetate. The terpenoids of the alcohols and aldehydes have a reasonable relationship between the $\delta$ value and dissolving power.

\begin{tabular}{llll}
\hline Terpenes & $M W$ & $d\left(\mathrm{~g} / \mathrm{cm}^{3}\right)$ & $\delta\left(\mathbf{M P a}^{1 / 2}\right)^{a}$ \\
\hline$\alpha$-Terpinene & 136.24 & 0.838 & 14.9 \\
\hline$\gamma$-Terpinene & 136.24 & 0.853 & 15.2 \\
\hline$d$-Limonene & 136.24 & 0.840 & 15.2 \\
\hline Terpinolene & 136.24 & 0.863 & 15.7 \\
\hline$\alpha$-Phellandrene & 136.24 & 0.846 & 14.7 \\
\hline$\beta$-Phellandrene & 136.24 & 0.850 & 15.0 \\
\hline$p$-Cymene & 134.22 & 0.857 & 14.6 \\
\hline
\end{tabular}




\begin{tabular}{llll}
\hline Terpenes & $M W$ & $d\left(\mathrm{~g} / \mathrm{cm}^{3}\right)$ & $\delta\left(\mathrm{MPa}^{1 / 2}\right)^{a}$ \\
\hline 1,8 -Cineole & 154.25 & 0.923 & 15.0 \\
\hline Terpinene-4-ol & 154.25 & 0.927 & 19.1 \\
\hline$\alpha$-Terpineol & 154.25 & 0.934 & 19.2 \\
\hline - $p$-Cymenol & 150.22 & 0.976 & 19.4 \\
\hline Geranyl acetate & 196.29 & 0.909 & 16.9 \\
\hline Geranyl acetone & 194.32 & 0.873 & 16.8 \\
\hline Geranyl formate & 182.29 & 0.908 & 16.9 \\
\hline Citronellyl acetate & 198.31 & 0.890 & 17.8 \\
\hline Citral & 152.24 & 0.890 & 17.4 \\
\hline Citronellal & 154.25 & 0.855 & 15.9 \\
\hline Myrcene & 136.24 & 0.794 & 15.8 \\
\hline Bornyl acetate & 196.29 & 0.980 & 13.6 \\
\hline$\alpha$-Pinene & 136.24 & 0.859 & 14.2 \\
\hline$\beta$-Pinene & 136.24 & 0.874 & 174 \\
\hline
\end{tabular}

a) Partly cited from references [10] and [14].

Table 8. Solubility parameter of some terpenes calculated by the Hoftyzer and Krevelen method.

\section{Dissolution rate of PS in monoterpenes}

When the recycling efficiency of PS is being considered, not only dissolving power but also dissolution rate is one of the important factors on evaluating the performance of a solvent.

\begin{tabular}{lcccccc}
\hline \multirow{2}{*}{ Terpenes } & \multicolumn{5}{c}{ Dissolution Time ${ }^{\mathbf{a}}(\mathbf{s e c})$} & $E_{a}\left(\mathbf{k J} / \mathbf{m o l}^{b}\right.$ \\
\cline { 2 - 6 } & $\mathbf{3 0}{ }^{\circ} \mathbf{C}$ & $\mathbf{4 0}{ }^{\circ} \mathbf{C}$ & $\mathbf{5 0}{ }^{\circ} \mathbf{C}$ & $\mathbf{6 0}{ }^{\circ} \mathbf{C}$ & $\mathbf{7 0}^{\circ} \mathbf{C}$ & 20.3 \\
\hline$\alpha$-Terpinene & 545 & 401 & 334 & 262 & 208 & 19.7 \\
\hline$\gamma$-Terpinene & 496 & 359 & 289 & 240 & 196 & 20.7 \\
\hline$d$-Limonene & 519 & 471 & 375 & 283 & 200 & 16.0 \\
\hline Terpinolene & 525 & 425 & 365 & 301 & 248 & 25.2 \\
\hline$\alpha$-Phellandrene & 390 & 321 & 235 & 166 & 125 & 23.1 \\
\hline$\beta$-Phellandrene & 263 & 191 & 147 & 114 & 90 & 25.1 \\
\hline$p$-Cymene & 215 & 149 & 109 & 85 & 66 & 56.3 \\
\hline 1,8 -Cineole & 4,480 & 1,390 & 626 & 478 & 302 & 25 \\
\hline
\end{tabular}




\begin{tabular}{|c|c|c|c|c|c|c|}
\hline \multirow{2}{*}{ Terpenes } & \multicolumn{5}{|c|}{ Dissolution Time $^{\mathrm{a}}$ (sec) } & \multirow{2}{*}{$E_{a}(\mathrm{~kJ} / \mathrm{mol})^{b}$} \\
\hline & $30^{\circ} \mathrm{C}$ & $40^{\circ} \mathrm{C}$ & $50^{\circ} \mathrm{C}$ & $60^{\circ} \mathrm{C}$ & $70^{\circ} \mathrm{C}$ & \\
\hline Terpinene-4-ol & $-^{c}$ & 4,430 & 1,810 & 950 & 610 & 59.0 \\
\hline$\alpha$-Terpineol & 3,025 & 1,289 & 715 & 418 & 344 & 47.7 \\
\hline 2-p-Cymenol & 11,458 & 3,830 & 1,991 & 829 & 403 & 71.2 \\
\hline Geranyl acetate & 719 & 543 & 493 & 424 & 269 & 19.1 \\
\hline Geranyl acetone & 748 & 505 & 451 & 323 & 211 & 25.7 \\
\hline Geranyl formate & 628 & 527 & 325 & 253 & 152 & 30.7 \\
\hline Citronellyl acetate & 869 & 507 & 411 & 292 & 265 & 25.5 \\
\hline Citral & 1,168 & 712 & 490 & 347 & 230 & 34.3 \\
\hline Citronellal & 597 & 380 & 290 & 231 & 150 & 28.2 \\
\hline Myrcene & 435 & 297 & 200 & 165 & 117 & 27.9 \\
\hline Bornyl acetate & 14,900 & 3,660 & 1,590 & 862 & 558 & 69.8 \\
\hline$\alpha$-Pinene & $-^{c}$ & 1,860 & 852 & 600 & 503 & 38.5 \\
\hline$\beta$-Pinene & 3,213 & 690 & 366 & 242 & 142 & 63.5 \\
\hline
\end{tabular}

a) The average of five times measurements.

b) Partly cited from references [10] and [14].

c) Insoluble.

Table 9. Dissolution time and apparent activation of $\left(E_{\mathrm{a}}\right)$ for the dissolution of PS in the terpenes.

Therefore, the dissolution time of PS in each terpene was measured at several different temperatures, and then the apparent activation energy $\left(E_{\mathrm{a}}\right)$ of dissolution was evaluated $[10,14]$. The experimental results are shown in Table 9 . Here, the dissolution time means a time required for the dissolution of $2.30 \mathrm{mg}$ of a PS disk in $0.5 \mathrm{~mL}$ of a terpene at each temperature. The $E_{\mathrm{a}}$ is estimated from the slope of an Arrhenius plot of the logarithm of dissolution time versus the inverse of dissolution temperature. Limonene and its isomers have similar low $E_{\mathrm{a}}$ of ca. $20-25 \mathrm{~kJ} / \mathrm{mol}$ one another. A group of the subsequent low an $E_{\mathrm{a}}$ of $25-35 \mathrm{~kJ} / \mathrm{mol}$ is the acyclic terpenes except for aldehydes in Figure 5. The dissolution rate of this group is relatively fast. The $E_{\mathrm{a}} \mathrm{s}$ of Abies leaf oil and Eucalyptus oil are 34 and $39 \mathrm{~kJ} / \mathrm{mol}$, respectively. The alcohols of terpinene-4-ol, $\alpha$-terpineol, and 2-p-cymenol have almost $50 \mathrm{~kJ} / \mathrm{mol}$ or higher of $E_{\mathrm{a}}$. The order of $E_{\mathrm{a}}$ agrees with that of dissolving power for PS well. These results on $E_{\mathrm{a}}$ suggest that terpinene-4-ol, 2- $p$-cymenol, bornyl acetate, and $\alpha$-pinene are not suitable for practical use as a solvent for PS recycling due to their long dissolution time even though they dissolve PS. To increase the dissolution rate of PS, Noguchi et al. attempted the addition of ethanol to limonene [6]. Although ethanol is not a solvent for PS, a small amount of ethanol gives the viscosity of the PS solution to lower. This method will be effective when the terpenes have a considerable 
high dissolving power for PS and a high viscosity of the PS solution prevents PS from diffusing in the solution.

\section{Recovery of PS and natural solvents, and physical properties of the recycled PS}

Currently, it entails a high cost to gather natural solvents such as essential oils for the recycling of waste EPS, so that the recovery and reuse of the solvent are required. In addition, the properties and performance of the recycled PS are important. Terpenes and PS can be simply recovered by steam distillation of a solution of PS in terpenes; a typical example is as follows. A $10 \%$ solution of PS in geranyl acetate is subjected to steam distillation to recover $98 \%$ of the geranyl acetate used. The $\bar{M}_{n}$ of the PS recovered slightly decreased from $1.2 \times 10^{5}$ to $1.0 \times 10^{5}$, and polydispersity of the molecular weight distribution increases from 2.5 to 3.1 [10]. This means that small degradation of PS occurs during steam distillation process. However, in other petroleum-based solvents, further degradation takes place owing to the oxidative scission of PS chains by air [21]. Most terpenes have $C=C$ groups that inhibit PS from oxidative decomposition by self-oxidation of the $\mathrm{C}=\mathrm{C}$ groups. The PS recycled from limonene solutions has almost the same elastic modulus and glass transition temperature [8], indicating that it retains original mechanical properties.

\section{Conclusion}

The essential oil in plants and its main components, terpenes and terpenoids, are good solvent for PS. EPS is recyclable by using those natural solvents in place of petroleum-based ones. The dissolving power of terpenes for PS strongly depends on their chemical structure. Basically, terpenes of which solubility parameter is close to that of PS dissolve much PS as predicted from the theory, as well as the dissolution rate is high as that of toluene, a petroleum-based solvent. In oxygen-containing terpenes, the ethers and esters show higher dissolving power than the alcohols according to the rule of solubility parameter. However, even though the solubility parameter is close to that of PS, acyclic terpenes have higher dissolving power compared to cyclic ones and bicyclic terpenes show relatively low dissolving power and dissolution rate for PS. These findings enable the judgment whether a certain terpene is suitable for the solvent of PS recycling from the chemical structure. The PS recovered by means of steam distillation of a solution of PS in terpenes shows slightly reduced molecular weight, but almost the same mechanical properties, compared to the original PS. Such reduction of molecular weight can be minimized by steam distillation under nitrogen atmosphere. Since Abies sachalinensis and Eucalyptus species are of fast-growing and the leaf oils contain many monoterpenes, they will be useful biomass for the solvent of PS recycling. 


\section{Acknowledgements}

Some terpenes were kindly gifted from Tokyo Chemical Industry, Inc., and Toyotama International, Inc. The author gratefully acknowledges both companies.

\section{Author details}

Kazuyuki Hattori*

Address all correspondence to: hattori@chem.kitami-it.ac.jp

Department of Biological and Environmental Chemistry, Kitami Institute of Technology, Koen-cho, Kitami, Japan

\section{References}

[1] United Nations Statics Division. http://unstats.un.org/unsd/databases.htm.

[2] Khait K. Recycling, Plastics. In: Kroschwitz JI. (ed.) Encyclopedia of Polymer Science and Technology, 3rd ed. vol. 7, Hoboken, New Jersey: John Wiley \& Sons; 2003. p657-678.

[3] Ehrig RJ., editor. Plastics Recycling Products and Processes. Munich: Hanser Publishers; 1992.

[4] Moore LA. US Patent 5,300,267, 1994.

[5] Nagamatsu T. Japanese Patent 10-219024, 1998.

[6] Noguchi T, Miyashita M, Inagaki Y, Watanabe H. A New Recycling System for Expanded Polystyrene using a Natural Solvent. Part 1. A New Recycling Technique. Packaging Technology and Science 1998; 11(1) 19-27.

[7] Noguchi T, Inagaki Y, Miyashita M, Watanabe H. A New Recycling System for Expanded Polystyrene using a Natural Solvent. Part 2. Development of a Prototype Production System. Packaging Technology and Science 1998; 11(1) 29-37.

[8] Noguchi T, Tomita H, Satake K, Watanabe H. A New Recycling System for Expanded Polystyrene using a Natural Solvent. Part 3. Life Cycle Assessment. Packaging Technology and Science 1998; 11(1) 39-44.

[9] Coleman RL, Lund ED, Moshonas MG. Composition of Orange Essence Oil. Journal of Food Science 1969; 34(6) 610-611. 
[10] Hattori K, Naito S, Yamauchi K, Nakatani H, Yoshida T, Saito S, Aoyama M, Miyakoshi T. Solubilization of Polystyrene into Monoterpenes. Advances in Polymer Technology 2008; 27(1) 35-39.

[11] Yatagai M, Sato T. Terpenes of Leaf Oils from Conifers. Biochemical Systematics and Ecology 1986; 14(5) 469-478.

[12] Yatagai M, Takahashi T. An Approach to Biomass Utilization II. Components of Eucalyptus Leaf Oils. Mokuzai Gakkaishi 1983; 29(5) 396-399.

[13] von Rudloff E. Volatile Leaf Oil Analysis in Chemosystematic Studies of North American Conifers. Biochemical Systematics and Ecology 1975; 2(3) 131-167.

[14] Hattori K, Shikata S, Maekawa R, Aoyama M. Dissolution of Polystyrene into $p$-Cymene and Related Substances in Tree Leaf Oils. Journal of Wood Science 2010; 56(2) 169-171.

[15] Caccioni D RL, Guizzardi M, Biondi DM, Renda A, Ruberto G. Relationship Between Volatile Components of Citrus Fruit Essential Oils and Antimicrobial Action on Penicillium digitatum and Penicillium italicum. International Journal of Food Microbiology 1998; 43(1-2) 73-79.

[16] Hildebrand JH. Solubility. Journal of the American Chemical Society 1916; 38(8) 1452-1473.

[17] Hansen CM. The Universality of the Solubility Parameter. Industrial and Engineering Chemistry. Product Research Development 1969; 8(1) 2-11.

[18] Barton AFM. Solubility Parameters. Chemical Reviews 1975; 75(6) 731-753.

[19] Hoftyzer PJ, Van Krevelen DW. Cohesive Properties and Solubility. In: Van Krevelen DW. (ed.) Properties of Polymers, 2nd ed. New York: Elsevier Science Publishers; 1976. p152-155.

[20] Van Krevelen DW. Cohesive Properties and Solubility. In: Van Krevelen DW. (ed.) Properties of Polymers, 3rd ed. New York: Elsevier Science Publishers; 1990. p189-225.

[21] Dickens B. Thermal Degradation and Oxidation of Polystyrene Studied by FactorJump Thermogravimetry. Polymer Degradation and Stability 1980; 2(4) 249-268. 

Chapter 2

\title{
Hydrothermal Depolymerization of Polyesters and Polycarbonate in the Presence of Ammonia and Amines
}

\author{
Toshitaka Funazukuri \\ Additional information is available at the end of the chapter \\ http://dx.doi.org/10.5772/59198
}

\section{Introduction}

Polyesters are widely employed as industrial uses and various consumer goods such as beverage and food bottle, container, packaging, textile etc. Along with the huge amounts of the production, the wastes are increasingly discharged around the world. Thus, the chemical recycling is essential for energy savings and developing the sustainable society.

Reaction conditions, temperature and pressure ranges, for various chemical recycling processes of polyesters are sketched in Figure 1. So far, various recycling processes for polyesters have been investigated and developed, as reviewed by Paszun and Spychaj [1]: alcoholysis with methanol or ethanol, glycolysis with ethylene glycol or propylene glycol, alkali hydrolysis with sodium hydroxide, ammonolysis and aminolysis. Recently, hydrolysis with sub- and supercritical water or with high pressure steam is also investigated. Many studies have discussed the advantages or disadvantages, and new or modified methods have been continuously developed.

The above processes have advantages, but involve some disadvantages such as severe reaction conditions of high temperature and/or pressure, the use of uncommon compounds as reaction reagents or additives, difficulty or complex procedures for the separation/purification of solvent or products, and/or low yields of the desired monomers due to undesired by-products. Moreover, even though higher monomer yields are obtained from polymer made of chiral monomer, higher reaction temperatures are unfavorable due to racemization. For instance, in conversion of poly(L-lactic acid) to lactic acid under hydrothermal conditions D-lactic acid as well as L-form was produced [2]. The yield ratio of D-form to L-form increased with increasing temperature and time, and the rate was expressed by the zeroth order reaction kinetics, namely, only as a function of temperature. To eliminate/reduce racemization of monomers produced lower reaction temperatures are preferable. 


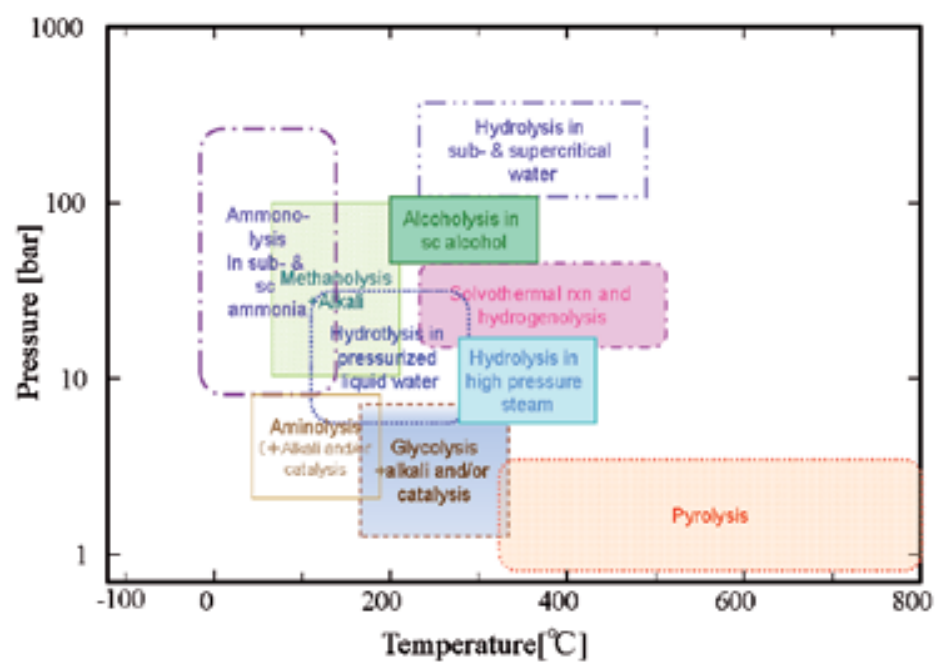

Figure 1. Reaction conditions for various degradation processes of polyesters.

Among the various chemical recycling methods, ammonolysis and aminolysis are promising for degrading polyesters due to the high reactivities of nucleophilic reagents such as ammonia and amines toward polyesters. In conventional ammonolysis/aminolysis processes, the main objective is not to recover the monomers but to obtain amide compounds from PET for use as coating materials, plasticizers, and ingredients which have a wide range of molecular weight. However, these methods have not yet been employed in industrial processes [1], and studies have been made since the 1960s [3-7]. In fact, most initial aminolysis studies were to investigate the surface morphology or modification and the strength of PET fibers [3-7], and not to recover the monomers. No reports on the measurements of reaction rates and the yields were available. In fact, ammonolysis/aminolysis processes had not been considered to be promising for converting the polymers to monomers.

As compared with the initial studies on ammonolysis/aminolysis, the use of sub-and supercritical ammonia (critical temperature of $405.6 \mathrm{~K}$ and critical pressure of $11.3 \mathrm{MPa}$ ) is more practical. Mormmans et al. [8] reported the ammonolysis of various polymers including PET with sub- and supercritical ammonia containing water, which mainly converted the PET into terephthalamide and EG. The reaction temperature is much lower than those in other processes (see in Fig. 1).

Recently, we have carried out the depolymerization of PET in a dilute aqueous ammonia solution under hydrothermal conditions [9-12]. This process can be conducted under milder reaction conditions of temperature and dilute alkaline, which lead to preventing the reactor from corrosion. Moreover, the products are mainly the monomers, and the production of oligomers is less likely in aqueous solutions. It can be speculated that oligomers produced are not dissolved from the solid surface due to the low solubilities, and the oligomers remained in polymer and/or on the surface are further degraded to monomers. The reaction is dominated 
by nucleophilic reaction with ammonia rather than alkali hydrolysis. Thus, a high concentration of ammonia/amine is not required, and ammonia/amine can be recovered by hydrolytic decomposition of the intermediate to monomers and ammonia/amine under hydrothermal conditions, whereas the intermediate products formed from some amines and polymers are stable. The products were mainly TPA and EG for PET [9-13], naphthalene dicarboxylic acid (NDC) and EG for PEN [12,14], bisphenol A for PC [12,15]. In this chapter, based on our recent studies [9-15] the effectiveness of monomerization with ammonia and amines is demonstrated in hydrothermal depolymerization of polyesters and polycarbonate.

\section{Experimental apparatus and procedures [11-15]}

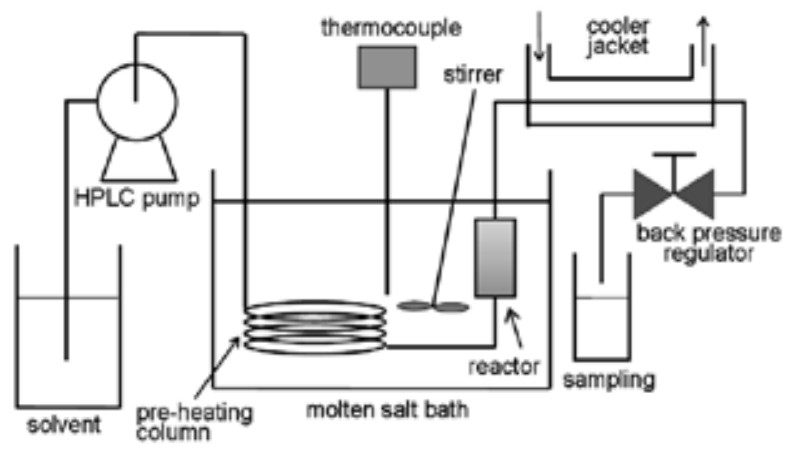

Figure 2. Schematic diagram of a semi-batch flow reactor.

A schematic diagram of the experimental set-up is shown in Figure 2. A small semi-batch flow reactor was mainly employed, and sometimes a small bomb type batch reactor was also used. The both reactors were the same structure and size (c.a. $3.6 \mathrm{~mL}$ ), and were made from $1 / 2$ inch O.D. stainless-steel. First, a couple of or a few pieces of particles (ca 60 to $150 \mathrm{mg}$ ) were charged in the reactor, and a frit disk was placed at the exit of the reactor not to remove the polymer samples out of the reactor. Distilled water was filled in the reactor and throughout a line at room temperature. The preheating column of $1 / 8$ inch O.D. tubing was placed in a molten salt bath, maintained at the intended value with a temperature fluctuation less than $\pm 2 \mathrm{~K}$. At time zero the solvent was fed, and then shortly the reactor was immersed in the bath. Apart from the reaction procedure, the temperature of the solvent in the reactor was found to reach the intended value within one minute by monitoring the temperature inside the reactor with a thermocouple directly placed in the center of the reactor. The solvent was supplied in most runs at a flow rate of $3 \mathrm{ml} / \mathrm{min}$ at ambient temperature and 5.0 or $10 \mathrm{MPa}$. Note that the saturation pressures of pure water at 493 and $523 \mathrm{~K}$ are 2.32 and $3.98 \mathrm{MPa}$, respectively. By tracer response measurements in the previous studies we confirmed that the flow in the reactor was almost a plug flow at the flow rates higher than 2 to $3 \mathrm{~mL} / \mathrm{min}$. The residence time of the solution in the reactor was negligible so that it took less than 30 seconds for the solvent to flow 
from the reactor exit to the outlet of the back pressure regulator [11-15]. The solvents eluted from the reactor were cooled down in a heat exchanger made of two co-axis cylinder tubes, 40 $\mathrm{cm}$ long by flowing with water. At every certain period, 2 minutes for early reaction times and 5 to 10 minutes for longer reaction times, the product solutions were collected from the outlet of the back pressure regulator. The yields of monomers in the each fraction were analyzed by HPLC. After the completion of reaction residual solid did not remain in most runs.

Due to low concentrations of ammonia and amines in the aqueous solutions, the densities of the aqueous solutions were assumed to be equal to those of pure water [16] at reaction conditions. The total organic carbon (TOC) and product yields were based on carbon weight as defined by Eqs (1) and (2), and the conversion $y$ by Eq. (3):

$$
\begin{aligned}
& \operatorname{TOC}(\%)=100 \times \frac{\text { organic carbon solution }(\mathrm{g})}{\text { carbon in initial polymer sample }(\mathrm{g})} \\
& \text { Yield }(\%)=100 \times \frac{\text { carbon in compound }(\mathrm{g})}{\text { carbon in initial polymer sample }(\mathrm{g})} \\
& \text { Conversion } y(-)=\frac{\text { yield of monomer }(\mathrm{s})(\%)}{\text { theoretical yield of } \operatorname{monomer}(\mathrm{s})(\%)}
\end{aligned}
$$

\section{Results and discussion}

\subsection{PET}

Figure 3 compares the effect of additives on the yields of TOC, TPA and EG at $493 \mathrm{~K}$ for 30 min and concentration of additives of $0.6 \mathrm{~mol} / \mathrm{kg}$ in aqueous solutions except for water in a batch reactor. Ammonia was found to be the most effective, as compared to $\mathrm{NaOH}, \mathrm{Na}_{2} \mathrm{CO}_{3}$ and $\left(\mathrm{NH}_{4}\right)_{2} \mathrm{CO}_{3}$. The yields did not increase in the order of basicity. When no additives were present, the yields were low. The TOC yield and total yield of TPA and EG were nearly equal in all cases. Thus, TPA and EG were highly selectively produced, and yields of oligomers and by products were quite low. As described later, in comparison with amine species for PET degradation the reactivity was also not the order of amine basicity.

Figure 4 plots EG yield vs. TPA yield at temperatures from $473 \mathrm{~K}$ to $553 \mathrm{~K}$ for 5 to $30 \mathrm{~min}$ with a $0.6 \mathrm{~mol} / \mathrm{kg}$ aqueous ammonia solution in a batch reactor. Due to the batch reactor without a stirrer, the time changes in yields were not smooth (not shown in figure), but the cross yield plots were well represented by a straight line. The yields of TPA were proportional to those of EG over an entire range of the conversion. While the yields of EG are reported to be lower than those of TPA at harsh reaction conditions, e.g. high temperature or in the presence of 


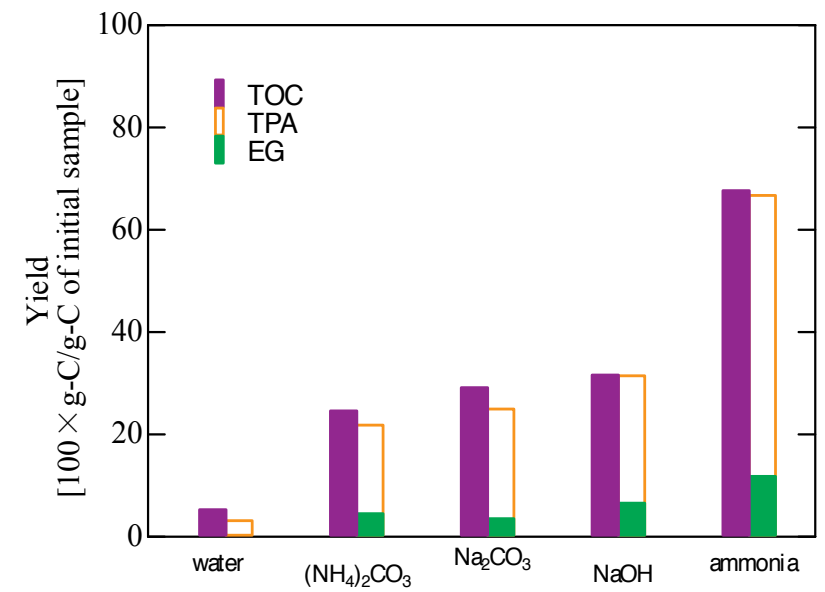

Figure 3. Effects of additives on TOC, TPA and EG yields at $493 \mathrm{~K}$ for $20 \mathrm{~min}$ and additive concentration of $0.6 \mathrm{~mol} / \mathrm{kg}$ in a batch reactor.

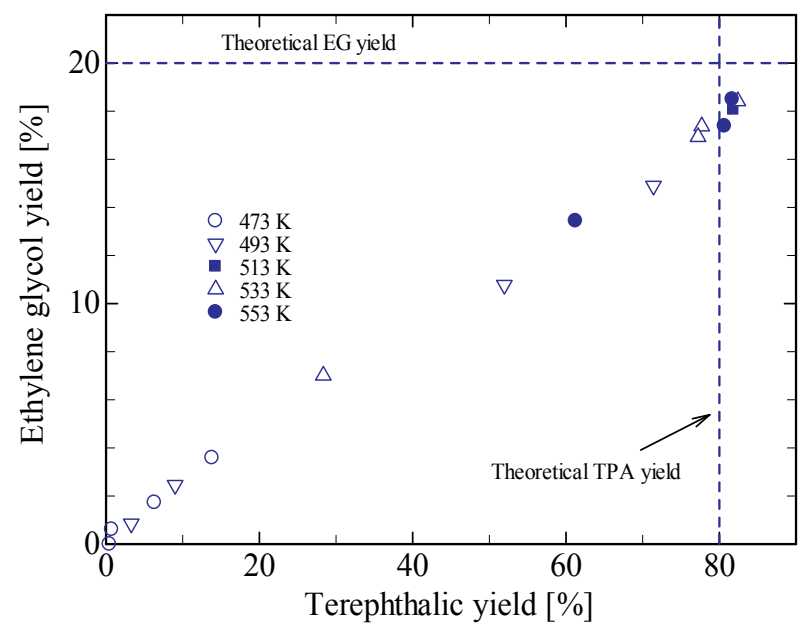

Figure 4. EG yield vs. TPA yield at various temperatures and reaction times from 5 to $30 \mathrm{~min}$ with $0.6 \mathrm{~mol} / \mathrm{kg}$ aqueous ammonia solution in a batch reactor [11]

strong acid, the process provides the equi-molar production of TPA and EG until the reaction is almost completed.

Figure 5 plots TOC values and product yields over flow time in an aqueous ammonia solution of $0.6 \mathrm{~mol} / \mathrm{kg}$ at $483 \mathrm{~K}$ and a constant flow rate of $3 \mathrm{~mL} / \mathrm{min}$ (at room temperature) in a semibatch flow reactor. When the reaction was also completed after $100 \mathrm{~min}$, TPA yield reached ca $70 \%$ on carbon weight basis, correspondingly $88 \%$ of the theoretical yield, and EG did $19 \%$ ( $95 \%$ of the theoretical value). Note that from the material balances about $10 \%$ of initial PET 


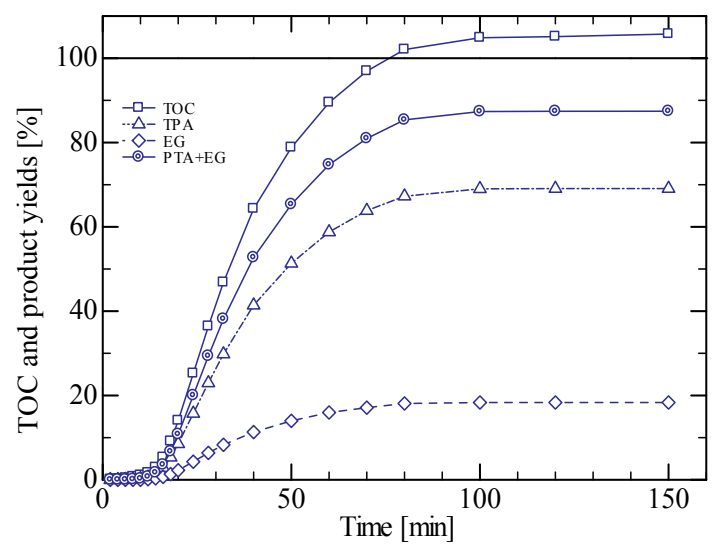

Figure 5. TOC and product yields over flow time at $483 \mathrm{~K}$ and $0.6 \mathrm{~mol} / \mathrm{kg}$ ammonia concentration at a flow rate of 3 $\mathrm{mL} / \mathrm{min}$ (set at room temperature) in a semi-batch reactor [11].

samples were not identified in the run. Whereas TOC value (105\%) was higher than $100 \%$, this may result from experimental error. It is interesting that the induction period of $20 \mathrm{~min}$ was observed, where no elution of TOC was made, as well as TPA and EG. Since the temperature of fluid in the reactor reached the prescribed temperature within $1 \mathrm{~min}$, it was the time for which ammonia solution diffused in solid sample, or decomposed products diffused out of inside solid sample. The induction time was shorter at higher temperature and/or higher concentration of ammonia. As described later, the induction times were also observed for all polymers and amines tested.

The depolymerization reaction is assumed to take place on the surface of polymer pellets in water with/without ammonia/amine and $\mathrm{NaOH}$, as seen for PET, PEN and PC in aqueous solutions of ammonia, amines and sodium hydroxide [9-15] and poly(lactic acid) in water and an aqueous sodium hydroxide solution [2]. This assumption can be verified from the direct observation of PET and PC samples in a view cell in the course of reaction [9]. The sizes of the cylindrical PET and PC sample decreased with time, but the shape remained. Moreover, since the solubilities of polymers PET, PEN, PC and their degradation products are low in aqueous solutions of ammonia and amine, and the reaction temperatures are lower than the melting points of the polymers, the reaction can be considered to proceed on the surface of polymers.

Although the further studies are required to explore the reaction mechanism, the reaction can be assumed to take place on the pellet surface. Thus, the overall reaction rate is expressed by the following surface reaction model for spherical particles, as derived in Appendix:

$$
\begin{aligned}
& \frac{d y}{d t}=k(1-y)^{2 / 3} \\
& y=0 \quad \text { at } \quad t=t_{i}
\end{aligned}
$$


where $y(-)$ is the conversion based on the monomer yield (e.g. TPA+EG yield for PET), $t$ and $t_{\mathrm{i}}$ are the reaction and induction times, respectively, and $k(1 / \mathrm{min})$ is the overall rate constant. By integrating Eq.(4) under condition of Eq.(5),

$$
(1-y)^{1 / 3}-1=-\frac{k}{3}\left(t-t_{i}\right)
$$

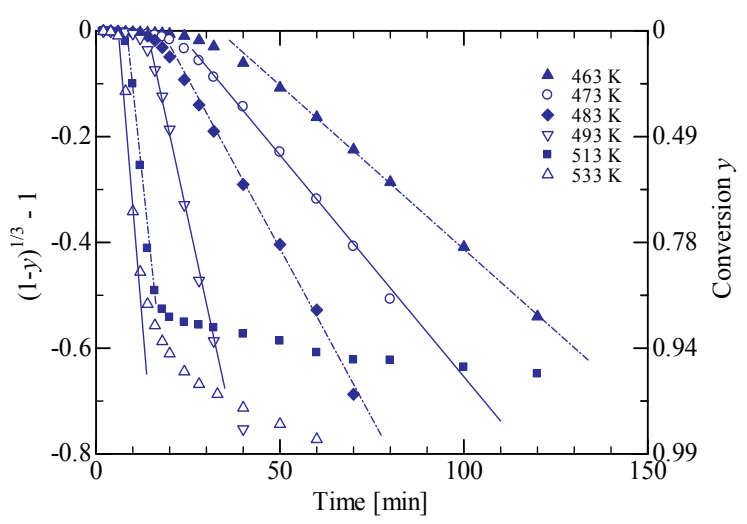

Figure 6. The validity of the surface reation model in plot of $\left[(1-y)^{1 / 3}-1\right]$ vs. time at various temperatures at $0.6 \mathrm{~mol} / \mathrm{kg}$ ammonia concentration in a semi-batch reactor[11]. The vertical axis on the right hand side was the conversion $y$, corresponding to that on the left hand side $\left[(1-y)^{1 / 3}-1\right]$.

Figure 6 indicates that Eq.(6) well represents the yield data over a wide range of conversion $y$ $\left([1-y]=0.86\right.$ to 0.13 , correspondingly $\left[(1-y)^{1 / 3}-1\right]=-0.05$ to -0.5$)$. Note that the induction times were observed and they increased with decreasing temperatures. Since the reaction temperatures were lower than the melting point of PET, during the reaction the polymer sample was solid and was remained in the shape until the reaction was nearly completed by observing from view cell experiments.

Figure 7 shows the effect of ammonia concentration on the rate [11]. Equation (6) satisfied the data, and the rate constants were $7.11 \times 10^{-2}, 8.40 \times 10^{-2}, 9.90 \times 10^{-2} 1 / \mathrm{min}$ at $0.006,0.06$ and $0.6 \mathrm{~mol} /$ $\mathrm{kg}$, respectively. Although the rate data at the three concentrations are only available, the rate constants slightly increased with increasing ammonia concentration, but the induction time significantly decreased with increasing the concentration.

Figure 8 shows the effect of flow rate on the reaction rates in plots of $\left[(1-y)^{1 / 3}-1\right]$ vs. time at 493 $\mathrm{K}$ and $0.6 \mathrm{~mol} / \mathrm{kg}$ ammonia concentration in a semi-batch reactor. It is interesting that the flow rate significantly affected the induction time, but hardly did the slope, namely the rate. This may suggest that the dissolution of decomposed components from pellet surface to the solvent could be controlled. 


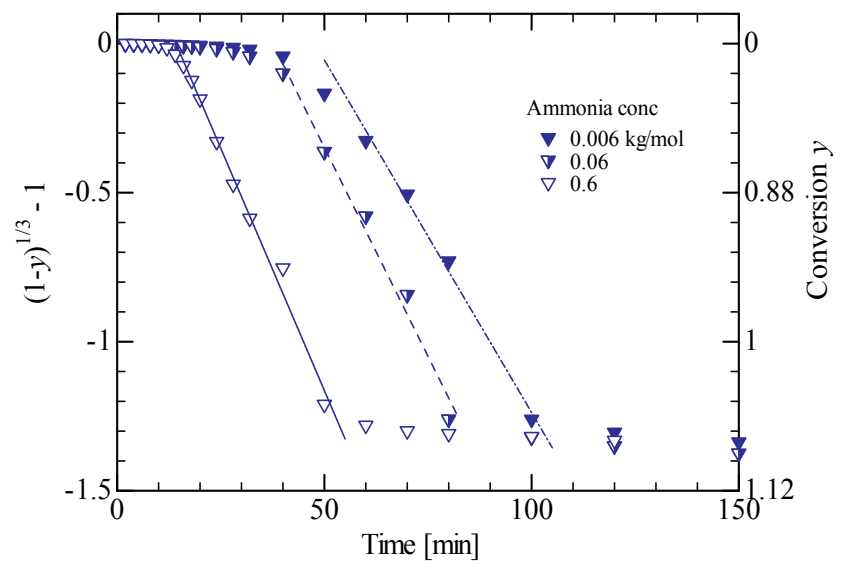

Figure 7. The effect of ammonia concentration on the reaction rate (slope) in plot of $\left[(1-y)^{1 / 3}-1\right]$ vs. time at ammonia concentrations of $0.006,0.06,0.6 \mathrm{~mol} / \mathrm{kg}, 493 \mathrm{~K}$ and solvent flow rate of $3 \mathrm{ml} / \mathrm{min}$ (set at ambient temperature) in a semi-batch reactor[11].

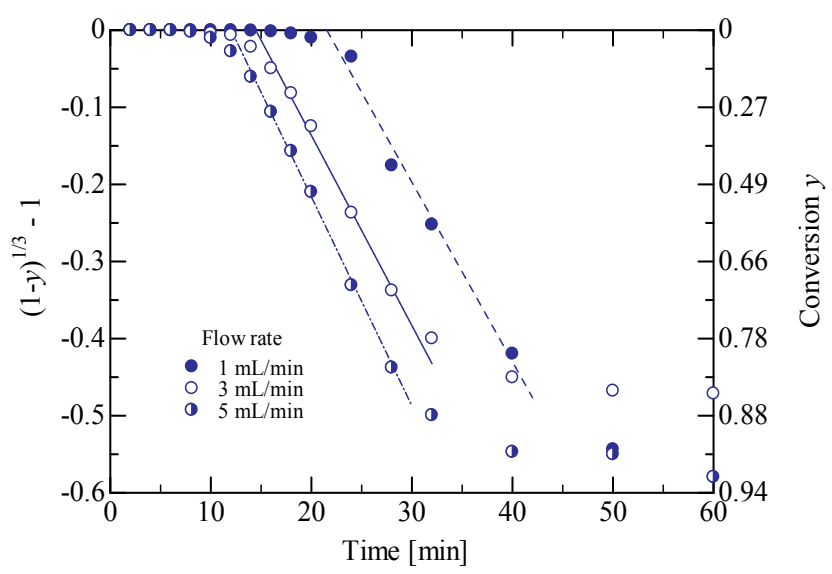

Figure 8. The effect of flow rates on the reaction rate (slope) in plot of $\left[(1-y)^{1 / 3}-1\right]$ over flow time at solvent flow rates of 1,3 and $5 \mathrm{ml} / \mathrm{min}$ (set at ambient temperature) and temperature of $493 \mathrm{~K}$ and $0.6 \mathrm{~mol} / \mathrm{kg}$ ammonia concentration in a semi-batch reactor.

Various amines as well as ammonia are also effective for PET degradation. As seen in Figure 9, at $473 \mathrm{~K}$ and $10 \mathrm{MPa}$ in a $0.6 \mathrm{~mol} / \mathrm{kg}$ aqueous trimethylamine solution at a $3.0 \mathrm{~mL} / \mathrm{min}$ solvent flow rate, the yields of TPA and EG for 50 min attained 77.6 and $18.6 \%$, respectively, close to the ideal values of 80 and 20\%, respectively. Note that the final TPA+EG yields with trimethylamine were higher than those in methylamine, dimethylamine, and ethylamine. The yields decreased in the order of trimethylamine $>$ ethylamine $>$ dimethylamine $>$ methylamine. The yields in trimethylamine and methylamine increased with flow time up to $30 \mathrm{~min}$, but then those in methylamine were suppressed. This could be attributed to the intermediate products formed from the reactions between the amine and the polymer. 


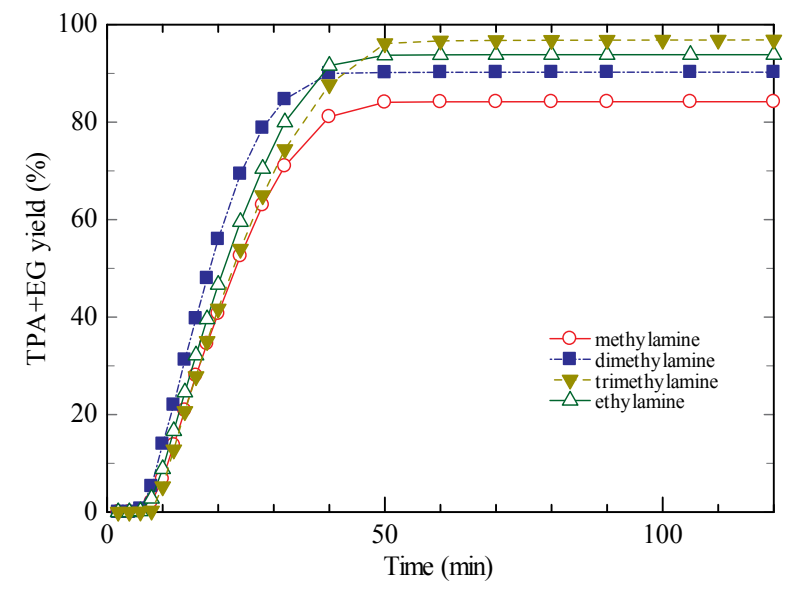

Figure 9. TPA+EG yields over flow time, in a $0.6 \mathrm{~mol} / \mathrm{kg}$ aqueous solution of methylamine, dimethylamine, trimethylamine or ethylamine at a solvent flow rate of $3 \mathrm{~mL} / \mathrm{min}, 473 \mathrm{~K}$ and $10 \mathrm{MPa}$ in a semi-batch flow reactor [13].

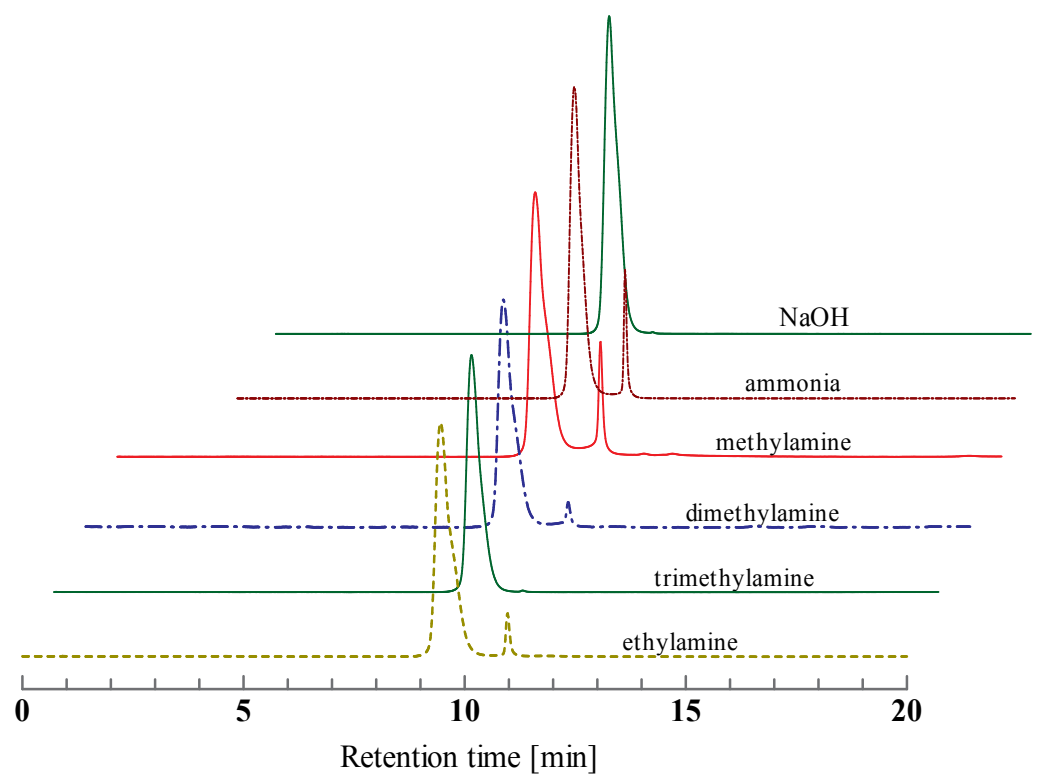

Figure 10. HPLC chromatograms of product solutions with various amines, ammonia and $\mathrm{NaOH}$ at $473 \mathrm{~K}$ and concentrations of $0.6 \mathrm{~mol} / \mathrm{kg}$ for $30 \mathrm{~min}$ [13].

Figure 10 compares the HPLC chromatograms, monitored at $254 \mathrm{~nm}$ using the UV-Vis detector, of the product solutions, obtained in various aqueous solutions such as methylamine, dimethylamine, trimethylamine, ethylamine, ammonia or $\mathrm{NaOH}$ at $0.6 \mathrm{~mol} / \mathrm{kg}$ concentration, 473 $\mathrm{K}$ and $10 \mathrm{MPa}$ for $30 \mathrm{~min}$. The highest peak in each chromatogram designated TPA and a smaller peak at a retention time of about 11 min was seen as a secondary product with 


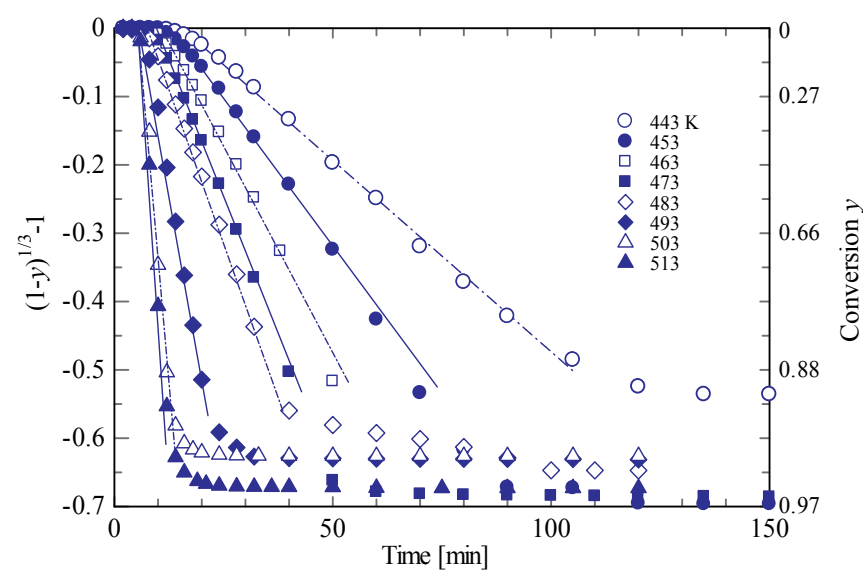

Figure 11. The validity of the surface reaction model in plot of [(1-y $\left.)^{1 / 3}-1\right]$ vs. flow time at temperatures from 443 to 513 $\mathrm{K}$ and $0.6 \mathrm{~mol} / \mathrm{kg}$ trimethylamine concentration in a semi-batch reactor [13].

methylamine, ethylamine, dimethylamine and ammonia, whereas no peak appeared with $\mathrm{NaOH}$ and trimethylamine. It can be considered that the highest monomer yields with trimethylamine depended on the hydrolytic conversion of the amide compounds to the TPA, whose yields in terms of peak area ratio of the peak to TPA peak increased in the order of tertiary amide $<$ secondary amide $<$ primary amide.

Figure 11 shows the temperature dependences of plots $\left[(1-y)^{1 / 3}-1\right]$ over flow time in a $0.6 \mathrm{~mol} /$ $\mathrm{kg}$ aqueous trimethylamine solution. As seen, the data are well represented by straight lines at all temperature studied over a nearly entire range of conversion $y$, up to those higher than 0.90. The induction time decreased with increasing reaction temperature, and the slope increased with increasing reaction temperature.
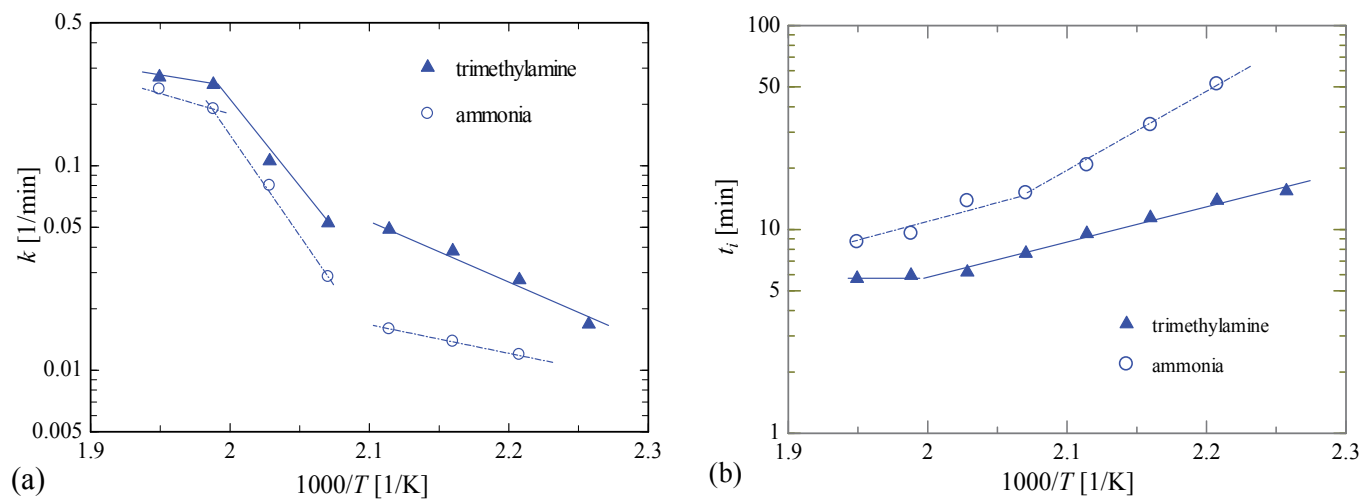

Figure 12. Arrhenius plots for (a) overall rate constants and (b) induction time as a function of 1000/T for trimethylamine and ammonia at concentrations of $0.6 \mathrm{~mol} / \mathrm{kg}[13]$. 


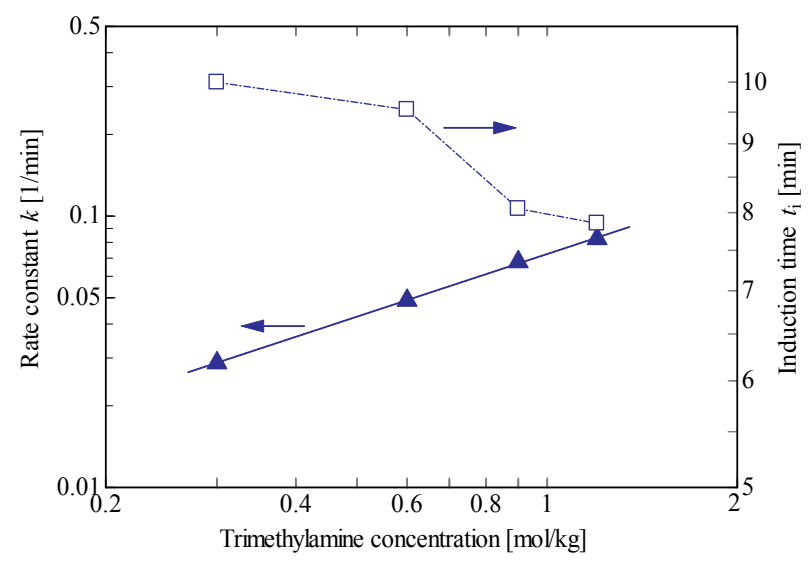

Figure 13. Effects of trimethylamine concentration on rate constant and induction time at $473 \mathrm{~K}$ and $10 \mathrm{MPa}$ [13].

\begin{tabular}{llll}
\hline & & Temperature & \\
\hline Additive & range(K) & $\mathbf{k}_{\mathbf{0}}(\mathbf{1} / \mathbf{m i n})$ & $\mathbf{E}(\mathbf{k J} / \mathbf{m o l})$ \\
\hline Trimethylamine & $443-473$ & $3.34 \times 10^{5}$ & 61.7 \\
\hline Ammonia & $483-503$ & $5.42 \times 10^{15}$ & 157 \\
\hline & $453-473$ & $1.09 \times 10^{1}$ & 25.7 \\
\hline
\end{tabular}

Table 1. Pre-exponential factors $k_{0}$ and activation energies $E$ for overall rate constants in $0.6 \mathrm{~mol} / \mathrm{kg}$ aqueous trimethylamine and ammonia solutions [13].

Figure 12 shows an Arrhenius plot for (a) overall rate constants and (b) induction time determined at a $0.6 \mathrm{~mol} / \mathrm{kg}$ trimethylamine concentration, as compared with those from a 0.6 $\mathrm{mol} / \mathrm{kg}$ ammonia concentration. The activation energies and pre-exponential factors are listed in Table 1. The rates in aqueous solutions of both ammonia and trimethylamine were slow below $473 \mathrm{~K}$, and the rate constants in trimethylamine were 2 to 3 times higher than those in ammonia. Around $480 \mathrm{~K}$, the rates in both solutions increased, and then level off above $503 \mathrm{~K}$. The values in trimethylamine were 1.3 to 2 times higher than those in ammonia at 483 to 503 K. Note that the reaction temperatures were lower than the melting point of the polymer. While the reason of the change in slopes is not known, the reaction involves some steps such as the polymer degradation, the decomposition of the intermediate products, and dissolution of the products, which may be affected by the reaction conditions.

The rate constants at $473 \mathrm{~K}$ and $10 \mathrm{MPa}$ were correlated with the trimethylamine concentration, the slope of 0.766, as shown in Figure 13. The induction times were also correlated, but not with a straight line. This suggested that the overall reaction could be attributed to the nucleophilic reaction with amine, not to alkaline hydrolysis. The induction times decreased with increasing amine concentrations, but the effect of this is not clear. 


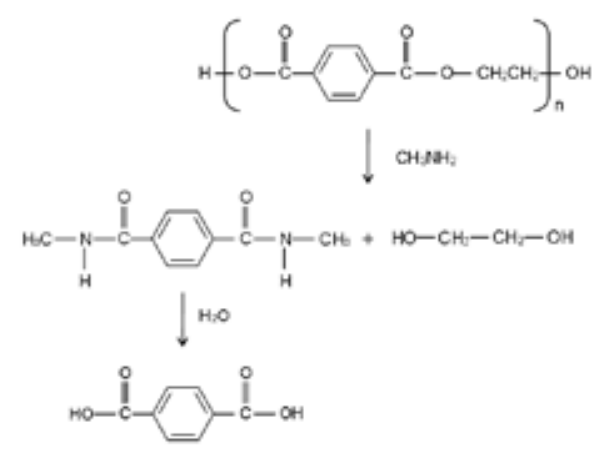

(a) Methylamine

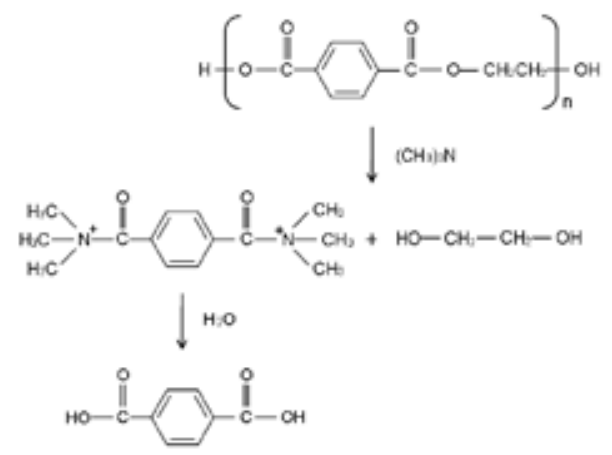

(b) Trimethylamine

Figure 14. Reaction scheme in aqueous (a) methylamine and (b) trimethylamine solutions [13].

Figure 14 shows possible reaction schemes for two typical cases, in aqueous methylamine and trimethylamine solutions, where the intermediate product formed are relatively stable and readily decomposable, respectively. In the case of aqueous solutions of ammonia, and primary and secondary amine, their amides will be produced from attacking carbonyl carbons in PET polymers by their nitrogen atoms. While the amides could be mainly decomposed, some of them remain as by-products, as seen in Figure 10. In contrast, tertiary amine such as trimethylamine also attacks carbonyl carbons in PET polymers as ammonia, and primary and secondary amines do, but the amides so produced are readily converted to terephthalic acid under hydrothermal conditions due to the unstable intermediate having positive charge. Thus, to accomplish this stage the presence of water could be essential.

\subsection{PEN}

Figure 15 shows yields of NDC, EG and the sum of NDC and EG yields from PEN over time at $493 \mathrm{~K}$ and $5.0 \mathrm{MPa}$ in $0.6 \mathrm{~mol} / \mathrm{kg}$ aqueous solutions of trimethylamine, dimethylamine and methylamine. While the EG yields and the production rates are almost the same for the three amines, those of NDC are influenced by the amine species: The final NDC yield $(83.4 \%$ on carbon mass basis of initial PEN pellets) with trimethylamine is the highest, that $(75.8 \%)$ with 
dimethylamine is lower, and that $(73.1 \%)$ with methylamine is the lowest. On the molar basis the NDC yields are 97.3, 88.5, 85.3\% (=100×mol-NDC/mol-NDC unit in PEN) and the EG yields are $96.6,97.7,94.6 \%(=100 \times$ mol-EG/mol-EG unit in PEN) with trimethylamine, dimethylamine and methylamine, respectively. However, the formation rates in terms of slopes increase in the order of methylamine to trimethylamine to dimethylamine. The order is not coincident with that of the reactivity, i.e. methylamine $>$ dimethylamine $>$ trimethylamine. This may be influenced by other factors such as the molecular size of amine and the reactivity of intermediate compounds produced with NDC and each amine, as seen for PET with the three amines [13]. The intermediate products formed from reactions between PEN/degraded products and trimethylamine may be more readily converted to NDC than those with methylamine and dimethylamine. According to almost the same EG yields with the three amines, the reaction stages to form the intermediates with amine and EG are hardly affected with amine species.

Figure 16 validates the surface reaction model in Eq. (6) in plots of [(1-y $\left.)^{1 / 3}-1\right]$ over time in the three aqueous solutions of amines such as trimethylamine, dimethylamine and methylamine for PEN with average molecular weight $=40,000$, together with PEN with 70,000 in an aqueous trimethylamine solution, where all amine concentrations were $0.6 \mathrm{~mol} / \mathrm{kg}$ at $493 \mathrm{~K}$ and $5.0 \mathrm{MPa}$. There are no significant differences in the rates between trimethylamine and dimethylamine, while the slope with methylamine is less steep. As seen in Fig. 15 the final NDC yield with methylamine was also the lowest among the three amines. It is interesting that the rates for PEN with $\mathrm{MW}=70,000$ and 40,000 were almost equal. The molecular weights of polymers did not influence the rates. Since solubility of NDC is low in the aqueous phase and the reaction temperature is lower than the melting point of PEN, oligomers may not be solubilized. The reaction may occur on the polymer surface, and the rate could be controlled not by degradation of polymers but by dissolution of NDC or decomposition reaction to produce NDC from intermediates, as seen for PET. In all the cases plots can be represented by the straight lines over a wide range of conversion $y$, up to $y$ of 0.8 , and Eq. (6) is found to be effective.

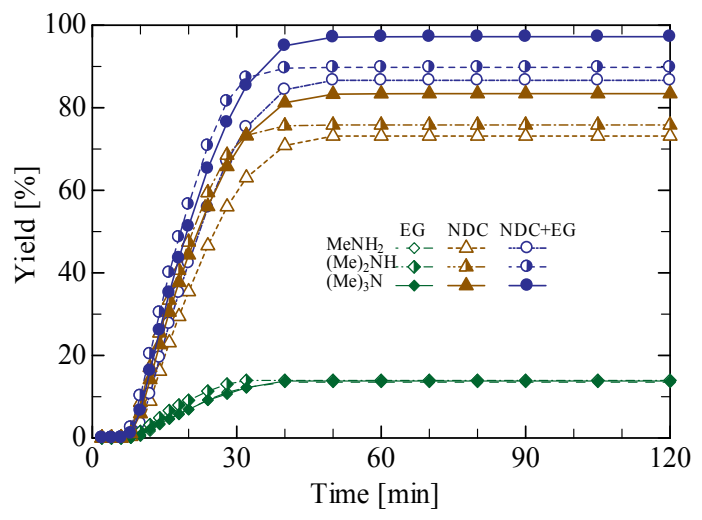

Figure 15. NDC, EG and NDC+EG yields over flow time at $493 \mathrm{~K}$ and $5.0 \mathrm{MPa}$ with methylamine, dimethylamine and trimetylamine at $0.6 \mathrm{~mol} / \mathrm{kg}$ concentration [14]. 


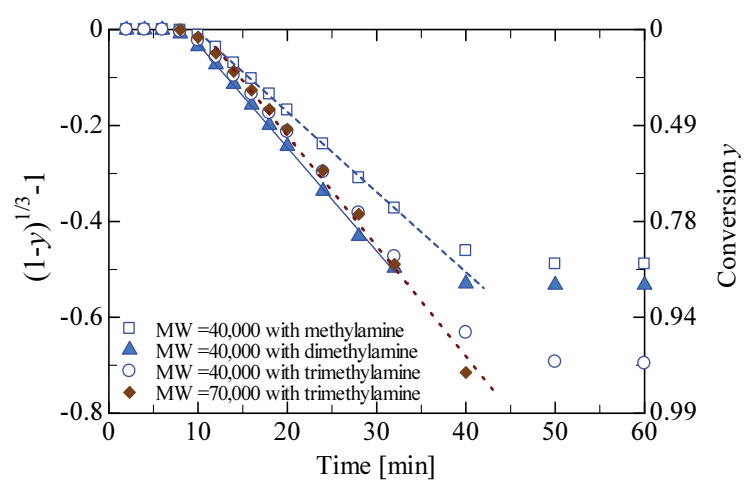

Figure 16. Effects of amine species on [(1-y $\left.)^{1 / 3}-1\right]$ over flow time at $493 \mathrm{~K}$ and $5.0 \mathrm{MPa}$ for PEN with average molecular weight $=40,000$ in $0.6 \mathrm{~mol} / \mathrm{kg}$ aqueous methylamine, dimethylamine, and trimethylamine solution, together with those for PEN with average molecular weight $=70,000$ in $0.6 \mathrm{~mol} / \mathrm{kg}$ aqueous trimethylamine solution [14].

Figure 17 shows Arrhenius plots for overall reaction rate constant $k$ for PEN [14], as compared to those for PET [13] and PEN with ammonia [12], at amine and ammonia concentrations of $0.6 \mathrm{~mol} / \mathrm{kg}$, together with the reciprocal induction time $1 / t_{\mathrm{i}}$ for PEN. The values of activation energy $E$ and pre-exponential factor $k_{0}$ in each stage for PEN with trimethylamine and ammonia are listed in Table 2. The temperature dependence of the reaction rates with trimethylamine are classified into the three stages in terms of slope as shown in Fig. 17: the moderately steep, and followed by the steeper, and almost the plateau, as observed for PET [13]. The transition temperature from the first to the second stage for PEN is higher than that for PET, and the rates for PET are higher than those for PEN. The transition temperature from the second to the plateau stage for PEN and PET are almost the same around $500 \mathrm{~K}$. The reciprocal induction times also show the similar tendency in rate constants. Up to $503 \mathrm{~K}$, the reciprocal values increase with decreasing $1 / T$ up to $1.988 \times 10^{-3} 1 / \mathrm{K}(503 \mathrm{~K})$, and then show constants. Since the reciprocal values of induction times may be proportional to the rate constants [13], if the reactions behave as the first or zero-th order reaction kinetics, the values indicate the times which are required to be degraded to so low DP values as the polymers are soluble in the solution.

\begin{tabular}{cccc}
\hline Additive & $\begin{array}{c}\text { Temperature range } \\
{[\mathbf{K}]}\end{array}$ & $\begin{array}{c}\mathbf{k} \mathbf{0} \\
{[\mathbf{1} / \mathbf{m i n}]}\end{array}$ & $\begin{array}{c}\text { E } \\
{[\mathbf{k J} / \mathbf{m o l}]}\end{array}$ \\
\hline Trimethylamine & 463 to 493 & $1.19 \times 10^{8}$ & 87.8 \\
\hline Ammonia & 493 to 503 & $6.26 \times 10^{22}$ & 226 \\
\hline & 503 to 523 & $k=0.219[1 / \mathrm{min}]$ & 158 \\
\hline
\end{tabular}

Table 2. Pre-exponential factor and activation energy in each stage for rate constants of PEN with trimethylamine [14] and ammonia [12] plotted in Fig. 16. (0.6 mol/kg aqueous trimethylamine at $5.0 \mathrm{MPa}$ and ammonia solution at 10.0 $\mathrm{MPa})$. 


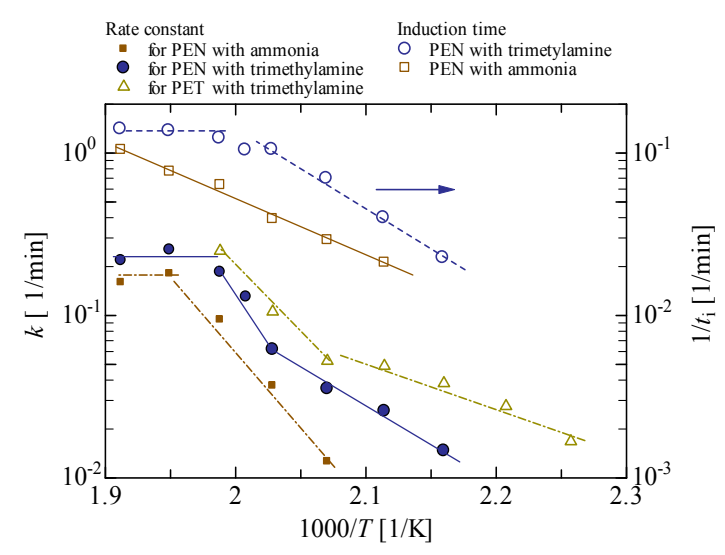

Figure 17. Arrhenius plots for overall rate constants for PEN [14] and PET [13] in $0.6 \mathrm{~mol} / \mathrm{kg}$ aqueous trimethylamine solution, and for PEN [12] in $0.6 \mathrm{~mol} / \mathrm{kg}$ aqueous ammonia solution, together with induction time $t_{\mathrm{i}}$ for PEN in 0.6 $\mathrm{mol} / \mathrm{kg}$ aqueous trimethylamine solution [14], and in $0.6 \mathrm{~mol} / \mathrm{kg}$ aqueous ammonia [12].

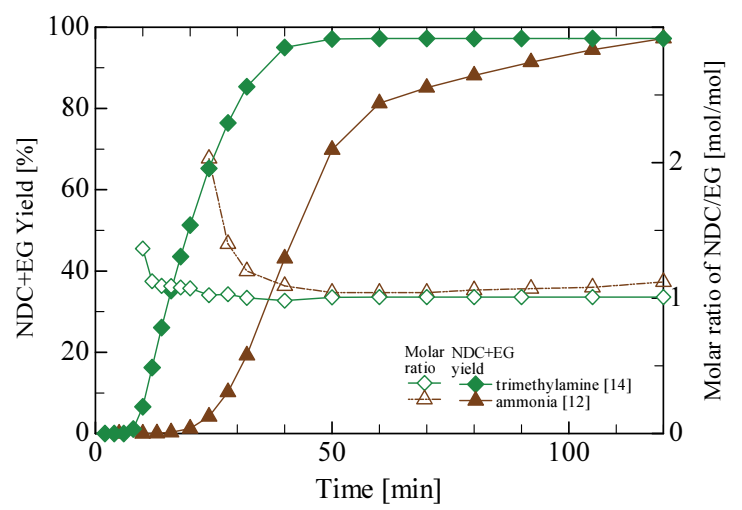

Figure 18. NDC+EG yields and molar yield ratio of NDC/EG over flow time at $493 \mathrm{~K}$ in $0.6 \mathrm{~mol} / \mathrm{kg}$ aqueous trimethylamine [14] and $0.6 \mathrm{~mol} / \mathrm{kg}$ ammonia [12] solutions. NDC+EG: solid key, NDC/EG: blank key.

The $k$ values for PEN with ammonia increased with increasing temperature, and above $503 \mathrm{~K}$ reached the plateau value, and were similar to that with trimethylamine. This can be considered to result from the mass transfer limitation. The reciprocal induction times with ammonia also increase with increasing temperature, and did not reach the plateau values. More reaction times are needed with ammonia due to lower reaction rates for degradation of molecular weights of PEN than those with trimethyamine.

Figure 18 compares the sum of NDC and EG yields and molar yield ratio of NDC/EG between ammonia and trimetylamine at $493 \mathrm{~K}$ and $0.6 \mathrm{~mol} / \mathrm{kg}$ concentration of trimethylamine or ammonia. The production rate of NDC+EG with trimethylamine is much faster than that with ammonia. However, the final NDC+EG yields with both solutions reach nearly $100 \%$, and the molar yield ratio of NDC/EG are almost unity in major conversion periods, excluding the initial 
reaction periods, i.e. lower than product yields of $20 \%$. This suggests that the reaction to produce NDC initially took place, and followed by that to produce EG from intermediate products in either an aqueous trimethylamine or an aqueous ammonia solution.

\subsection{PC}

Figures 19(a) and (b) show the changes in $\left[(1-y)^{1 / 3}-1\right]$ over time at various concentrations of (a) ammonia and (b) $\mathrm{NaOH}$ at a temperature of $433 \mathrm{~K}$ and a flow rate of $3 \mathrm{~mL} / \mathrm{min}$. In ammonia solution, each plot is expressed by approximately a straight line at each concentration over almost the entire range of conversion up to $y>0.9$. In $\mathrm{NaOH}$ solution plots also show similar manner whereas the conversions are lower. The rates in both alkaline solutions increase with the concentration.
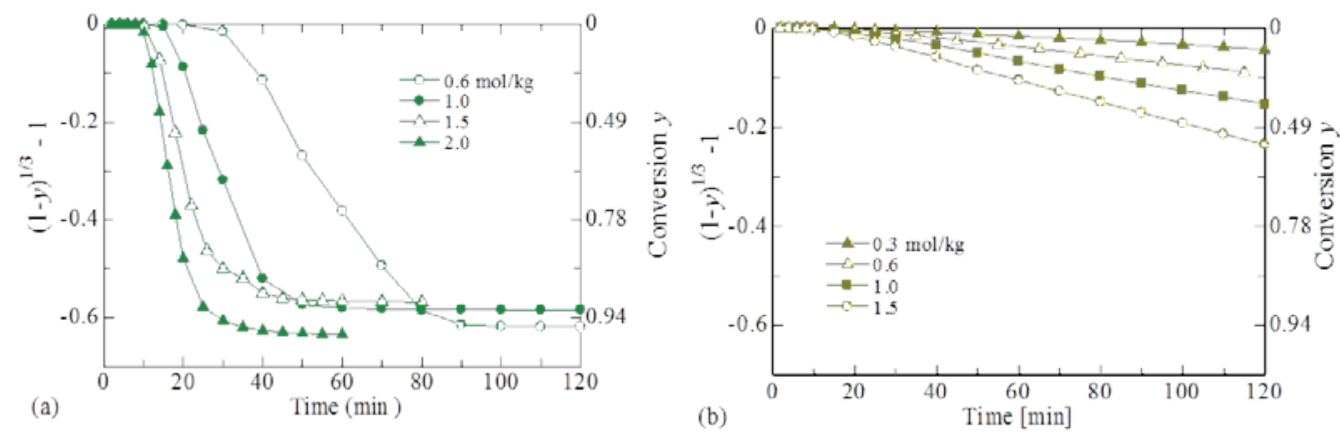

Figure 19. $\left[(1-y)^{1 / 3}-1\right]$ vs. flow time at various concentrations of (a) ammonia and (b) $\mathrm{NaOH}$, at $433 \mathrm{~K}$ and $10 \mathrm{MPa}$ in a semi-batch reactor [15].

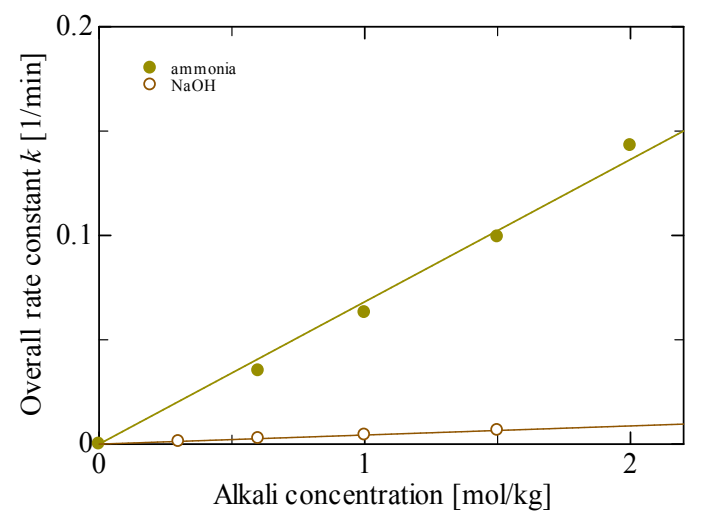

Figure 20. Effects of alkali concentration on the overall rate constant at $433 \mathrm{~K}$ and $10 \mathrm{MPa}$ with ammonia and $\mathrm{NaOH}$ in a semi-batch reactor [15]. 
Although the rates at various temperatures and ammonia/ $\mathrm{NaOH}$ concentrations were well represented by Eq. (6), based on Eq. (4), in which the reaction rates were proportional to the surface area of PC pellets, the controlling step in the reaction was not determined. Since the activation energy with ammonia was not so high, the chemical reaction cannot be concluded to be controlling. Thus, the rate constant $k$ in Eq. (6) is the overall value. The steps may consist of those in which the ammonia molecules are penetrated into polymer, those attack polymer, degraded components diffuse to the surface, and those dissolve into solution at pellet surfaces. The further studies are needed for clarifying the reaction mechanism and determining the controlling step.

The overall rate constants in both alkaline solutions at $433 \mathrm{~K}$ are plotted as a function of the alkaline concentration in Figure 20. Both the rate constants with ammonia and $\mathrm{NaOH}$ are proportional to the concentration, but the slope with ammonia is almost 15 times higher than that with $\mathrm{NaOH}$. Note that there was no significant reaction with only water (no additives) at $433 \mathrm{~K}$.

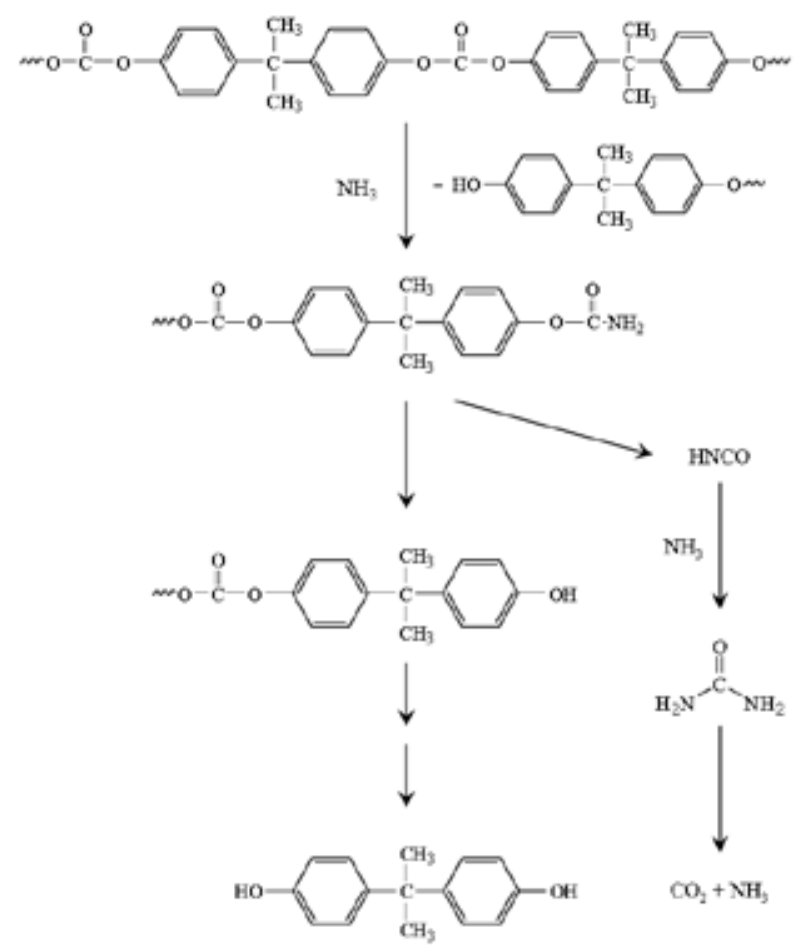

Figure 21. Reaction mechanism for conversion of polycarbonate to bisphenol A in aqueous ammonia solution under hydrothermal conditions [15].

The reaction mechanism shown in Figure 21 can be considered for the polycarbonate monomerization in an aqueous ammonia solution under hydrothermal condition. Carbonate 
bonding in PC is decomposed by ammonolysis, and the carbamate ester is formed. The ester is further decomposed into isocyanate and polymers having bisphenol A termination. By repeating these steps polycarbonate is degraded to BPA. The isocyanate formed is further reacted with ammonia molecule to produce urea, and then the urea is decomposed to carbon dioxide and ammonia. The reaction steps are verified because no other major products were produced with the evidence that BPA yield was almost consistent with TOC in solution. The reaction steps for ammonolysis proposed by Mormann et al. [8] with supercritical ammonia is the same as that in the present study, but the latter steps for the conversion of isocyanate to urea, and the urea decomposition into carbon dioxide and ammonia are characteristic to reactions carried out in the aqueous solutions of ammonia and amines under hydrothermal conditions.

\section{Conclusion}

The presence of ammonia and amines is effective for conversion of polyesters and polycarbonate to the monomers in an aqueous solution under hydrothermal conditions at temperatures lower than melting points of polymer. The reaction rates for all polymers studied were expressed by the surface reaction model, i.e. $2 / 3^{\text {rd }}$ order reaction kinetics with respect to unreacted mass of polymer. The reactivities of ammonia and amines tested are not dependent on the basicity, and the rates could be controlled by dissolution of intermediate products and/ or monomers. The monomer yields with trimethylamine for PET and PEN, and those with methylamine for PC were nearly equal to the theoretical values. The aqueous solutions of ammonia and amine at low concentrations can be considered to be a promising medium for chemical recycling of polyesters and polycarbonates under hydrothermal conditions.

\section{Appendix}

When polymer pellets are spherical, the initial polymer mass and that at time $t$ are $m_{0}$ and $m$ [kg], respectively, the reaction rate, i.e. the decrease rate of $m$ is assumed to be proportional to polymer surface area $S\left[\mathrm{~m}^{2}\right]$ with reaction rate constant $k^{\prime}\left[\mathrm{kg} /\left(\mathrm{min} \mathrm{m}^{2}\right)\right]$.

$$
-\frac{d m}{d t}=k^{\prime} S
$$

The conversion $y[-]$ is

$$
y=1-\frac{m}{m_{0}}=1-\frac{\frac{4 \pi R^{3}}{3} n \rho}{\frac{4 \pi R_{0}^{3}}{3} n \rho}
$$


where $R_{0}$ and $R$ are the particle radius of initial polymer and that at time $t, n$ is the number of particles in polymer mass $m_{0}$ and $\rho$ is the density of polymer. The rate is:

$$
\begin{aligned}
& -\frac{d m}{d t}=m_{0} \frac{d y}{d t}=k^{\prime}\left(4 \pi R^{2}\right) \frac{m_{0}}{\frac{4 \pi R_{0}^{3}}{3} \rho} \\
& \frac{d y}{d t}=\frac{3 k^{\prime}}{R_{0} \rho}\left(\frac{R}{R_{0}}\right)^{2}=k(1-y)^{2 / 3}
\end{aligned}
$$

where $k=3 k^{\prime} / R_{0} \rho[1 / \mathrm{min}]$.

\section{Author details}

Toshitaka Funazukuri*

Address all correspondence to: tfunazo@kc.chuo-u.ac.jp

Department of Applied Chemistry, Chuo University, Kasuga, Bunkyo-ku, Tokyo, Japan

\section{References}

[1] Paszun, D., and T. Spychaj, Ind. Eng. Chem. Res., 36, 1373-1383 (1997).

[2] Yagihashi, M., and T. Funazukuri, Ind. Eng. Chem. Res., 49, 1247-1251 (2010).

[3] Farrow, G., D. A. S. Ravens, and I. M. Ward, Polymer, 3, 17-25 (1962).

[4] Ellison, M. S., L. D. Fisher, K. W. Alger, and S. H. Zeronian, J. Appl. Polym. Sci., 27, 247-257 (1982).

[5] Awodi, Y. W., A. Johnson, R. H. Peters, and A. V. Popoola, J. Appl. Polym. Sci., 33, 2503-2512 (1987).

[6] Popoola, V. A., J. Appl. Polym. Sci. 36, 1677-1683 (1988).

[7] Collins, M. J., S. H. Zeronian, and M. L. Marshall, J. Macromol. Sci., Part A: Pure Appl. Chem. A28, 775-792 (1991).

[8] Mormann, W. H. Jung, and D. Spitzer, Ammonia as Reagent or Reaction Medium for Polymers, In Supercritical Fluids as Solvents and Reaction Media, Brunner, G. Eds.; Elsevier: Amsterdam, 2004; pp. 593-616. 
[9] Zenda, K., and T. Funazukuri, Joint 8th Int. Symp. on Hydrothermal Reactions and 7th Int. Conf. on Solvo-Thermal Reactions, Aug, Sendai, Japan (2006).

[10] Zenda, K., K. Hatakeyama, R. Arai, and T. Funazukuri, Proc. of Super Green 2007, The 5th Int. Conf. on Supercritical Fluids, Nov. Seoul, Korea (2007).

[11] Zenda, K., and T. Funazukuri, J. Chem. Technol. Biotechnol., 83, 1381-1386 (2008).

[12] Arai, R., K. Zenda, K. Hatakeyama, K. Yui, and T. Funazukuri, Chem. Eng. Sci., 65, 36-41 (2010).

[13] Wakabayashi, N., T. Kojima, and T. Funazukuri, Ind. Eng. Chem. Res., 51, 5699-5704 (2012).

[14] Wakabayashi, N., M. Taguchi, and T. Funazukuri, J. Chem. Eng. Jpn, 47, 908-913 (2014).

[15] Hatakeyama, K., T. Kojima, and T. Funazukuri, J. Mater. Cycles Waste Manag., 16, 124-130 (2014).

[16] JSME (Japan Society of Mechanical Engineers) Steam Tables Based on IAPWS-IF97 (International Association for the Properties of Water and Steam International Formulation 1997 for the Thermodynamic Properties of Water and Steam) 5th ed, JSME, Tokyo, 1999. 
Chapter 3

\title{
Chemical and Thermochemical Recycling of Polymers from Waste Electrical and Electronic Equipment
}

\author{
Dimitris S. Achilias and Eleni V. Antonakou \\ Additional information is available at the end of the chapter \\ http://dx.doi.org/10.5772/59960
}

\section{1. Introduction}

The production of electric and electronic equipment (EEE), including personal computers, compact disks, TV sets, refrigerators, washing machines, toasters and many other daily-life items, is one of the fastest growing areas of manufacturing industry today. The rapid development in the EEE technology combined with a short life cycle and a variety of uses, at least for most of the products, poses a significant issue as far as their disposal is concerned. This has resulted in a continuous increase of Waste Electric and Electronic Equipment (WEEE) with some representative numbers: in the EU only, 9.5 million tones have been disposed in 2008 and this is expected to increase to 12.3 million tones in 2020 [1, 2]. While there is no generally accepted definition of electronic waste in most cases electronic waste consists of electronic products that were used for data processing, telecommunications, or entertainment in private households and businesses and are now considered obsolete, broken, or unrepairable (Figure 1). Despite its common classification as a waste, disposed electronics are a considerable category of secondary resource due to their significant suitability for direct reuse and material recycling. In view of the environmental problem involved in the management of WEEE, many countries and organizations have drafted national legislation to improve the reuse, recycling and other forms of recovery of such wastes so as to reduce disposal. The EU in an attempt to deal with the necessity of a meaningful recycling system and at the same time to preserve oil and fossil fuel resources has introduced 2002/96/EC directive [2], which demands $70-80 \%$ of WEEEs to be recovered in the form of energy and/or materials [2]. The directive aims at the minimization of the percentage of the solid wastes which will be landfilled or incinerated the full conversion of all waste streams (including plastics) through thermal or mechanic treatment by 2020 . 


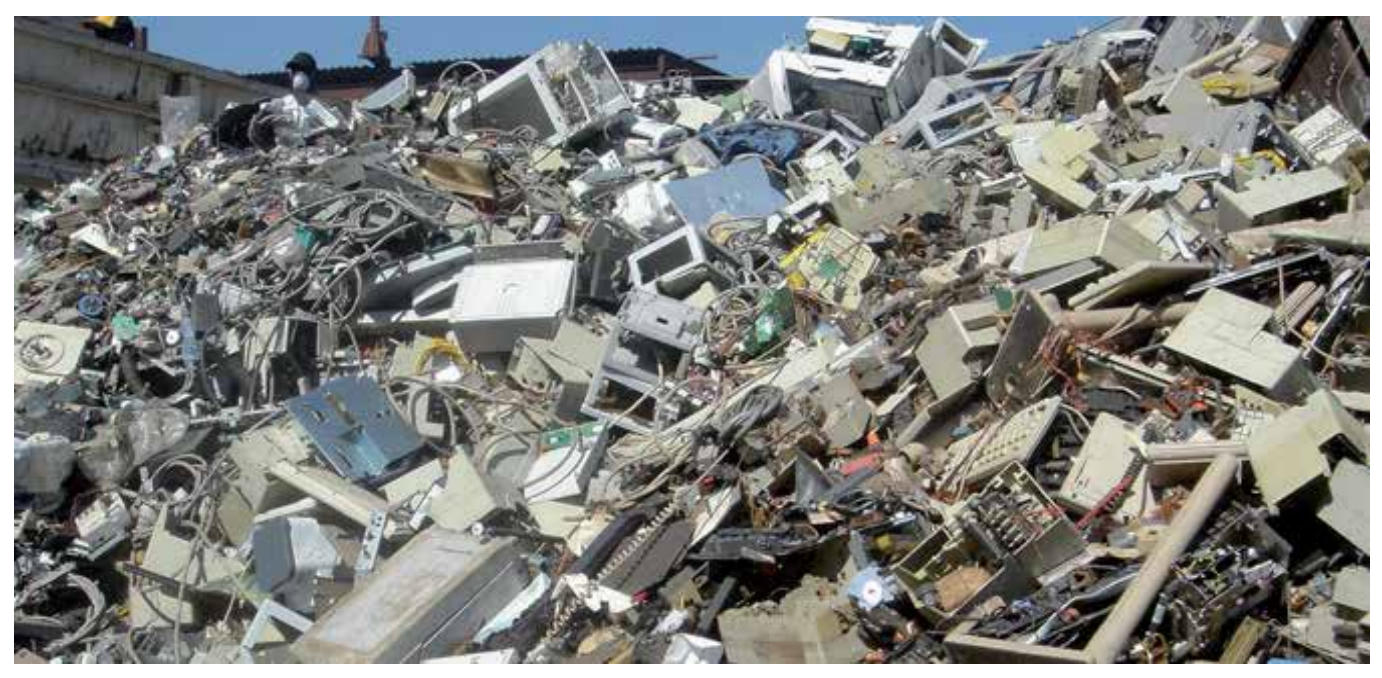

Figure 1. Waste electrical and electronic equipment

The necessity of the plastic wastes recycling becomes more urgent mainly due to the following reasons:

- Significant increase in plastics recycling, which leads to a successive increased volume in the final receptors.

- Significant low life cycle (less than a month for a high fraction of plastics).

- Low biodegradability and thus accumulation in the final receptors.

It should be mentioned that most of the polymers do not have a direct influence to humans due to toxicity but mainly due to their increased waste volume.

There are three main recycling methods for polymers treatment and all three find applications in the WEEEs recycling.

- primary

- secondary (mechanical)

- tertiary

- quaternary

Primary recycling is a term referring to the recycling of non-useful or problematic plastics which have not been used by the consumers and their quality has not deteriorated significantly. It is the simplest recycling method and its main advantage is the low cost, while the main disadvantage is that it cannot be used in products that have already been used.

Secondary recycling refers to the recycling of plastics that have been used by the consumers. During this form of recycling the plastics, after some form of treatment such as cleaning, decrease in size and separate into the mixture components, melt and then reform. The main 
advantage is that the quality of the final product is lower since the macromolecular chains might be broken after the exposure to the treatment techniques mentioned above.

Tertiary recycling refers to the process of breaking the polymeric bonds which leads to the production of either the initial monomers or fractions of oligomers. It applies mainly to condensation polymers such as polyesters and polyamides. Breaking of the polymeric chains can be done either chemically (chemical recycling) or with the use of heat (thermolysis). It is considered to be the method with the higher quality and value products. It is widely applied in condensation polymers such as polyesters and polyamides.

Quaternary recycling is related to the energy recovery of the plastic wastes in general and it includes mainly incineration. The method takes advantage of the high energy value of the waste polymers and significantly reduces their volume. The degradation of waste plastics into fuel represents a sustainable way for the recovery of the organic content of the polymeric waste will also help preserving petroleum and oil resources. The disadvantage of the method is that, mainly through incineration, a series of dangerous byproducts, such as dioxins, are been emitted.

The main problems concerning polymers recycling which do not allow their large scale applications are the variability of the product composition, the presence of polymers mixtures and the use of additives. The WEEE recycling is challenging, mainly because these types of wastes consist of many and different materials: metals, glass, elastics and plastics. Plastics usually contain metals incorporated in their structure and for this reason the separation and the mechanical recycling of the WEEE waste components contains a series of technical and economic challenges [3]. A typical WEEE fraction contains 20-30\% plastics. The composition can vary, but an example of the breakdown from actual collected WEEE is: acrylonitrilebutadiene-styrene (ABS) 30\%, high impact polystyrene (HIPS) $25 \%$, polycarbonate (PC) $10 \%$, PC/ABS 9\%, polypropylene (PP) 8\%, poly(phenylene ether) (PPE)/HIPS 7\%, poly(vinyl chloride) (PVC) 3\%, polystyrene (PS) 3\%, polyamide (PA) 3\%, poly(butylene terephthalate) (PBT) $2 \%[4,5]$. A schematic representation of a WEEE composition appears in Figure 2.

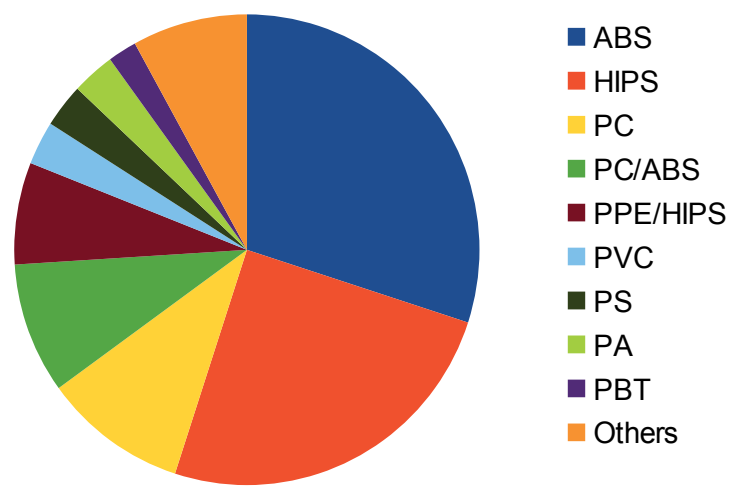

Figure 2. Typical WEEE composition 


\section{Mechanical recycling of WEEEs using the dissolution/reprecipitation technique}

During this technique the polymer can be separated and recycled using a solvent/non-solvent system. Separating and recycling polymers by this method appear to be technologically feasible and of considerable commercial interest. The effect of different solvent/nonsolvent systems and dissolution temperatures on the \% recovery of polymers from the corresponding model polymers or WEEE was investigated by Achilias et al. [6].

The main parameters affecting the dissolution/reprecipitation technique are: solvent/ nonsolvent type and portion, dissolution temperature and time and polymer concentration. All of them must be optimized in order to minimize polymer degradation, cost and environmental impact of the recycling process. With respect to the dissolution, solvents used in this recycling process are selected based on the principle that polymers in general, can be dissolved in solvents having similar values of the solubility parameter, $\delta$. A good solvent to be used in polymer recycling should combine high dissolution ability and volatility that will allow its removal with minimum chain degradation, with low cost and toxicity. The solvents used were dichloromethane, toluene, chloroform and acetone, while methanol was always employed as a non-solvent. The dissolution temperatures investigated were $25^{\circ} \mathrm{C}, 50^{\circ} \mathrm{C}$ and $100^{\circ} \mathrm{C}$, in the cases of dichloromethane and toluene, while only $25^{\circ} \mathrm{C}$ and $50^{\circ} \mathrm{C}$ in the cases of acetone and chloroform (below their boiling point). (C) [2015] IEEE. Reprinted, with permission, from Achilias D.S., Antonakou E., Koutsokosta E., Lappas A. Chemical recycling of polymers from WEEE. J. of Applied Polymer Science, 2009; 114, 212-221 [6]

The effect of solvent type, dissolution temperature and polymer concentration on the $\%$ recovery of three model polymers commonly found in WEEEs (i.e. ABS, PC and PS) appears in Table 1. Polymer recoveries were high enough at all experimental conditions. An increase in dissolution temperature leads to increased polymer recovery values, while an increase in polymer concentration to slightly lower. The system dichloromethane/methanol was found to produce high PC recoveries even at low dissolution temperatures. For PS, both dichloromethane and toluene could be used as solvents with higher recoveries at increased dissolution temperatures. For ABS high recoveries were measured when using dichloromethane at $100^{\circ} \mathrm{C}$ but also with acetone at lower temperatures. Since acetone can dissolve ABS at room temperature, eliminating thus the risk of thermal degradation at elevated temperatures, it has been proposed as the best solvent for ABS in this recycling technique. (C) [2015] IEEE. Reprinted, with permission, from Achilias et al. Chemical recycling of polymers from WEEE. J. of Applied Polymer Science, 2009; 114, 212-221 [6].

Apart from model polymers, the recovery of the specific polymer from the plastic part of several WEEEs was also investigated. Results under different experimental conditions appear in Table 2. The recovery of PC from compact disks was high enough (98 wt.-\%) at the specific conditions used, in accordance with results of the model polymer. Concerning the system acetone/methanol, although it resulted in good recoveries when used in model ABS it was not effective in WEEEs based on ABS (i.e computer monitor and electronic toy). For all different 


\begin{tabular}{|c|c|c|c|c|c|}
\hline \multirow[b]{2}{*}{ Solvent/Nonsolvent } & \multirow{2}{*}{ Temperat $\left({ }^{\circ} \mathrm{C}\right)$} & \multirow{2}{*}{$\begin{array}{c}\text { Polymer } \\
\text { concentration } \\
(\mathrm{g} / 100 \mathrm{~mL})\end{array}$} & \multicolumn{3}{|c|}{ Polymer } \\
\hline & & & ABS & PC & PS \\
\hline Dichloromethane/Methanol & 25 & 5 & 86 & 98 & 92 \\
\hline Dichloromethane/Methanol & 50 & 5 & 89 & 98 & 94 \\
\hline Dichloromethane/Methanol & 100 & 5 & 96 & 98 & 98 \\
\hline Dichloromethane/Methanol & 25 & 10 & 84 & 95 & \\
\hline Dichloromethane/Methanol & 50 & 10 & & 97 & \\
\hline Acetone/ Methanol & 25 & 5 & 90 & & \\
\hline Acetone/ Methanol & 50 & 5 & 94 & & \\
\hline Chloroform/Methanol & 25 & 10 & & 95 & \\
\hline Chloroform/Methanol & 50 & 10 & & 96 & \\
\hline Toluene / Methanol & 25 & 5 & & & 93 \\
\hline Toluene / Methanol & 50 & 5 & & & 95 \\
\hline Toluene / Methanol & 100 & 5 & & & 97 \\
\hline
\end{tabular}

Table 1. Polymer recovery (wt.-\%) by the dissolution/reprecipitation technique from model polymers (C [2015] IEEE. Reprinted, with permission, from Achilias et al. Chemical recycling of polymers from WEEE. Journal of Applied Polymer Science, 2009; 114, 212-221 [6]

WEEEs, based on ABS the best solvent was found to be dichloromethane at $100^{\circ} \mathrm{C}$ with recoveries greater than $90 \mathrm{wt.}$. $\%$. Finally, the recovery of PS from the WEEE based on this polymer was high enough at both solvents used (i.e. dichloromethane and toluene). (C) [2015] IEEE. Reprinted, with permission, from Achilias D.S., Antonakou E.V., Koutsokosta E., Lappas A.A. Chemical recycling of polymers from waste electric and electronic equipment. Journal of Applied Polymer Science, 2009; 114, 212-221 [6]

\begin{tabular}{lllcc}
\hline \multicolumn{1}{c}{ WEEE } & Polymer & \multicolumn{1}{c}{ Solvent/nonsolvent } & Temperature $\left({ }^{\circ} \mathbf{C}\right)$ & Recovery (wt.-\%) \\
\hline Computer monitor & ABS & Dichloromethane/Methanol & 100 & 91 \\
\hline & & Toluene/Methanol & 100 & 70 \\
\hline TV set & ABS & Acetone/Methanol & 25 & 68 \\
\hline & & Dichloromethane/Methanol & 100 & 96 \\
\hline Electronic toy & ABS & Acetone/Methanol & 100 & 69 \\
\hline & & Dichloromethane/Methanol & 25 & 90 \\
\hline Compact Disk & PC & Toluene/Methanol & 100 & 90 \\
\hline
\end{tabular}




\begin{tabular}{lllcc}
\hline WEEE & Polymer & \multicolumn{1}{c}{ Solvent/nonsolvent } & Temperature $\left({ }^{\circ} \mathrm{C}\right)$ & Recovery (wt.- $\%)$ \\
\hline Radio & PS & Dichloromethane/Methanol & 100 & 98 \\
\hline & & Toluene/Methanol & 100 & 95 \\
\hline Vacuum cleaner & PS & Dichloromethane/Methanol & 100 & 95 \\
\hline & & Toluene/Methanol & 100 & 91 \\
\hline Electronic toy & PS & Dichloromethane/Methanol & 100 & 95 \\
\hline & & Toluene/Methanol & 100 & 97 \\
\hline
\end{tabular}

Table 2. Polymer recovery by the dissolution/reprecipitation technique from the plastic part of different WEEE ( [2015] IEEE. Reprinted, with permission, from Achilias D.S., Antonakou E.V., Koutsokosta E., Lappas A.A. Chemical recycling of polymers from waste electric and electronic equipment. Journal of Applied Polymer Science, 2009; 114, 212-221 [6]

\section{Chemical and thermo-chemical recycling methods}

Thermal cracking or pyrolysis, involves the degradation of the polymeric materials by heating in the absence of oxygen (usually in a nitrogen atmosphere) to yield valuable products (e.g. monomers, or fuel-type oils). During pyrolysis at increased temperatures, depending on polymer type, the monomer can be produced in a large amount (i.e in poly(methyl methacrylate)), or a fuel-type liquid fraction, occurring mainly in polyolefins (LDPE, HDPE, PP), or other secondary useful products. An overview of the science and technology of pyrolysis of waste plastics has been recently presented in an excellent book by Scheirs and Kaminsky [7].

Thermal cracking (pyrolysis) of WEEE streams is receiving increasing attention, due to the potential recovery of either monomer(s) or secondary valuable materials, leading to a more sustainable waste management. Disadvantages of pyrolysis are related to the variable product composition and the low selectivity concerning the respective monomers and /or products of commercial value. The use of suitable catalysts in the pyrolysis process can offer the possibility to control the selectivity towards the desired products.

A significant number of electrical and electronic equipment has been studied in the recent literature. Kowalska and his team [8] reported thermogravimetric studies of two types of electronic wastes: a mixture of three types of printed circuit boards and a mixture of electronic junctions with metal wires. Despite the brominated and chlorinated flame retardants present in the two samples (which remain one of the main challenges in the pyrolysis process), preliminary HPLC analysis of the liquid fraction produced indicated that it consists of a series of two to four unsaturated ring hydrocarbons and it could potentially be used as a fuel. De Marco et al. [3] have reported the pyrolysis in an autoclave of four types of real WEEEs streams: wires of polyethylene (PE), table phones, mobile phones and printed circuit boards (PCB). They found that pyrolysis liquids vary significantly depending on the WEEE pyrolysed. Molto et al. [9] reported the pyrolysis and combustion of different parts of a mobile phone (printed circuit board, mobile case and a mixture of both materials) at $850{ }^{\circ} \mathrm{C}$ in a horizontal laboratory 
furnace. They found the liquid fraction to consist of mainly phenols and hydrocarbons. More than 100 compounds have been detected in the liquid phase, most of them straight chain and aromatics. Acomb et al. [10] studied the pyrolysis-gasification of a plastic waste collected from a commercial WEEE recycling plant, mainly consisting from waste computer monitors and television sets, by using a two-stage reaction system in order to produce hydrogen. Hall et al., pyrolysed fire retarded high impact polystyrene using a fluidized bed reactor [11]. Although the emphasis was on the bromine distribution on the pyrolysis products, the yields and compositions of the main fractions were also reported. In a later study of the same research group, three different plastic fractions from commercial waste electrical and electronic equipment (WEEE) processing plant were collected and investigated through batch pyrolysis. The first plastic was from equipment containing cathode ray tubes (CRTs), the second from refrigeration equipment, and the third from mixed WEEE. Analysis of the pyrolysis products was provided and the pyrolysis oils were found to contain valuable chemical products while the pyrolysis gases were mainly halogen free, making them suitable to be used as a fuel [12]. Pinto et al. [13] investigated the influence of several catalysts on product distribution from plastic waste pyrolysis. The waste under study had the typical composition of Portuguese municipal solid wastes (68\% PE, 16\% PP and 16\% PS) while the catalysts selected were zeolites and a series of metallic catalysts. Similar results were obtained from the catalytic and noncatalytic runs, in terms of total conversion, product yields and composition.

Advanced thermochemical methods for WEEE treatment appear to be a sustainable and promising recycling suggestion since, as it has widely been reported in the literature, not only a high percentage of the monomer can be recovered (up to 60\%) but also a variety of compounds of a commercial and research interest such as low molecular weight hydrocarbons, tar (waxes and liquid with a high percentage of aromatic compounds) and carbon (elemental as well as activated carbon). Chemical recycling methods (such as solvolysis) could be interesting alternatives but they are not able to deal with the high content of additives or the mixtures of polymers which are usually present in the used WEEEs [14].

The process of pyrolysis seems as a promising alternative for the degradation of WEEEs since it can, under controlled conditions, deal with a number of organic macromolecules and decompose them into useful products (usually the polymers' monomer and other organic compounds, some of which, of a commercial value). Significant levels of lead, mercury, cadmium, chromium (VI), polybrominated biphenyls and polybrominated diphenylethers can be found in electrical and electronic waste [15]. Most of the inorganic material included (which in some cases is or can be related to a catalytic activity in the polymer's degradation) is located in the solid residue after the pyrolysis process, with a problematic exception in the case of halogenated compounds which usually lead to the formation of undesirable organo-halogenated compounds in all fractions. The problem becomes more demanding when the halogen atoms come from halogenated aromatic compounds (such as in the case of PC) since they require more energy in order for the bonds to break, not only because of the bond energy of the $\mathrm{C}_{\text {aromatic }}-\mathrm{X}$ bond which is higher compared to $\mathrm{C}_{\text {aliphatic }}-\mathrm{X}$ bond, but also because of the lack of favorable geometry which will have as a result an increase in the activation energy of the reaction [15]. 
Williams [16] in a recent review paper reported the use of pyrolysis for the treatment of wastes from electronic printed circuit boards as a recovery method for useful products such as metals, liquid and gaseous products as well as glass fibres. He also stated that the circuit boards contain significant concentrations of bromine in the form of bromine containing flame retardants, which also appears in the liquid fraction in the form of brominated organic compounds, a property which could possibly affect the the potential end uses of the produced oil. It seems that a meaningful debromination method could be a determining step which could be crucial for the economic viability of the recycling method.

Vasile et al [15] attempted to improve the quality of the pyrolysis oil produced from WEEE during catalytic hydrogenation, in order to find applications as fuel or source of chemicals. Apart from the halogen removal, the removal of nitrogen and sulphur were also among the aims of this study. The authors have introduced a conventional acidic catalyst (DHC-8) as well as a neutral catalyst in the hydrogenation process and showed that both catalysts improved the quality of the pyrolysis oil by removing oxygen, nitrogen, halogen and sulphur containing compounds and thus improving its stability. A main disadvantage of the catalytic process is that the amount of aromatics in the produced oil remained high and this could affect a possible application of the produced oil if it is to be directly used as a fuel.

Balart et al [17] investigated the thermal properties of PC-ABS mixtures obtained from WEEE by using thermogravimetric analysis (TGA). Kinetic parameters, such as apparent activation energies (Ea) were calculated by the application of the autocatalytic method, which has been successfully applied to other polymer systems. Activation energies determined from TGA data were practically independent of heating rates in the case of ABS-based mixtures, while there seems to be some influence of the heating rates in the PC-based mixtures. The authors suggest that the thermal degradation mechanism of these samples is composed of several complex processes, and that the use of a complex stabilizing system will be necessary for an efficient stabilization of these mixtures but also a limitation of the action of the main degradation processes. The same authors [18] reported a decrease on mechanical properties of the PC-ABS blends when compared to the original polymers in compositions in the range $20-80 \mathrm{wt} \% \mathrm{PC}$.

Among the polymeric materials used in electronic equipment the most important are the terpolymer of Acrylonitrile-Butadiene-Styrene (ABS), polycarbonates (PC) and High Impact Polystyrene (HIPS) and recycling methods for these type of plastics are presented next.

\section{PC recycling}

Polycarbonate poly(bisphenol A carbonate) (PC) is an important engineering plastic featuring good optical clarity, high impact resistance and ductility at room temperature and below. Because of these attributes, PC is used in a wide variety of applications including electrical and electronic equipment, digital media (e.g. CDs, DVDs), automobiles, glazing in the building and construction industry, sports safety equipment and reusable food and drink containers. A major concern when PC is used as plastic packaging, and especially in baby bottles, is to do with the release of the toxic bisphenol-A (BPA) into the food. 
Recycling of polycondensation polymers, such as PC, via pure chemical routes can be summarised by the following technologies: hydrolysis (in acid, neutral or alkaline environment), glycolysis, hydroglycolysis, methanolysis and aminolysis [19-23]. These techniques have been recently reviewed [19]. Most of the depolymerisation processes lead to decomposition of PC into its original monomer, bisphenol-A. However, due to the insolubility of PC in some of these reagents (e.g., water or methanol), depolymerisation requires severe conditions, such as long reaction time and high temperature and pressure, or even take place under supercritical conditions and in the presence of a large amount of concentrated bases or acids [23]. (c [2015] IEEE. Reprinted, with permission, from Tsintzou G.P., Antonakou E.V., Achilias D.S. Environmentally friendly chemical recycling of poly(bisphenol-A carbonate) through phasetransfer catalysed alkaline hydrolysis under microwave irradiation. Journal of Hazardous Materials 2012; 241-242, 137-134 [37].

Several research groups have suggested the introduction of different types of solvent systems and catalysts [24-29], such as methylene chloride with ammonia and phenol in combination with an alkali catalyst. There are two main problems with the use of an effective solvent system in the degradation process: one problem has to do with the high cost of the separation of the product (and the high content of additives included in some of the polymer blends), and the second problem is the environmental and safety issues related to the use of toxic organic solvents. Alkali-catalysed methanolysis has been used by Hu et al. [28], Pinero et al. [30], Chen et al. [31] and Liu et al. [32]. Supercritical or near-critical conditions for the recovery of the BPA monomer and DMC have been employed [14,33]. Moreover, ionic liquids have been used as catalysts during the methanolysis of polycarbonate [34], and the characteristics of depolymerisation in supercritical ethanol were also investigated [35]. As might be expected, the most environmentally friendly reagent in PC degradation is water and the chemical recycling process of hydrolysis. However, one study found that in liquid water at $573 \mathrm{~K}$, polycarbonate still remained even after $50 \mathrm{~min}$ [5]. Therefore, high-pressure, high-temperature water, which is also referred to as supercritical water, has been used for rapid hydrolysis without a catalyst [5,36]. (C) [2015] IEEE. Reprinted, with permission, from Tsintzou G.P., Antonakou E.V., Achilias D.S. Environmentally friendly chemical recycling of poly(bisphenol-A carbonate) through phase-transfer catalysed alkaline hydrolysis under microwave irradiation. Journal of Hazardous Materials 2012; 241-242, 137-134 [37].

\subsection{Microwave assisted chemical recycling of PC}

Nowadays, recycling using some environmentally friendly degradation method is of paramount importance. To this direction, microwave irradiation was employed by Tsintzou et al. [37] to study the chemical recycling of PC in relatively mild experimental conditions that do not require large amounts of chemicals or energy. The method of hydrolysis in an alkaline $(\mathrm{NaOH})$ solution was applied to poly(bisphenol-A carbonate) to depolymerize it into its starting monomer, BPA. The hydrolysis mechanism appears in Figure 3. It was found that degradation hardly occurs at relatively low temperature, except if a phase-transfer catalyst (1hexadecyl trimethyl ammonium bromide) is employed. The combination of irradiation time and $\mathrm{NaOH}$ concentration resulted in similar results, meaning that increased alkaline concentrations require less time. In all conditions, degradation of PC was minimal at temperatures below $110^{\circ} \mathrm{C}$ (Fig. 4). A significant increase was observed in the region from 130 to $160{ }^{\circ} \mathrm{C}$ and 
degradation values more than $80 \%$ were measured at $170{ }^{\circ} \mathrm{C}$. Since the glass transition temperature, $\mathrm{Tg}$, of $\mathrm{PC}$ is near $150{ }^{\circ} \mathrm{C}$, it seems that its alkaline hydrolysis under microwave irradiation, is facilitated when the reaction temperature approaches this value. A polymer at its $\mathrm{Tg}$ changes from a stiff (hard) to a softer rubbery state, which causes the polymer to swell more easily in response to the alkaline reagent and hence facilitates the reaction. Finally, the importance of applying the microwave irradiation during PC alkaline hydrolysis was confirmed, since at $160^{\circ} \mathrm{C}$, high PC decomposition was achieved after only $10 \mathrm{~min}$ of reaction with $10 \% \mathrm{NaOH}$ as compared with conventional heating, where more than $8 \mathrm{~h}$ is needed for similar results.
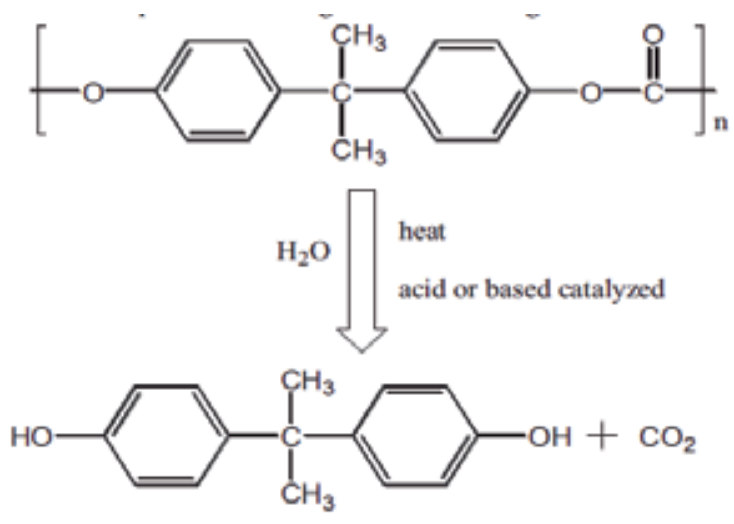

BPA

Figure 3. Mechanism of PC hydrolysis to its monomer BPA

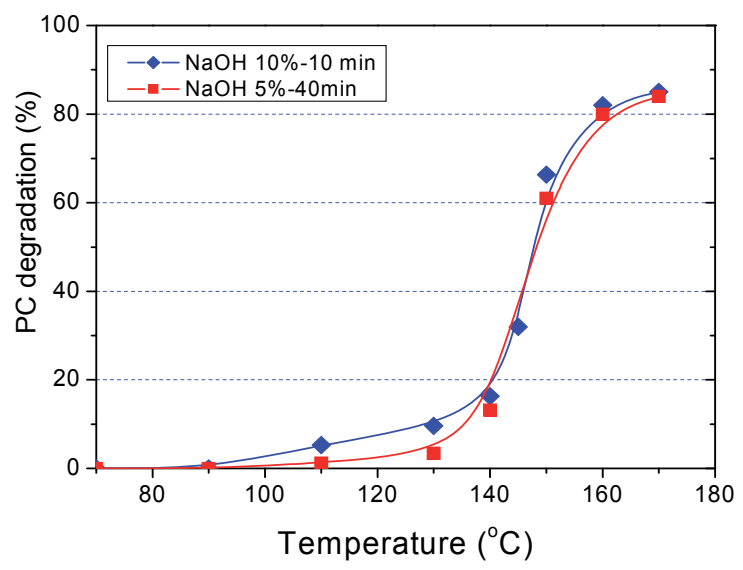

Figure 4. Effect of depolymerization temperature on the amount of polycarbonate (PC) reacted during microwave-assisted PC alkaline hydrolysis after $40 \mathrm{~min}$ at $5 \% \mathrm{w} / \mathrm{v} \mathrm{NaOH}$, or $10 \mathrm{~min}$ at $10 \% \mathrm{w} / \mathrm{v} \mathrm{NaOH}$ [37]. (C [2015] IEEE. Reprinted, with permission, from Tsintzou G.P., Antonakou E.V., Achilias D.S. Environmentally friendly chemical recycling of poly(bisphenol-A carbonate) through phase-transfer catalysed alkaline hydrolysis under microwave irradiation. Journal of Hazardous Materials 2012; 241-242, 137-134 [37]

In the hydrolysis products, BPA monomer was obtained and identified by FTIR measurements. However, from GPC measurements, the average molecular weight of the PC residues only 
slightly decreased even after $70 \%$ degradation. These results confirm that in alkali solutions, the rate of polymer hydrolysis is so fast that the reaction occurs mainly at the surface and degradation follows a 'surface erosion' mechanism. The products, such as monomer and oligomer, are released from the surface, and the polymer mass rapidly decreases, though its number average molecular weight $\left(\bar{M}_{N}\right)$ is almost constant. Diffusion of the reactant into the bulk phase is slower than the rate of the chemical reaction. In contrast, during the 'bulk erosion' mechanism occurring under acidic conditions, the reaction rate is so slow that the hydrolysis proceeded in the bulk phase of the polymer. The polymer mass does not change during the early stage of the reaction, while $\left(\bar{M}_{N}\right)$ continuously decreases with the reaction time. The latter mechanism seems to be dominant during PC hydrolysis in high-pressure and high-temperature steam.In addition, the same technique was applied to the degradation of waste compact disks. Depolymerization as high as $85 \%$ was achieved at $160{ }^{\circ} \mathrm{C}$ using a $10 \% \mathrm{NaOH}$ solution after microwave irradiation for $10 \mathrm{~min}$ [37].

Nikje, 2011 [38] also studied glycolysis of PC from waste compact discs with EG using microwave irradiation in the presence of $\mathrm{NaOH}$ as catalyst in order to obtain the monomer BPA. The influence of various parameters, such as concentration of the alkali metal catalyst and microwave irradiation power on product yield was reported in detail. The optimum concentration of $\mathrm{NaOH}$ was found to be $2 \mathrm{wt} \%$ and the optimum microwave power was $600 \mathrm{~W}$. BPA recovery was affected by the reaction time and reached to an optimum yield at $500 \mathrm{~s}$ [38].

\subsection{Thermo-chemical recycling of PC}

In this section, results are presented for the pyrolysis of waste CD's and compared to corresponding from model PC. It should be pointed out here that in order to remove the Al layer on the $\mathrm{CD}$, initially it was pre-treated with a $\mathrm{NaOH}$ solution. The model polycarbonate used in this investigation was based on poly(bisphenol A carbonate), the same used in the electronics industry because of its desirable combination of toughness and thermal stability.

Results on the product yield from the fixed bed pyrolysis of either model poly(bisphenol A carbonate) or the compact disk appear in Table 3. The model PC pyrolysed to form a large amount of oil (i.e. $63 \mathrm{wt} . \%)$ a smaller amount of gas (6.6 wt.\%) while leaving a rather large amount of residue (30.4 wt.\%). The total degradation of poly(bisphenol A carbonate) (i.e. 70 wt.\%) was slightly lower from that reported by Chiu et al. [39] (i.e. 76 wt.\%) using a quartz reactor operating at $550^{\circ} \mathrm{C}$ after $1 \mathrm{~h}$ degradation. The pyrolysis of the $\mathrm{CD}$ produced a much larger amount of liquid fraction (80.4 wt.\%) with almost the same gaseous fraction (8.6 wt.\%) while leaving a much smaller amount of residue (11 wt.\%). In the only one published paper on pyrolysis of waste CDs the amount of residue measured was much larger (i.e. 39\%), while a lower liquid fraction was measured (i.e 47\%) [40]. This could be due to the lower pyrolysis temperature (i.e. $450^{\circ} \mathrm{C}$ ) used by these author [40].The pyrolysis oil in both cases had a low viscosity and was brown in colour. Very recently, Hall and Williams [41], found approximately a similar composition from a mixed WEEE plastic (i.e. oil product $70.6 \%$, gaseous fraction $7.8 \%$ and char plush ash 21.1\%). (C) [2015] IEEE. Reprinted, with permission, from Achilias D.S., Antonakou E.V., Koutsokosta E., Lappas A.A. Chemical recycling of polymers from waste electric and electronic equipment. Journal of Applied Polymer Science, 2009; 114, 212-221 [6] 


\begin{tabular}{ccccc}
\hline Polymer & Temperature $\left({ }^{\circ} \mathbf{C}\right)$ & Gas (wt.\%) & Liquid (wt.\%) & Residue (wt.\%) \\
\hline Model PC & 550 & 6.57 & 63.03 & 30.4 \\
\hline CD & 550 & 8.64 & 80.36 & 11.0 \\
\hline
\end{tabular}

Table 3. Product yield from the pyrolysis of model PC and a Compact Disk (wt \% on polymer)

The mass composition of the pyrolysis gases (on a nitrogen free basis) is presented in Table 4. The presence of carboxyl units -COO- in the macromolecular chain of polycarbonates leads to the production of large amounts of $\mathrm{CO}_{2}$ and $\mathrm{CO}$ in the gaseous fraction. Thus, the amount of carbon dioxide measured in the model PC gas released was $58 \%$ of the total fraction, while that from the CD pyrolysis was even more and nearly $66 \mathrm{wt} . \%$. The amount of carbon monoxide was $21 \mathrm{wt} . \%$ in both cases. A smaller amount of $\mathrm{CH}_{4}$ was also measured (17 wt.\% and $6 \mathrm{wt} . \%$ from model $\mathrm{PC}$ and the $\mathrm{CD}$, respectively), which is formed from the degradation of the methylene $\left(-\mathrm{CH}_{3}\right)$ branches of the polycarbonates. $\mathrm{CO}_{2}, \mathrm{CO}$ and $\mathrm{CH}_{4}$ consisted of $96 \mathrm{wt} . \%$ and $93 \mathrm{wt}$ \% of the total gaseous fraction from model PC and CD pyrolysis, respectively. Pyrolysis gases from both samples investigated, contained also smaller amounts of $\mathrm{H}_{2}$ and other $\mathrm{C}_{2}-$ $\mathrm{C}_{5}$ alkanes and alkenes. Very interesting was the comparison of results obtained from $\mathrm{CD}$ pyrolysis with those reported by Hall and Williams [41] on a mixed WEEE sample. The amounts reported by these authors on the gaseous fraction (i.e. $\mathrm{CO}_{2} 65$ wt.- $\%, \mathrm{CO} 15$ wt.- $\%$ and $\mathrm{CH}_{4} 6$ wt.-\%) were very similar to those presented in this investigation. (C) [2015] IEEE. Reprinted, with permission, from Achilias D.S., Antonakou E.V., Koutsokosta E., Lappas A.A. Chemical recycling of polymers from WEEE. Journal of Applied Polymer Science, 2009; 114, 212-221.

\begin{tabular}{lll}
\hline & & Sample \\
\hline Compound & Model PC & CD \\
\hline Hydrogen, $\mathrm{H}_{2}$ & 0.047 & 0.058 \\
\hline Carbon dioxide, $\mathrm{CO}_{2}$ & 3.807 & 5.711 \\
\hline Carbon monoxide, $\mathrm{CO}$ & 1.364 & 1.851 \\
\hline Methane, $\mathrm{CH}_{4}$ & 1.097 & 0.547 \\
\hline Ethane, $\mathrm{C}_{2} \mathrm{H}_{6}$ & 0.060 & 0.131 \\
\hline Ethylene, $\mathrm{C}_{2} \mathrm{H}_{4}$ & 0.100 & 0.122 \\
\hline Propane, $\mathrm{C}_{3} \mathrm{H}_{8}$ & 0.010 & 0.008 \\
\hline Propylene, $\mathrm{C}_{3} \mathrm{H}_{6}$ & 0.063 & 0.065 \\
\hline Butane-Butene, $\mathrm{nC}_{4}$ & 0.018 & 0.035 \\
\hline Pentane-Pentene, $\mathrm{nC}_{5}$ & 0.008 & 0.010 \\
\hline Isopentane-Isopentene, $\mathrm{iC}_{5}$ & 0.000 & 0.088 \\
\hline Hexanes-Hexenes, $\mathrm{C}_{6}$ & 0.000 & 0.014 \\
\hline Total & 6.574 & 8.640 \\
\hline
\end{tabular}

Table 4. Composition of the gaseous fraction (wt \% on polymer) from the pyrolysis of model PC and a Compact Disk (C) [2015] IEEE. Reprinted, with permission, from Achilias D.S., Antonakou E.V., Koutsokosta E., Lappas A.A. Chemical recycling of polymers from WEEE. Journal of Applied Polymer Science, 2009; 114, 212-221 [6] 
The composition of theliquid fraction was analysed using GC-MS and the componentsidentified are shown in Table 5. The largest component of the model PC oil was phenol (32.1\%), followed by bisphenol A (16\%) and cresol (12.9\%). From the CD pyrolysis the monomer bisphenol A was detected in the largest amount (31.9\%) followed by phenol (24.9\%) and cresol (8.8\%).

\begin{tabular}{|c|c|c|c|}
\hline \multirow[b]{2}{*}{ Compound } & \multirow[b]{2}{*}{ Chemical formula } & \multicolumn{2}{|c|}{ Sample } \\
\hline & & Model PC & $\mathrm{CD}$ \\
\hline Toluene & & 0.4 & 0.2 \\
\hline Xylene & & 0.4 & 0.1 \\
\hline Cumene & & 0.3 & - \\
\hline Phenol & & 32.1 & 24.9 \\
\hline Methyl phenol (cresol) & & 12.9 & 8.8 \\
\hline Ethyl phenol & & 2.8 & 5.3 \\
\hline Propylphenol / isopropylphenol & & 5.6 & 7.6 \\
\hline tert-butylphenol & & 0.4 & 0.3 \\
\hline 4-(1-methyl-1-phenylethyl)- phenol & & 6.4 & 3.4 \\
\hline 4-(phenylmethyl)- phenol & & 3.4 & 2.2 \\
\hline Bisphenol A & & 16.0 & 31.9 \\
\hline Other phenols & & 3.8 & 1.2 \\
\hline Tetramethyl benzene & & 9.9 & 9.3 \\
\hline Diphenyl ether & & 0.4 & 0.1 \\
\hline Diphenyl carbonate & & 0.3 & 0.4 \\
\hline Benzofuranes & & 0.9 & 0.2 \\
\hline Other aromatic compounds & & 4.0 & 4.1 \\
\hline
\end{tabular}

Table 5. Compounds identified in the liquid pyrolysis fraction of model PC and Compact Disk (wt.-\% on liquid produced) (C [2015] IEEE. Reprinted, with permission, from Achilias D.S., Antonakou E.V., Koutsokosta E., Lappas A.A. Chemical recycling of polymers from WEEE. Journal of Applied Polymer Science, 2009; 114, 212-221 [6] 
Large amount of phenols and bisphenol A in the oil fraction of PC and CD pyrolysis as well as from mixed WEEE plastic was also reported by Mitan et al. [40] and Hall and Williams [41], respectively. Other phenols, like ethyl-, propyl and tert-butyl phenols were also detected in quantifiable amounts, together with phenols having two phenyl rings in their molecular structure. Ethers and carbonates were recorded in smaller amounts, together with some benzene based compounds (i.e. tetramethyl benzene, toluene, xylene, cumene, etc.). The amount of benzofuranes was less than $1 \%$ in both samples. Increased pyrolysis temperatures may lead to increased amounts of PAHs and dibenzofuranes in the liquid fraction as it was found by Becker et al. [42]. A similar distribution of liquid products measured during pyrolysis of some polycarbonate materials has been reported in literature [43, 44, 38, 45]. (C [2015] IEEE. Reprinted, with permission, from Achilias D.S., Antonakou E.V., Koutsokosta E., Lappas A.A. Chemical recycling of polymers from waste electric and electronic equipment. Journal of Applied Polymer Science, 2009; 114, 212-221 [6]

According to Jang and Wilkie [43], the main thermal degradation pathways of PC follow chain scission of the isopropylidene linkages, rearrangement and alcoholysis/hydrolysis of carbonate linkages. Alcoholysis/hydrolysis of carbonate linkages produces alcohol compounds, such as those observed in large amounts also in this investigation (i.e. phenol, methyl phenol, ethyl phenol and isopropyl phenol), while phenyl or aliphatic end groups are primarily produced due to chain scission.[43, 44] Some carbonate linkages may react with alcohol end groups to form eventually char like structures. The presence of Bisphenol A in large amounts implies that hydrolysis/alcoholysis of carbonate linkage is the pathway for the formation of that compound.[43] Moreover, chain scission of the isopropylidene linkages and rearrangement of carbonate linkages form carbonate and ether compounds. Xanthone units and cyclic oligomers were not detected among the evolved products in nitrogen.[25] The number of liquid compounds produced from PC pyrolysis can be diminished using active metal catalysts, such as $\mathrm{ZnCl}_{2}$ or $\mathrm{SnCl}_{2}$ [39].

\section{Recycling of HIPS}

Polystyrene recycling can also be performed through a series of mechanical, chemical and thermal methods. High impact polystyrene (HIPS) is a less studied but promising material, especially for mechanical recycling technologies since its properties are not significantly affected even after multiple recovery cycles. During thermal treatment methods the liquid and gaseous products recovery depend significantly on the reaction conditions, while the catalytic methods favor the production of specific liquid and gaseous products.

High impact polystyrene (HIPS) consists of a composite material with a polystyrene base and a dispersed butadiene phase [46]. The chemical structure of HIPS appears in Figure 5. It appears to be one of the main fractions of the Waste Electrical and Electronic Equipment. It is produced through the free radicals polymerisation of the styrene polymer in the presence of butadiene aiming at a product with increased impact strength and toughness of polystyrene (PS) [47]. The properties of the produced composite material mainly depend on the percentage of the 
butadiene in the initial polymer, which varies between 3-10 mol\%. It is widely used in electrical and electronic equipment, in construction and packaging materials and in storage bottles, appliance parts, housewares, and interior parts in household electronics [48].

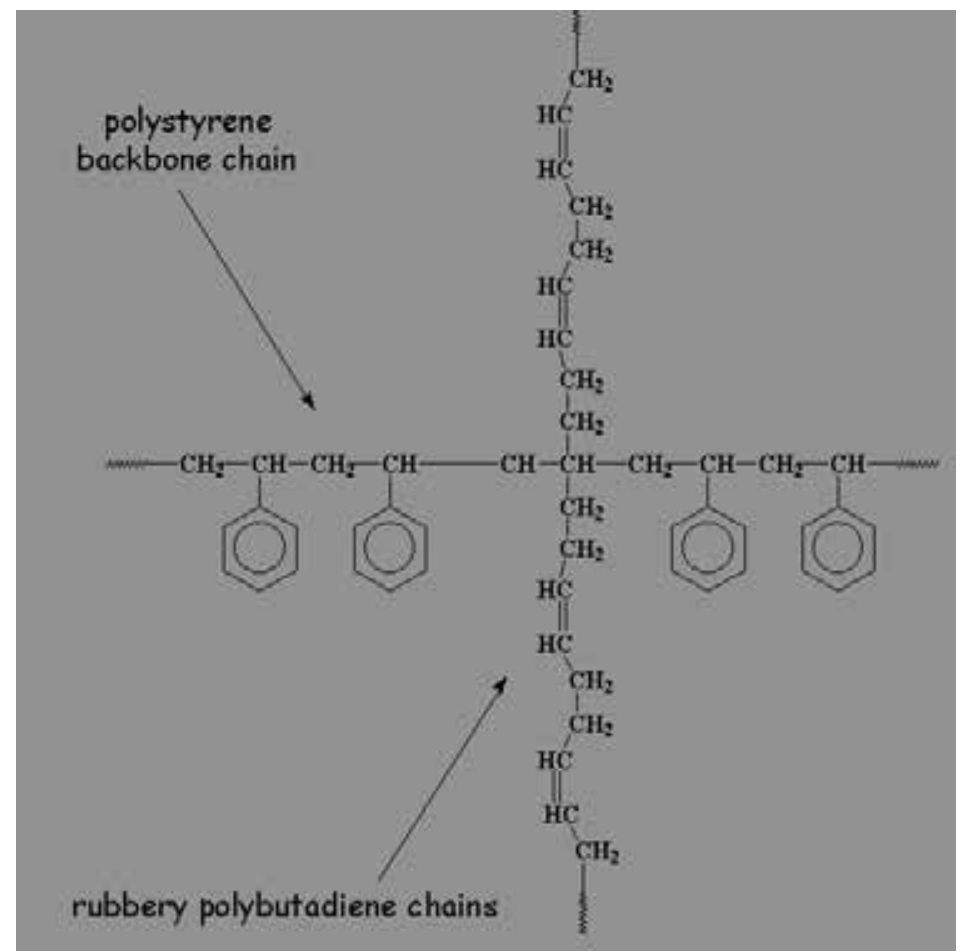

Figure 5. Chemical structure of HIPS. (www.chemsrv1.uwsp.edu)

\subsection{Mechanical recycling}

A recycling technique aiming at the study of the mechanical properties recycling of commercial ABS and HIPS and their mixtures has been suggested by Brennan et al. [49]. Previous studies have reported that when the polymers under study undergo multiple recycling series results are move obvious concerning properties related to impact resistance. It has also been suggested that most of the thermoplastic can be treated together with small quantities of other polymers with minimum effect on their mechanical properties, while their impact resistance can be further improved with the introduction of a suitable modifier. Recycling does not seem to have a significant effect on properties such as glass transition temperature or impact resistance concerning polymers like ABS and HIPS, while their malleability decreases significantly, especially in the case of HIPS. Generally, it is expected that the combination of small quantities of ABS in HIPS and HIPS in ABS will improve the mechanical properties that have been lost due to decomposition during recycling with an exception concerning impact resistance which can be improved with the introduction of a suitable modifier [49]. 
In another published work of Mural et al, mixtures of polypropylene (PP) and HIPS have been recovered mechanically from waste electronics. More specifically, mixtures of polymers have been produced with ratios PP/HIPS 30/70, 50/50 and 70/30 and their thermal properties have been studied with a variety of techniques such as DSC and TGA. Additionally, DMA analysis has shown the presence of two distinct glass transition temperatures $(\mathrm{Tg})$ which correspond to PP and HIPS and are indications for the formation of a two phases morphology [50].

\subsection{Pyrolysis}

In one of the few studies on the thermal degradation of HIPS in the presence of a catalyst it has been reported that the introduction of a nickel catalyst results in an increased production of gases from the HIPS polymer [10]. Jakab and his team [51] have studied the thermal decomposition of four samples of HIPS in the presence of flame retardants by using methods such as TG/MS, Py-GC/MS and Py-MS. It has been found that the presence of flame retardants affects the thermal decomposition of HIPS, not as much in terms of thermal decomposition but mainly concerning the composition of the pyrolysis products. Some years later Grause and his co-workers, in an attempt to study the kinetics of the thermal decomposition reaction of HIPS [46] have used the method of thermogravimetric analysis (TGA) in samples of pure HIPS as well as HIPS in the presence of brominated flame retardant with heating rates between 2.5 and $10 \mathrm{~K} \mathrm{~min}^{-1}$. The activation energy was found to be $200 \mathrm{~kJ} \mathrm{~mol}^{-1}$, using the Avrami-Eroféev kinetics. This value is at the range of the polystyrene decomposition activation energy so it seems that the effect of polybutadiene on the $\mathrm{E} \alpha$ is not significant. The flame retardants generally seem to reduce the activation energy value, while for higher percentages of weight loss (more than $80 \%$ ) even higher values of $\mathrm{E} \alpha$ have been found, possibly due to the separate decomposition of polystyrene-polybutadiene in the presence of the retardants. Although the emphasis in both cases was on the study of the effect of the flame retardants on the pyrolysis process, a series of useful conclusions concerning the decomposition reaction kinetics could be extracted.

Marcilla and his team $[52,48]$ also worked on the catalytic pyrolysis of mixtures of Al-MCM-41 catalysts and a series of polymers and copolymers with a styrene base by the means of thermogravimetric analysis, and they reported that the mesoporous catalysts appear to be interesting in the process of HIPS thermal degradation. In a published paper of 2007 [52] they studied, with the thermogravimetric technique, the effect of parameters such as particle size and method of contact between polymer/catalyst in the HIPS pyrolysis. In a later study of 2009 [48] they also studied the pyrolysis of a series of polystyrene/polybutadiene copolymers in the presence of Al-MCM-41 in an attempt to compare their behaviour in the pyrolysis process with that of HIPS. Results have shown the importance of parameters such as the copolymer structure, the flow characteristics and the method of contact between the polymer and the catalyst in the pyrolysis process. Hall and Williams have studied the HIPS pyrolysis in the presence of decabromodiphenylether (retardant) in a fluidised bed reactor and they reported that the $90 \mathrm{wt} . \%$ of the initial polymer has been converted to a liquid pyrolysis product [11].

Jung et al [53] extensively studied the pyrolysis of HIPS in the presence of bromine containing retardants and $\mathrm{Sb}_{2} \mathrm{O}_{3}$ in a fluidised bed reactor. The pyrolysis process took place in the absence and presence of three Ca containing additives: $\mathrm{Ca}$ : $\mathrm{CaO}, \mathrm{Ca}(\mathrm{OH})_{2}$ and oyster shells. It was found that the presence of $\mathrm{Ca}$ affected the produced liquid fraction composition, also increas- 
ing the concentration of the styrene produced. In a more recent study [54] the same group has studied the effect of a series of parameters such as temperature, feed rate and the type of fludising medium on the HIPS (as well as ABS) pyrolysis, also in a fluidised bed reactor. It was found that the higher feed rates and the use of product gas as a fluidising medium increased the liquid fraction production. The produced liquid fraction for HIPS reaches $87.3 \mathrm{wt}$ \% and consists mainly of the styrene monomer, aromatic hydrocarbons and oligomers and could potentially be used as a fuel with no significant treatment.

\subsubsection{Pyrolysis mechanism}

During the thermal degradation of different forms of polystyrene with enhanced properties such as HIPS, a series of changes in the physical properties of the initial polymer have been observed, depending on factors such as the polymer density and the bead structure. Researchers have shown that the polymer structure was destroyed in temperatures between $110-120^{\circ} \mathrm{C}$. The polymer particles melt in temperatures higher than $275^{\circ} \mathrm{C}$, while the complete gasification takes place in temperatures between $460-500{ }^{\circ} \mathrm{C}$ [55].

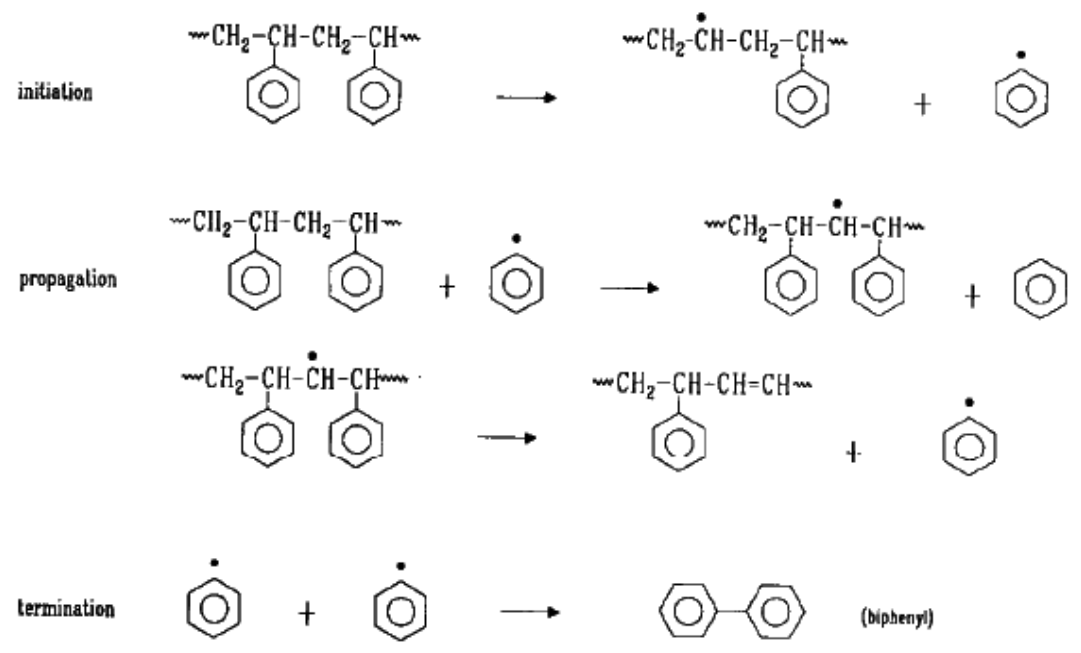

Figure 6. Thermal degradation reactions during HIPS pyrolysis

The studies on the mechanism of HIPS thermal degradation are limited but it has been suggested that the decomposition mechanism is the free radicals mechanism which takes place in three steps: initiation, propagation and termination (figure 6). A basic step of the mechanism is the formation of a phenyl free radical, which later leads to the formation of a stable biphenyl through the termination step. The determination of the benzene molecule on the pyrolysis products from many researchers leads to the hypothesis that the free radicals mechanism takes place together with some elimination reactions which possibly lead in the benzene formation. The benzene formation seems to be favored by an increase in temperature and leads to the formation of unsaturated bonds in the molecule of the remaining polymer. These bonds can 
facilitate the initiation process of the free radicals mechanism acting as weak links. In fact a single $\mathrm{C}-\mathrm{C}$ bond which is placed next to an unsaturated bond is more likely to participate in scission reactions through the free radicals mechanism [56].

In the case of HIPS, the polybutadiene phase can be the first step in the thermal decomposition of the polymer. As it has already been reported, the HIPS polymer is formed with the introduction of a polybutadiene phase in the polystyrene. The resulting copolymer can be structurally determined as a multiple phase system in the form of dispersed butadiene granules on a continuous polystyrene network. This phase consists of three basic isomeric units of polybutadiene: vinyl-1,2, cis-1,4, and trans-1,4 (figure 7) and the initial decomposition is related with the chemistry of these three butadiene microstructures [57]

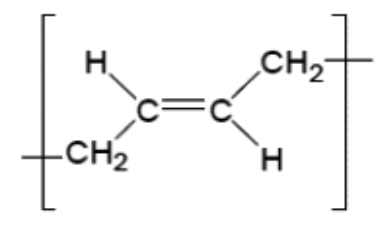

trans $-1,4$

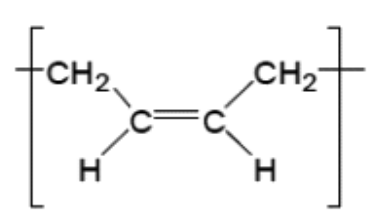

cis $-1,4$<smiles>C=CC(C)CC(C)(C)C</smiles>

vinyl-1,2

Figure 7. The three microstructures of polystyrene [57]

\subsection{Photodegradation}

The research team of Fernardes and coworkers [58] have studied the effect of the presence of the HIPS polymer on the photodegradation of polypropylene. The concentrations of the HIPS varied between 10 and $30 \mathrm{wt} \%$. The polymer mixtures as well as the original polymers have been exposed to UV radiation for periods up to 15 weeks. After the third week of exposure to the UV radiation all the materials appear to have mechanical properties comparable to those of the initial. For time periods longer than 3 weeks, increased HIPS concentrations lead to a better photostability of the polypropylene polymer.

\section{Recycling of ABS}

The ABS resin is basically a terpolymer consisting of three monomers: acrylonitrile, butadiene and styrene. The ABS polymer can be of various compositions and its properties vary depending on the structure and chemical microstructure of the different phases. Generally in the more classical form of ABS the continuous phase consists of copolymers of styrene and acrylonitrile, while the butadiene usually forms the dispersed phase. ABS polymers find a variety of applications since they are tough and with enhanced resistance to heat, cold, chemicals and alteration of environmental conditions. They are widely used in construction and environmental industry, in a variety of household applications and as a thermoplastic. 


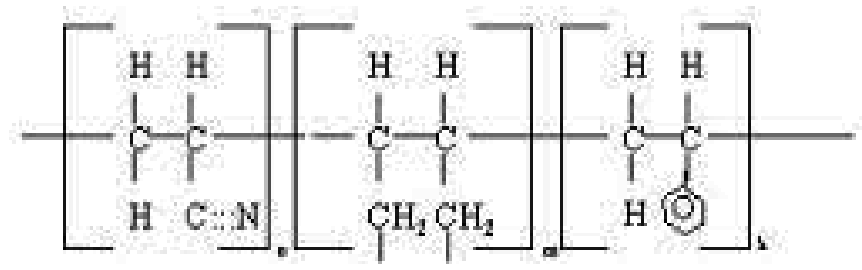

Figure 8. Chemical structure of ABS (www.cucd2011.mae.carleton.ca)

Most of the research in the area of ABS recycling is devoted in the study of ABS containing waste electronics and/or blends. Brebu et al. [59] studied the thermal and catalytic degradation of ABS polymers and the distribution of nitrogen containing compounds in the degradation products. Liu et al [60] in an attempt to upgrade recycled engineering plastics with ABS as their main component studied the possibility of blending ABS with PA, in order to maintain the advantages of both materials. They reported that the mechanical properties of ABS/PA can be upgraded with the introduction of small amounts of a compatibilizer and a core-shell impact modifier when they were working with "fresh" polymeric materials but the same technique did not apply for recycled materials.

In a study of 2003, Bhaskar et al [61] reported the thermal degradation of the ABS terpolymer which contained about $10 \mathrm{wt} . \%$ of a brominated flame retardant. It was found that the heating rate has a significant effect on the yields and compositions of the pyrolysis products (liquid, gas and solid residue). The solid residue consisted of the carbon residue and the wax, while the majority of the bromine was concentrated in the carbon residue. Studies to remove the bromine (as well as and nitrogen) containing products from the ABS liquid products is suggested by the researchers as the next step, if the pyrolysis oil is to find further applications and to be used as a fuel.

In a more recent study, Du et al [62] investigated the thermal degradation of ABS and denitrogenated ABS samples (DABS), by means of TGA, TGA-IR, and TGA-MS, in order to study the link between the original structure of DABS and the effect of the pyrolysis process. Degradation process of DABS was faster, initiating at a lower degradation temperature, while the amount of HCN decreases and the percentage of nitrogen in residue increases for DABS. The liquid product consists mainly of compounds of an aromatic origin. The authors suggested that effective denitrogenation of ABS before pyrolysis is beneficial for the quality of the produced pyrolysis oil, since they significantly decrease the nitrogen content and thus the HCN evolution.

In a study of 2014, Sun et al [63] in one of the few studies on the reuse of non metal parts of a real waste, investigated the co-recycling of acrylonitrile-butadiene-styrene waste plastic and nonmetal particles from waste printed circuit boards to manufacture reproduction composites (RC) in an attempt to co-recycle the two waste electronics. Results showed that the presence of nonmetal particles significantly improved the mechanical properties and the physical performance of the RC. This research suggests that this could act as a viable method to reuse waste ABS and WPCB nonmetals for manufacturing high value-added product. The composite material can find applications in panels, wall coverings and furniture. 


\section{Conclusion}

This chapter outlines the recent advances in the area of chemical and thermo-chemical recycling of polymers from waste electrical and electronic equipments. Particularly, recycling methods were presented for polycarbonate (PC), High impact polystyrene (HIPS) and the $\mathrm{ABS}$ resin, a terpolymer consisting of acrylonitrile, butadiene and styrene.

The dissolution-re precipitation method which uses an appropriate solvent/non-solvent system was critically reviewed. Furthermore, pyrolysis methods were presented as a promising alternative to produce a number of secondary value-added products.

\section{Author details}

Dimitris S. Achilias* and Eleni V. Antonakou

*Address all correspondence to: axilias@chem.auth.gr

Laboratory of Organic Chemical Technology, Department of Chemistry, Aristotle University of Thessaloniki, Thessaloniki, Greece

\section{References}

[1] Alston S., Clark A., Arnold J., Stein B. Environmental Impact of Pyrolysis of Mixed WEEE Plastics Part 1: Experimental Pyrolysis Data. Environmental Science Technology 2011; 45 9380-9385.

[2] Kantarelis E., Yang W., Blasiak W., Forsgren C., Zabaniotou A. Thermochemical treatment of E-waste from small household appliances using highly pre-heated nitrogen-thermogravimetric investigation and pyrolysis kinetics. Applied Energy 2011; 88 922-929.

[3] De Marco I., Caballero B.M., Chomon M.J., Laresgoiti M.F., Torres A., Fernandez G., Arnaiz S. 2008. Pyrolysis of electrical and electronic wastes. Journal of Analytical and Applied Pyrolysis 2008 82; 179-183.

[4] Martinho G., Pires A., Saraiva L., Ribeiro R. Composition of plastics from waste electrical and electronic equipment (WEEE) by direct sampling. Waste Management 2012 32; 1213-1217.

[5] Develop a Process to Separate Brominated Flame Retardants from WEEE Polymers UK Waste \& Resources Action Programme: Banbury, UK, 2007; http:// www.wrap.org.uk/recycling_industry/publications/develop_a_process_1.html; Final Report. 
[6] Achilias D.S., Antonakou E.V., Koutsokosta E., Lappas A.A. Chemical recycling of polymers from waste electric and electronic equipment. Journal of Applied Polymer Science, 2009; 114, 212-221.

[7] Scheirs J., Kaminsky W., Eds. Feedstock Recycling and Pyrolysis of Waste Plastics. J. Wiley \& Sons, W. Sussex, UK., 2006.

[8] Kowalska E., Radomska J., Konarski1 P., Diduszko R., Oszczudowski J., Opaliska T., Wich M., Duszyc Z. Thermogravimetric investigation of wastes from electrical and electronic equipment (WEEE). Journal of Thermal and Analytical Calorimetry 2006 $86 ; 137-140$.

[9] Molto J., Font R., Galvez A., Conesa J.A. Pyrolysis and combustion of electronic wastes. Journal of Analytical and Applied Pyrolysis 2009 84; 68-78.

[10] Acomb J.C., Nahil M.A., Williams P.T. Thermal processing of plastics from waste electrical and electronic equipment for hydrogen production. Journal of Analytical and Applied Pyrolysis. 2013 103; 320-327.

[11] Hall, W.J., Williams, P.T. Pyrolysis of brominated feedstock plastic in a fluidised bed reactor. Journal of Analytical and Applied Pyrolysis 2006 77; 75-82.

[12] Hall W.J., Williams P.T. Analysis of products from the pyrolysis of plastics recovered from the commercial scale recycling of waste electrical and electronic equipment. Journal of Analytical and Applied Pyrolysis 2007 79; 375-386.

[13] Pinto F., Costa P., Gulyurtlu I., Cabrita I. Pyrolysis of plastic wastes 2. Effect of catalyst on product yield Journal of Analytical and Applied Pyrolysis 1999 51; 57-71.

[14] Grause G., Sugawara K., Mizoguchi T., Yoshioka, T. Pyrolytic hydrolysis of polycarbonate in the presence of earth-alkali oxides and hydroxides. Polymer Degradation and Stability 2009 94; 1-6.

[15] Vasile C., Brebu M.A., Karayildirim T., Yanik T., Darie H. Feedstock recycling from plastics and thermosets fractions of used computers. II. Pyrolysis oil upgrading. Fuel 2007 86; 477-485.

[16] Williams P.T. Valorization of Printed Circuit Boards from Waste Electrical and Electronic Equipment by Pyrolysis. Waste and Biomass Valorization 2010 1; 107-120.

[17] Balart R., Sanchez L., Lopez L., Jimenez A. Kinetic analysis of thermal degradation of recycled polycarbonate/acrylonitrilebutadiene-styrene mixtures from waste electric and electronic equipment. Polymer Degradation and Stability 2006 91; 527-534.

[18] Balart R., Lopez J., Salvador M.D. Recycling of ABS and PC from electrical and electronic waste. Effect of miscibility and previous degradation on final performance of industrial blends. European Polymer 2005 41; 2150-2160. 
[19] Antonakou E. and Achilias D. Recent advances in polycarbonate recycling- a review of degradation methods and their mechanisms, Waste and Biomass Valorization 2012 DOI 10.1007/s12649-012-9159-x

[20] Bozzano G., Dente M. and Del Rosso R. Poly(bisphenol A carbonate) recycling: High pressure hydrolysis can be a convenient way, Material Recycling - Trends and Perspectives, D. Achilias (Ed.), 2012, ISBN: 978-953-51-0327-1, InTech, Available from: http://www.intechopen.com/books/material-recycling-trends-andperspectives/ polybisphenol-a-carbonate-recycling-high-pressure-hydrolysis-can-e-a convenient-way.

[21] Karayannidis G., D.S. Achilias D. Chemical recycling of PET, Macromolecular Materials and Engineering 2007 292;128-146.

[22] Liu F., Li Z., Yu S., Cui X., Ge X., Environmentally benign methanolysis of polycarbonate to recover bisphenol $\mathrm{A}$ and dimethyl carbonate in ionic liquids. Journal of Hazardous Materials 2010 174; 872-875.

[23] Watanabe M., Matsuo Y., Matsushita T., Inomata H., Miyake T., Hironaka K. Chemical recycling of polycarbonate in high pressure high temperature steam at $573 \mathrm{~K}$., Polymer Degradation and Stability 2009 94; 2157-2162.

[24] Grause G., Sugawara K., Mizoguchi T.,Yoshioka T. Pyrolytic hydrolysis of polycarbonate in the presence of earth-alkali oxides and hydroxides, Polymer Degradation and Stability 2009 94; 1-6.

[25] Pan Z.Y., Zhen B., Chen Y.X. Depolymerization of Poly(Bisphenol A Carbonate) in Subcritical and Supercritical Toluene, Chinese Chemical Letters 2006 17; 545-548.

[26] Sato Y., Kondo Y., Tsujita K., Kawai N. Degradation behaviour and recovery of bisphenol-A from epoxy resin and polycarbonate resin by liquid-phase chemical recycling. Polymer Degradation and Stability 2005 89; 317-326.

[27] Oku A., Tanaka S., Hata S. Chemical conversion of poly(carbonate) to bis(hydroxyethyl) ether of bisphenol A. An approach to the chemical recycling of plastic wastes as monomers. Polymer 2000 4; 6749-6753.

[28] Hata S., Goto H., Yamada E., Oku A. Chemical conversion of poly(carbonate) to 11,3dimethyl-2-imidazolidinone (DMI) and bisphenol A: a practical approach to the chemical recycling of plastic wastes. Polymer 2002 43; 2109-2116.

[29] Hu L., Oku A., Yamada E. Alkali-catalyzed methanolysis of polycarbonate. A study on recycling of bisphenol A and dimethyl carbonate. Polymer 1998 39; 3841-3845.

[30] Pinero R., Garcia J., Cocero M.J. Chemical recycling of polycarbonate in a semicontinuous lab-plant: a green route with methanol and methanol-water mixtures. Green Chemistry 2005 7; 380-387. 
[31] Chen L.,Wu Y., Ni Y., Huang K., Zhu Z. Degradation kinetics of polycarbonate in supercritical methanol. Journal of Chemical and Industrial Engineering 2004 55; 1787-1792.

[32] Liu F., Li Z., Yu S., Cui X., Xie C., Ge X. Methanolysis and hydrolysis of polycarbonate under Moderate Conditions. Journal of Polymers and the Environment 2009 17; 208-211.

[33] Chiu S.J., Tsai C.T., Chang Y.K. Monomer recovery from polycarbonate by ethanolysis. E-Polymers; 2008. No. 132. Available from: http://www.e-polymers.org.

[34] Liu F., Li L., Yu S., Lv Z., Ge X. Methanolysis of polycarbonate catalysed by ionic liquid [Bmim][Ac]. Journal of Hazardous Materials 2011 189; 249-254.

[35] Jie H., Ke H., Qing Z.,Lei C., Yongqiang W., Zibin Z. Study on depolymerization of polycarbonate in supercritical ethanol. Polymer Degradation and Stability 2006 91(10); 2307- 2314.

[36] Tagaya H., Katoh K., Kadokawa J., Chiba K. Decomposition of polycarbonate in subcritical and supercritical water. Polymer Degradation and Stability 1999 64; 289-292.

[37] Tsintzou G.P., Antonakou E.V., Achilias D.S. Environmentally friendly chemical recycling of poly(bisphenol-A carbonate) through phase-transfer catalysed alkaline hydrolysis under microwave irradiation. Journal of Hazardous Materials 2012; 241-242, 137-134.

[38] Nikje M.M.A. Glycolysis of polycarbonate wastes with microwave irradiation. Polimery/Polymers 2011; 56: 381-384.

[39] Chiu S.J., Chen S.H., Tsai C.T. Effect of metal chlorides on thermal degradation of (waste) polycarbonate Waste Management. 2006 26; 252-259.

[40] Mitan N., Brebu M., Bhaskar T., Muto A., Sakata Y., Kaji M., J. Mater. Cycles Waste Manag. 2007; 9, 62-68.

[41] Hall W., Williams P. Analysis of products from the pyrolysis of plastics recovered from the commercial scale recycling of waste electrical and electronic equipment.J. Analyt. Appl. Pyrol. 2007 79; 375-386.

[42] Becker L., Lenoir D., Matuschek G., Kettrup A. Thermal degradation of halogen-free flame retardant epoxides and polycarbonate in air. Journal of Analytical and Applied Pyrolysis 2001 60; 55-67.

[43] Jang B., Wilkie C. A TGA-FTIR ans mass spectral study on the thermal degradation of bisphenol A polycarbonate. Polymer Degradation and Stability 2004 86; 419-430.

[44] Zhou W., Yang H., Zhou J. The thermal degradation of bisphenol A polycarbonate containing methyl phenyl containing additive. Journal of Analytical and Applied Pyrolysis 2007 78;413-418. 
[45] Day M., Cooney J., Touchette-Barrette C., Sheehan S. Pyrolysis of mixed plastics used in the electronics industry. Journal of Analytical and Applied Pyrolysis 1999 52; 199-224.

[46] Grause G., Ishibashi J., Kameda T., Bhaskar T., Yoshioka T. Kinetic studies of the decomposition of flame retardant containing high-impact polystyrene. Polymer Degradation and Stability 2010 95; 1129-1137.

[47] Marcilla A., Gomez-Siurana A., Garcia Quesada J.C., Berenguer D. Characterization of high-impact polystyrene by catalytic pyrolysis over Al-MCM-41: Study of the influence of the contact between polymer and catalyst. Polymer Degradation and Stability 2007 92;1867-1872.

[48] Marcilla A., Garcia Quesada J.C., Gomez-Siurana A., Berenguer, D. Characterization of styrene-butadiene copolymers by catalytic pyrolysis over Al-MCM-41. Journal of Analytical and Applied Pyrolysis 2009 85; 327-333.

[49] Brennan L.B., Isaac D.H., Arnold J.C. Recycling of Acrylonitrile-Butadiene-Styrene and High-Impact Polystyrene from Waste Computer Equipment Journal of Applied Polymers Science 2001 86; 572-578.

[50] Prasanna K. S. Mural P.K.S., Mohanty S., Nayak S.K., Anbudayanidhi K., 2011.Int J Plast Technol 15(Suppl 1):S46-S60.

[51] Jakab E., Uddin M.A., Bhaskar T., Sakata Y., 2003. Thermal decomposition of flameretarded high impact polystyrene. Journal of Analytical and Applied Pyrolysis 68-69; 83-99.

[52] Marcilla A., Gomez-Siurana A., Garcia Quesada J.C., Berenguer D. Characterization of high-impact polystyrene by catalytic pyrolysis over Al-MCM-41: Study of the influence of the contact between polymer and catalyst. Polymer Degradation and Stability 2007 92;1867-1872.

[53] Jung S.W., Kim S.J., Kim J.S. Fast pyrolysis of a waste fraction of high impact polystyrene (HIPS) containing brominated flame retardants in a fluidized bed reactor: The effects of various Ca-based additives $(\mathrm{CaO}, \mathrm{Ca}(\mathrm{OH}) 2$ and oyster shells) on the removal of bromine Fuel 2012 95; 514-520.

[54] Jung S.W., Kim S.J., Kim J.S.The influence of reaction parameters on characteristics of pyrolysis oils from waste high impact polystyrene and acrylonitrile-butadiene-styrene using a fluidized bed reactor. Fuel Processing Technology 2013 116; 123-129.

[55] Maharana T., Negi Y.S., Mohanty B. Review Article: Recycling of Polystyrene 2007 46(7); 729-736, DOI: 10.1080/03602550701273963.

[56] Audisio G., F. Bertini F. Molecular weight and pyrolysis products distribution of polymers I. Polystyrene. Journal of Analytical and Applied Pyrolysis, 1992 24; 61-74. 
[57] Francisco Vilaplana F. Modelling the degradation processes in high-impact polystyrene during the first use and subsequent recycling. $2007 \mathrm{PhD}$ Thesis, KTH Chemical Science and Engineering.

[58] Fernandes L.L., Freitas C.A., Demarquette N.R., Fechine G.J.,2011. Photodegradation of Thermodegraded Polypropylene/High-Impact Polystyrene Blends: Mechanical Properties Journal of Applied Polyners Science 2011 120; 770-779.

[59] Brebu M., Uddin M., Muto A., Sakata Y., Vasile C. The role of temperature programme on the quality of ABS degradation oil. Journal of Analytical and Applied Pyrolysis $200263 ; 43-57$.

[60] Liu X.,Boldizar A., Rigdahl, Bertilsson H. Recycling of blends of ABS and polyamide. Journal of Applied Polymer Science 2002 86; 2535-2543.

[61] Bhaskar T., Murai K.,Matsui, T., Bredu M., Uddin M., Muto A. Sakata Y. and Murata K.Studies on thermal degradation of acrylonitrile butadiene styrene copolymer (ABS$\mathrm{Br}$ ) containing brominated flame retardantsJornal of Analytical and Applied Pyrolysis 2003 70;369-381.

[62] Du A., Zhou Q., van Kasteren J. and Wang Y. Fuel oil from ABS using a tandem PEG-enhanced denitrogenation-pyrolysis method:Thermal degradationof denitrogenated ABS. Journal of Analytical and Applied Pyrolysis 2011 92;267-272.

[63] Sun Z., Shen Z., Zhang X., Ma S. Co-recycling of acrylonitrile-butadiene-styrene waste plastic and nonmetal particles from waste printed boards to manufacture reproduction composites. Environmental Technology http://dx.doi.org/ 10.1080/09593330.2014.940399 

Chapter 4

\title{
Compostable Polymers and Nanocomposites - A Big Chance for Planet Earth
}

\author{
Gity Mir Mohamad Sadeghi and Sayaf Mahsa \\ Additional information is available at the end of the chapter \\ http://dx.doi.org/10.5772/59398
}

\section{Introduction}

In this chapter, the significance of composting composites and nanocomposites based on biobased polymers used in various applications to reduce the amount of solid waste in landfills is presented. Furthermore, composting methods to produce compostable materials and international standard test methods for evaluation of the above mentioned materials have been explained.

Our every action must have an impact on the well-being of our planet, and our everyday decisions can help create a better world for all. Reducing the amount of solid waste in landfills and the addition of nutrient-rich organic matter are the help that composting gives to the Earth because organic content in the soil encourages the passage of air and water. The introduction of various contaminants into natural environments that have resulted in instability, disorder, harm, or discomfort to an ecosystem is known as pollution and includes different forms such as air, soil, water, sound, etc.

Chemicals that are released into the ground deliberately, accidentally, or by underground leakage have resulted in soil pollution, and these can include hydrocarbons, herbicides, pesticides, chlorinated hydrocarbons, and heavy metals such a chromium and cadmium. Natural and man-made sources such as vehicle emissions and other principal sources including chemical plants, petrochemical plants, PVC factories, and other plastic factories have caused air pollution [1, 2].

Waste can result in the obstruction of storm water runoff which causes stagnant water bodies to form, hence becoming a means of disease. Furthermore, waste dumped near water sources results in contamination of the groundwater source as well as the water body. 
Plastic pollution is also a serious threat to some of the world's oceans. Ocean currents cause plastic detritus to cumulate together to form large garbage patches. Therefore, polymer pollution is a serious threat that is presented as follows.

\subsection{Polymer pollution: A serious threat}

Polymers are materials that the earth cannot digest and cause serious damage to the environment during their production and disposal process. All polymers produced thus far still exist and could remain with us for more than hundreds of years. Polymers break down into smaller particles which attract toxic materials and are swallowed by wildlife in the ocean or land and then contaminate our food chain. The growth rate in polymer production is significantly fast. Figure 1 presents rates of past and future plastic growth during a 60-year time period (1960 to 2020) through a semilog graph. In order for any of these four plastic categories to slightly change their order of magnitude, a long time duration is necessary. In addition, among the different plastics, polycarbonate and some alloys might be ones that achieve the commodity plastics status by 2020. An average of $8.1 \%$ annual growth rate brought solid polymers from seven million tons to 196 million tons between the years 1960 and 2005. This number will continue to escalate to over 365 and 540 million tons in 2015 and 2020, respectively, with a more conservative yearly rate of $6.5 \%$. The overall production/consumption of plastics worldwide at the turn of the century had an average yearly growth rate of $15 \%$. In other words, the growth rate doubled every five years, until around 1979, when the trend broke at the first oil shock. Such a high growth rate was seen only then, as the average annual growth rate of plastics went from $15 \%$ between the years 1960 and 1974 to $8 \%$ between the years 1974 and 2000 and 2005. The expanding and fast developing markets, with more than a 10-15\% growth rate per year, were similar to the times of great success for the plastics built up in Europe, the USA, and Japan, in the 1960-1975 era [2].

World plastics production includes thermoplastics, polyurethanes, thermosets, elastomers, adhesives, coatings and sealants, and PP fibers, not including PET-, PA- and Polyacryl fibers as shown in Fig. 2 that is reported by the PlasticsEurope Market Research Group (PEMRG) [3]. Once the polymer is produced, the harm introduced is almost permanent. This results in a serious waste disposal and pollution problem. Solid waste is significantly increasing within the world. Where municipal waste is concerned, from the year 1995 to 2003, the average European citizen's municipal waste generation has continually increased by about $2 \%$ per year from 204 million tons ( $457 \mathrm{~kg} /$ person) in 1995 to 243 million tons (534 kg/person) in 2003 [5]. The proportion of postconsumer waste in EU-27, Norway, and Switzerland according to the function could be observed in Fig 3. It is extremely difficult to measure the state of plastic waste. Statistics show that in 2008, an average of 24.9 megatons of plastic waste $[4,5,6]$ was produced in EU-27, Norway, and Switzerland; however, confirming this distribution is quite difficult. Conventional polymers which are made from a hydrocarbon base, such as polyethylene, polypropylene, polystyrene, polyethylene, terephthalate, etc., are virtually nonbiodegradable [6].

In addition to their extreme effects on the ecosystem, chemicals can cause a range of illnesses including birth defects, cancer, and damage to the nervous and immune system and also affect the blood and the kidneys. Many of these toxic substances are also given off during the 


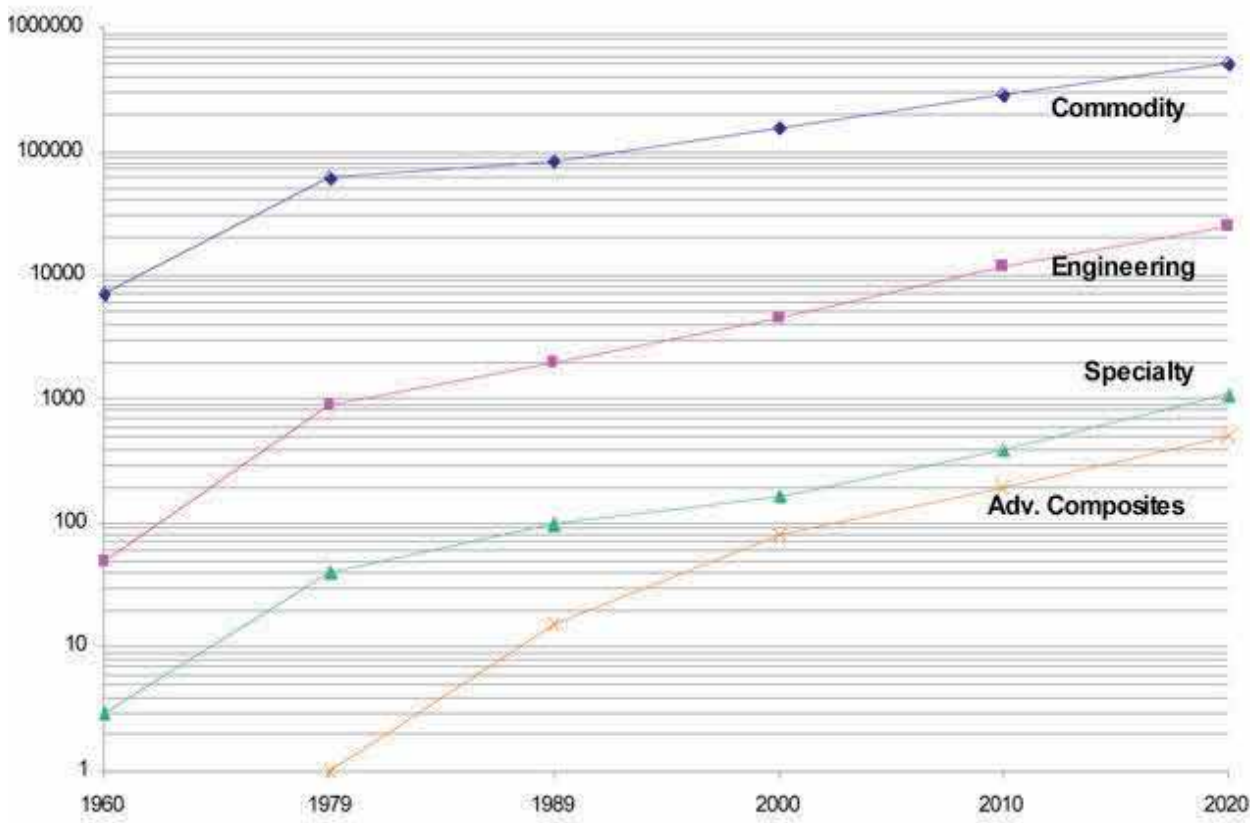

Figure 1. Rates of past and future plastics growth, over a 60-year time span [2]

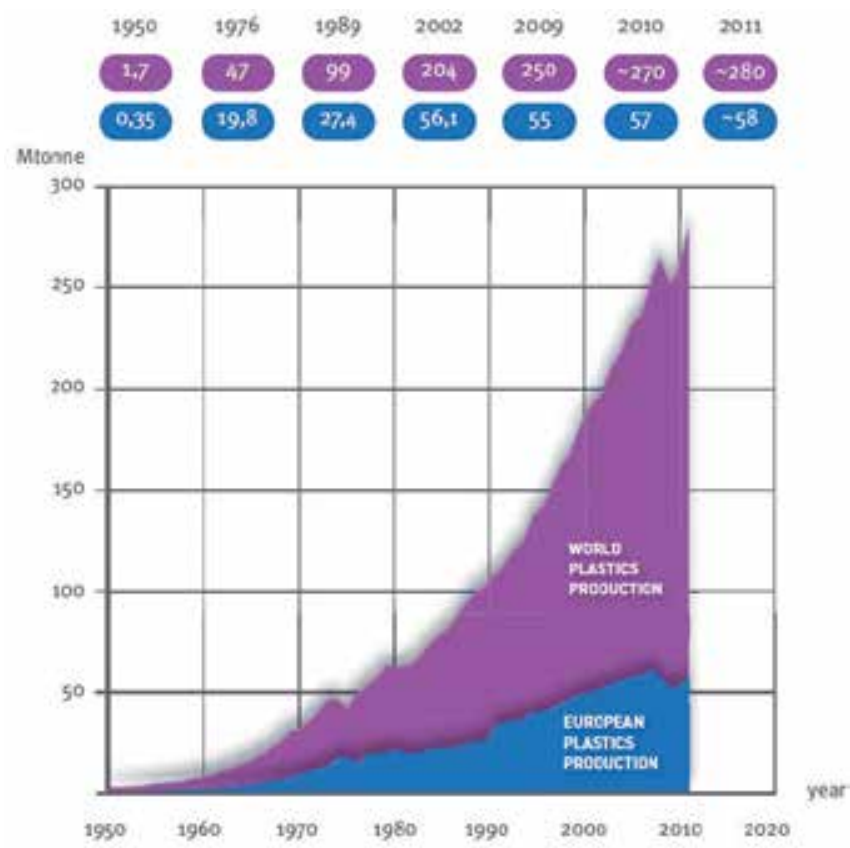

Figure 2. World plastics production 1950-2011 shows that the plastics industry continues to grow rapidly [3] 


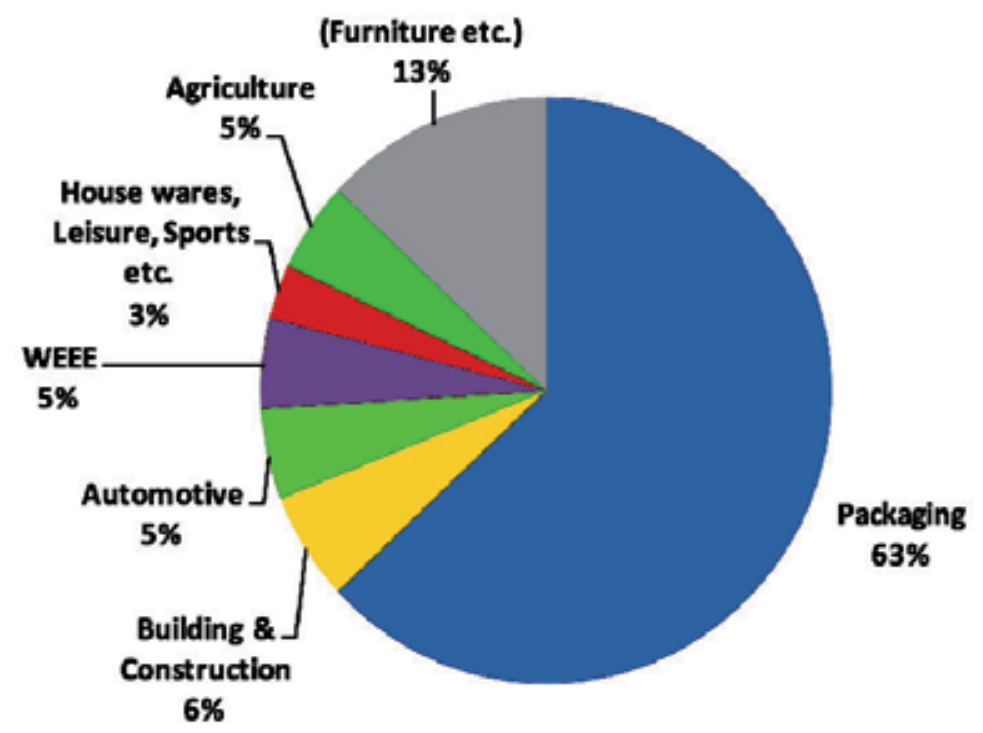

Figure 3. Proportion of postconsumer waste [5]

recycling of polymer. As is the case with all other chemical substances, the "disposal" of polymer seems to be a fallacy.

Polymeric wastes cause drain blockage and irreparable damages to the urban sewage systems. Plastic wastes that are constantly dumped into rivers, streams, and sea pollute the water, soil, marine life, and also the air we breathe. Clogged drains can create extremely bad conditions for mosquitoes to gather while also causing flooding during the monsoon.

Fig. 4 shows Pacific Garbage Patch, as a result of the mentioned condition [7]. Since plastic does not undergo bacterial decomposition, landfilling using plastic would mean preserving the poison forever. Stability of plastics to degradation, closing of landfill sites, and growing water and land pollution problems caused lots of concern about polymers. Waste problem and its serious impact on the environment lead to new interest in the area of degradable polymers. Waste plastic fills bird's stomachs and slowly kills them (see Fig. 5). The interest in environmental issues is growing up; also there are increasing demands to develop materials that do not burden the environment. With the excessive use of plastics and increasing pressure being placed on available capacities for plastic waste disposal, the need for biodegradable plastics and biodegradation of plastic wastes has led to its increased importance in the past few years [8].

Polymers are made of major chemicals that are highly toxic and pose a serious threat to all living species on the planet Earth. Some of the polymer components such as benzene and vinyl chloride are proven to cause cancer, and other gases and liquid hydrocarbons bring about great damages to the earth and air. The toxic substances that are emitted during polymer production are synthetic chemicals like ethylene oxide, benzene, and xylene [9]. Figures $6 a$ and $6 \mathrm{~b}$ show acid rain production cycle and huge smoke that are produced by polymers production plants. 


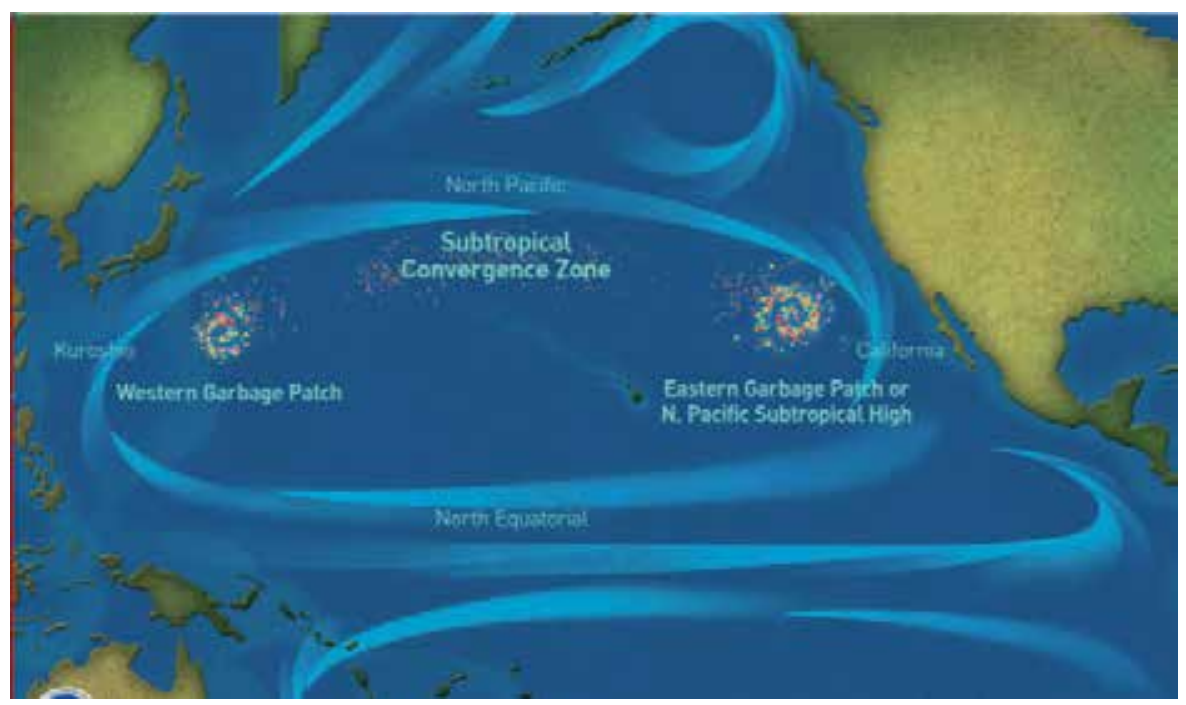

Figure 4. Pacific Garbage Patch [7]

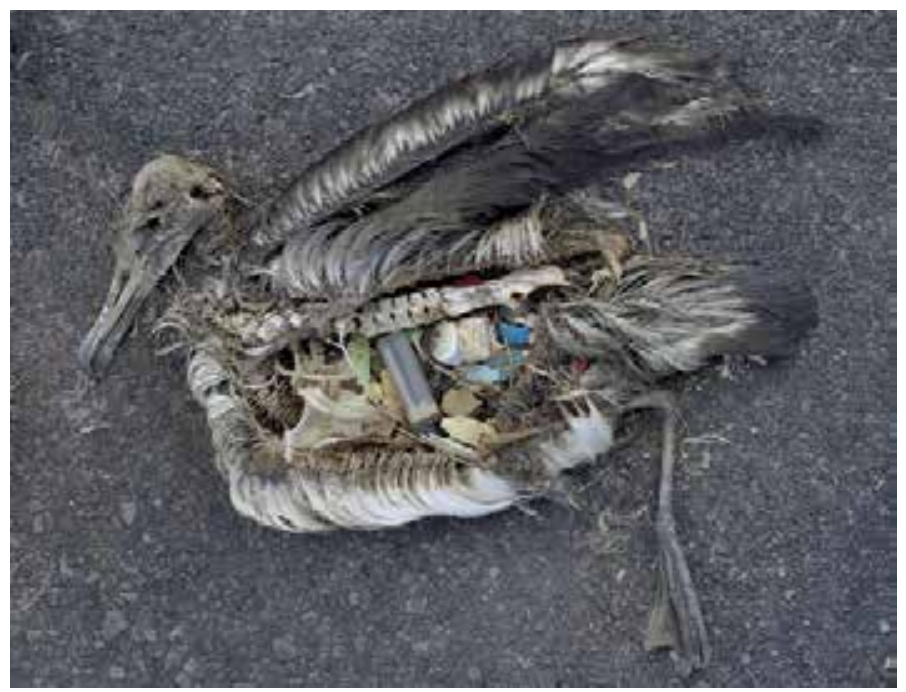

Figure 5. Bird corpse, photo: Chris Jordan

Contaminants such as persistent organic pollutants (POPs) are also attracted by polymeric waste, especially in marine life. Many of these contaminants are hydrophobic; therefore, mixing or binding with water is not possible.

The role of plastics waste on the impact of the toxic chemicals is not evident. These chemicals could potentially move to clean environments by plastics, and when taken in by wildlife, the chemicals could transfer into the organism's system by plastics. However, in certain conditions, plastic could become less available to wildlife and act as a sink, particularly if they are 


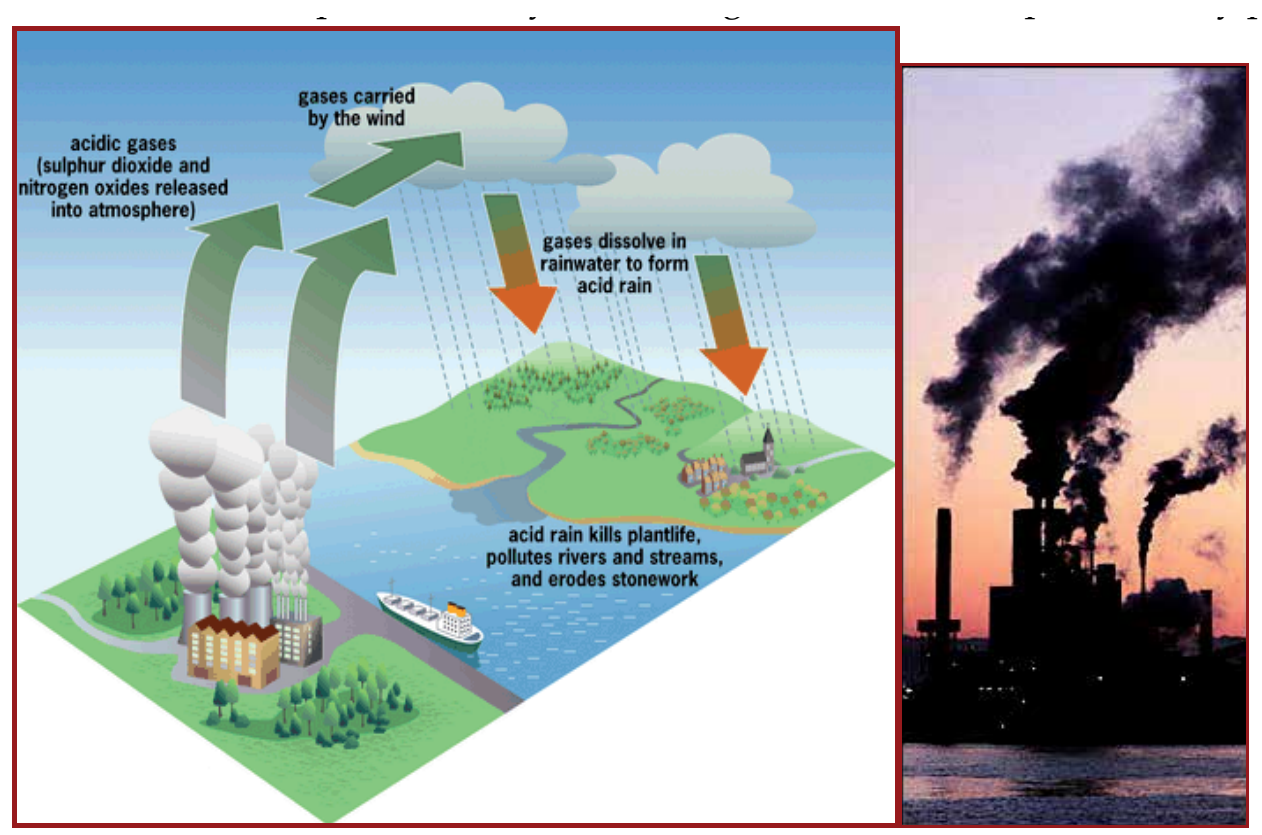

(a)

(b)

Figure 6. (a). Production cycle of acid rain in the Earth [10] (b). Huge dangerous smoke: A result of plastics production [10]

buried on the seafloor. Microplastics have a large surface area-to-volume ratio and are prone to make chemicals more available to wildlife and the environment compared to larger-sized plastics [11].

However, microplastics could pass through the digestive system faster than larger plastics once they have been ingested, potentially giving less chance for chemicals to be absorbed into the circulatory system [8]. A descriptive example is presented in the next section.

\subsubsection{Descriptive example}

In 2002, the production of PET worldwide was 26 million tons which is expected to rise to 85 million tons in 2018. Numerous postconsumer PET products, especially bottles and containers, are not directly hazardous to the environment. You can see a photograph in Fig. 7 that shows the Caspian Sea beach captured by the author. However, its substantial volume fraction in solid waste streams, high resistance to the atmosphere, poor biodegradability, and photo degradability has caused serious problems. Each year, it is estimated that a billion plastic bottles are disposed, while recycling only one plastic bottle can conserve enough energy to light a $60 \mathrm{~W}$ light bulb for up to $6 \mathrm{~h}$ [12].

PET waste can be seen everywhere, so the world production rate of PET waste grows fast (Fig. 8). A greater necessity is felt for the recycling of this product. 

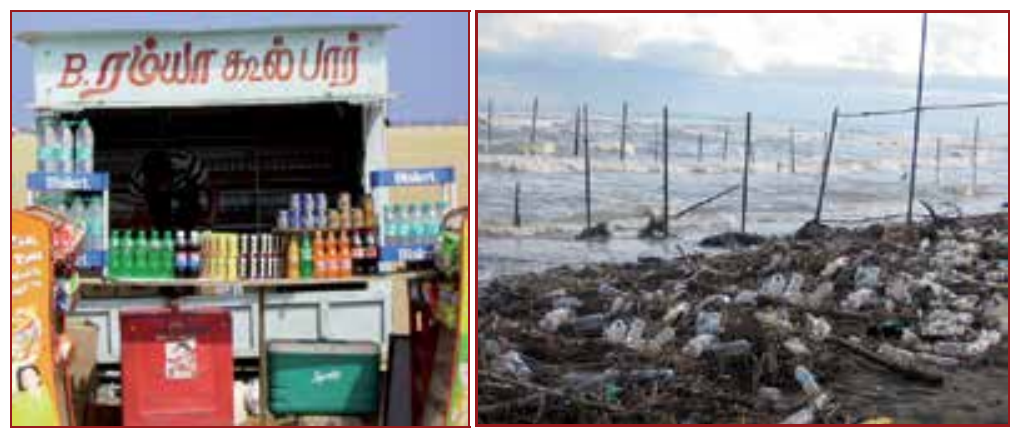

Figure 7. PET waste as a threat, serious cause of concern to the environmentalists

In Singapore, 684,400 tons of plastic wastes were generated in 2008, and the recycling rate was $9 \%$. Even though PET has major advantages for use, such as its nontoxic nature, durability, and crystal-clear transparency, its nonbiodegradability seems to be the serious cause of concern to environmentalists [13].

Since it is not appropriate to dispose of waste PET by landfills, other recycling methods of waste PET products including physical and chemical recycling have been developed. Chemical recycling of PET includes chemolysis of the polyester with an excess of reactants such as water (hydrolysis), alcohols (alcoholysis), glycols (glycolysis), amines [14], and ammonia (ammonolysis) [15].
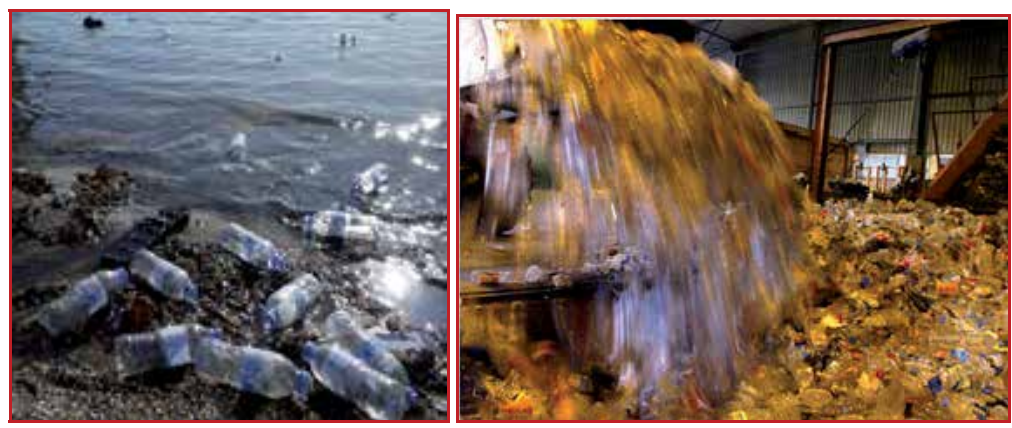

Figure 8. PET waste can be seen everywhere (left image), so the world production rate of PET waste grows fast (right image)

\subsection{Which way must be chosen to save our planet? [7]}

It is believed that any attempt to dispose of plastic through landfills is also harmful. In addition to the toxic seepage from the landfill which caused to contamination of precious water sources, the waste mass hinders the flow of groundwater. As landfills are also prone to leakages, the lead and cadmium in the wastes mix with rain water and then drip through the ground and drain into nearby streams and lakes and other water sources, poisoning the water we use. 
Others believe that polymers refuse any attempt at disposal, whether through recycling, burning, or landfilling. When one hazard is done away with, it paves the way for another to come. One of the only ways to overcome the noxious danger of plastic pollution is to reduce the use of plastic and completely avoid it if possible.

Some people are of the belief that one of the ways to cut off the hazards of polymer pollution is to reduce the use of polymer and thereby force a reduction in its production. It is best to refrain from using plastic whenever and wherever you can. It is better to opt for the use of a cloth bag when carrying your groceries. Any attempt we make to end polymer pollution will have long-term benefits for the generations to come.

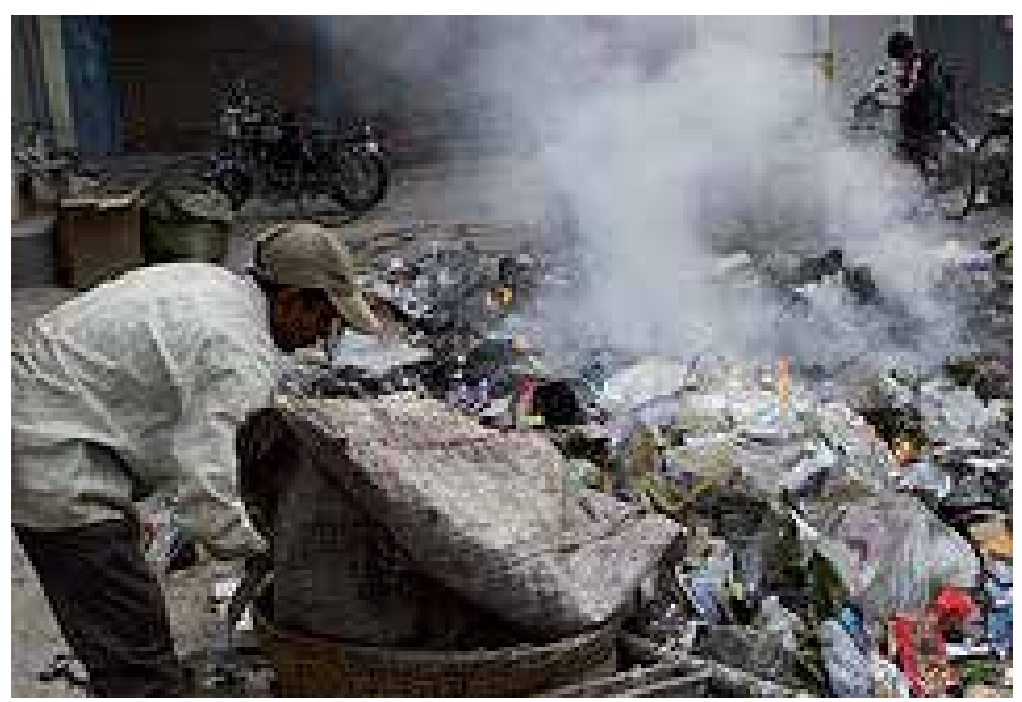

Figure 9. Burning a polymer caused releases of poisonous chemicals. Photo courtesy of Flickr

Waste strategies used across the globe are quite similar and are based upon the prevention and recycling of waste. For example, Japan has extensive rules and regulations pertaining to waste and other sustainable production and consumption policies under the "3Rs - reducing, reusing, and recycling" umbrella.

The European Union has its own strategy in dealing with waste, by preventing waste from the start, recycling waste, and optimizing the disposal of waste [5].

By recycling polymers, we are only returning them back into the marketplace and eventually into the environment, hence causing no reduction in its use. The recycled polymer is degraded in quality and requires the production of a newer polymer to make the original product. Burning a polymer has its own disadvantages. When burned, it could release a great number of poisonous chemicals into the air (Fig. 9). In addition to these dangers, recycling polymers is not very economical. Studies conducted by many "Public Interest Research Groups" have indicated that it is also a very dirty task, requiring hard physical work. Recycling of polymer 
has been connected to skin and respiratory problems as a result of being exposed to toxic fumes, especially hydrocarbons and residues emitted during the process [7], [12].

\subsubsection{Serious response to polymer pollution}

As regards to the increasing challenges of waste production and its management, the European Parliament and the Council have fostered a number of official orders. These orders are critical to ensure that waste is recovered or disposed of without harming the environment and human health.

According to the European official order on packaging and packaging waste [13], the management of packaging and packaging waste's utmost priority should be the prevention of packaging waste. In addition, the reuse of packaging, recycling, and other forms of recovering packaging waste and, therefore the reduction of the final disposal of such waste should be considered fundamental.

As observed in Fig. 10, some solutions are provided for reducing polymer pollution. Prevention refers to the reduction of the quantity of materials and substances that are included in packaging and packaging waste that can be harmful to the environment. It includes developing clean production methods and technology for packaging and packaging waste at the production process level for marketing, distribution, and utilization stages. Reuse is the process in which packaging is refilled or used once more for the same purpose which it was produced. Recovery includes operations such as using a fuel to generate energy, recycling of organic substances which are not used as solvents, etc. (including composting and other biological transformation processes). Energy recovery is defined as the use of combustible packaging waste in order to generate energy by completely burning the substance (incineration) with or without other wastes but with recovery of heat.

Recycling is a process in which waste materials are reprocessed for the original purpose or for other purposes including organic recycling but excluding energy recovery.

Disposal operations include deposit into or onto land (e.g., landfilling), incineration, etc. Compostable polymers, known as biological or organic recycling, are a valuable recovery option.

The EU official order on packaging and packaging waste defines organic recycling as the aerobic (composting) or anaerobic (bio methanization) treatment of the biodegradable parts of packaging waste under controlled conditions and using microorganisms. This process produces stabilized organic residues or methane. It is noteworthy to mention that landfills are not considered as a form of organic recycling.

Most developed countries have put the waste management hierarchy to use, i.e., minimization, recovery and transformation, and land disposal, using strategies that depend on factors such as population density, transportation infrastructure, and socioeconomic and environmental regulations. Let us also contribute our part, and save our environment from polymer pollution 


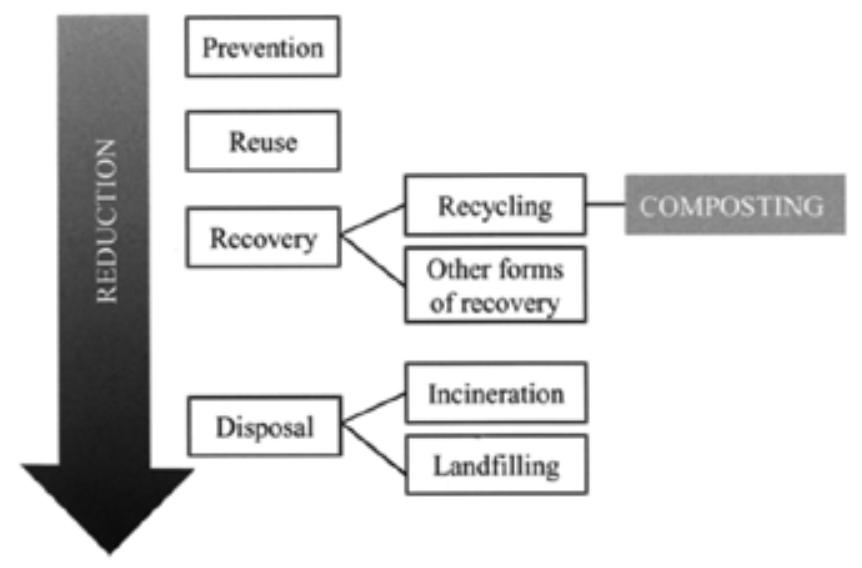

Figure 10. Composting, as a solution to solve Earth problem

to make it a better environment for the future. To do so, one of the best ways to reduce the hazards of polymer pollution is changing them to compost.

\section{Compost [11, 23]}

Compost is a versatile product and obtained from composting, biodegradation of organic waste that is industrially, commercially, or domestically produced. Its fundamental use is in conditioning and fertilizing soil by the addition of humus, nutrients, and beneficial soil bacteria, with a wide range of specific applications.

Methane is an organic material produced via organic materials "anaerobically" without air in landfills and is a gas with 25 times the global warming impact of $\mathrm{CO}_{2}$ ! This same organic mulch helps to absorb carbon back into the soil if it is composted.

\section{Better Soil, Better Life, Better Future}

It is interesting to note that about $60 \%$ of the garbage Australians throw out could be put to better use as mulch to improve soil quality and in the garden as compost.

Composts improve soil quality, assist plant growth, increase water holding capacity, store carbon in the soil, and reduce the need for chemical fertilizer and pesticides.

Earthworms flourish in enriched soils. Activities of earthworms help release essential nutrients strengthen plants and also increase their resistance to various diseases.

Compost is an organic matter that has been decomposed and recycled as a fertilizer and soil strengthener. Compost is a very important component of organic farming. Simply put, composting process merely requires making a heap of wetted organic matter that is known as green waste (leaves, food waste) and waiting for the materials to decompose to humus after a period of weeks or months. Composting nowadays includes a multi-step monitored process 
with exact inputs of air, water, and carbon-rich and nitrogen-rich materials. In order to assist the decomposition process, the plant matter is shredded, water is added, and proper aeration is ensured by regularly turning the mixture. Worms and fungi can also further decompose or break up the material. Aerobic bacteria and fungi manage a chemical process by converting the inputs into heat, carbon dioxide, and ammonium. Ammonium is a form of nitrogen $\left(\mathrm{NH}_{4}\right)$ used by plants. When existing ammonium is not used by plants, it is converted by bacteria into nitrates $\left(\mathrm{NO}_{3}\right)$ through a process known as nitrification. Compost production is shown in Fig. 11.
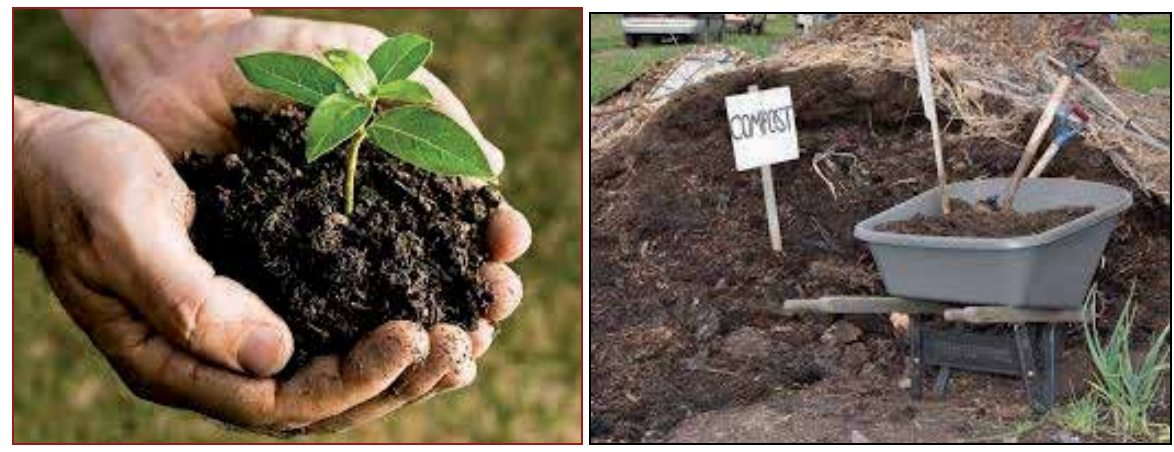

Figure 11. Compost

Compost is rich in nutrients that are used in gardens, landscaping, horticulture, and agriculture. Compost has itself advantages for the land in many ways, including as a soil conditioner, as a fertilizer, as an additive of vital humus or humic acids, and finally as a natural pesticide for soil. Compost is useful for erosion control, land and stream reclamation, wetland construction, and as a landfill cover in various ecosystems. Organic ingredients that are considered useful for composting can also be used to generate biogas through anaerobic digestion. Anaerobic digestion is quickly replacing composting in some parts of the world (especially central Europe) as a main means of downcycling waste organic matter.

\footnotetext{
- The soil structure, porosity, bulk density improves caused to create a better plant root environment

- Reduces runoff and erosion, Increases infiltration, increases permeability of heavy soils

- The capacity of water holding in sandy soils improves, reducing leaching and water losing

- Create a variety of macro and micronutrients

- Suppresses or controls or certain soil-borne plant pathogens as well as nematodes

- Supplies considerable quantities of organic matter

- Modifiescation exchange capacity (CEC) of soils, improve their ability to maintain nutrients for plant use

- Givesbeneficial microorganisms to soils

- Improving and stabilizing of soil $\mathrm{pH}$

- Can attach and degrade special pollutants
}

Table 1. Benefits of Using Compost [15] (taken from www.epa.gov) 


\section{Applications of compost [2]}

Compost is used as an organic fertilizer, to improve and condition soil, to manufacture topsoil, as a growing medium and mulch for use in:

- Agriculture (intensive, organic)

- Growing fruit and producing wine

- Horticulture

- Potting

- Nurseries

- Greenhouses

- Private gardens

- Landscaping (e.g., parks)

- Ground rehabilitation

- Silviculture

There are a variety of benefits in using compost on roadside applications (Table 1). In the following section, these benefits are discussed in greater detail.

\subsection{Improved structure}

Compost has a significant impact on the physical structure of soil. In fine-textured (clay, clay loam) soils, adding compost can reduce bulk density, improve workability and porosity, and enhance its gas and water permeability, thus reducing erosion. When an adequate amount is used, its addition can have both an immediate and long-term positive effect on soil structure. It opposes compaction in fine-textured soils and enhances water-holding capacity and enriches soil aggregation in coarse-textured (sandy) soils. The high degree of organic matter decomposition results in a stable residue known as humus. The components of humus act as a kind of soil adhesive and hold the particles together, making them more resistant to erosion and improving the soil's ability to hold moisture. With its humus content, compost has soil-binding properties.

\subsection{Moisture management}

Drought resistance and efficient water utilization can be enhanced by adding compost. As a result, the intensity and frequency of irrigation may be decreased. Whereas compost can maintain many times its own weight in moisture, indeed its use can greatly contribute to establish roadside plantings. Furthermore, studies have suggested that adding compost in a sandy soil can facilitate moisture dispersion. Using of compost caused to allowing the movement of water laterally, more lightly from its point of application. 


\subsection{Modifies and stabilizes $\mathrm{pH}$}

Adding compost to soil may modify the $\mathrm{pH}$ of the final mix. Depending on the $\mathrm{pH}$ of the compost and native soil, adding compost may increase or decrease the $\mathrm{pH}$ of the final mix. Therefore, adding neutral or slightly alkaline compost to acidic soil will increase the soil $\mathrm{pH}$ if sufficient amounts are added.

In certain conditions, where compost was applied at low amounts such as 10-20 tons per acre, it was found to have an effect on soil $\mathrm{pH}$. Using compost also allows the ability to buffer or stabilize soil $\mathrm{pH}$. This phenomenon could be more useful where it will effectively resist to $\mathrm{pH}$ change.

\subsection{Increases cation exchange capacity}

Compost can also modify the cation exchange capacity of soils, making it possible to hold nutrients longer. It can also enable crops to utilize nutrients more efficiently while decreasing nutrient loss by leaching. Therefore, soils' fertility and their organic matter content are closely linked. In addition, adding compost can greatly improve the retention of plant nutrients in the root zone by enhancing the cation exchange capacity of sandy soils.

\subsection{Provides nutrients}

Compost products include various kinds of macronutrients and micronutrients. While they are often good source of nitrogen, phosphorous, and potassium, composts also include micronutrients that are essential for plant growth. Since composts contain relatively stable sources of organic matter, the nutrients are supplied in a slow-release form. Large amounts of nutrients are normally not found in compost compared to most commercial fertilizers. However, compost is usually added at much greater rates. As a result, it can have a great effect on nutrient availability. By adding compost, significant effects can be observed in both the fertilizer and $\mathrm{pH}$ adjustment (lime/sulfur addition). Compost has benefits of both providing nutrition and making the common fertilizer programs more effective.

\subsection{Provides soil biota}

Soil organism's activity is very significant in productive soils as well as healthy plants. Their activity depends mainly on the presence of organic matter. Bacteria, protozoa, actinomycetes, and fungi consist soil microorganisms. They are not only found in compost but spread in soil media quickly. Microorganisms have an essential role in organic matter decomposition. After that, humus formation and nutrient availability will occur. Furthermore, microorganisms have benefits for root activity as special fungi do symbiotically with plant roots which help them extract nutrients from soils.

\subsection{Suppresses plant diseases}

The level and type of organic matter and microorganisms present in soils may have an influence on the disease rates of many plants. Previous studies have indicated that the 
increased population of certain microorganisms may suppress specific plant diseases such as pythium and fusarium as well as nematodes. Numerous attempts are being made to optimize the composting process so that the population of these beneficial microbes might increase.

\subsection{Binds contaminants}

Another capability of compost is binding heavy metals as well as other contaminants that caused to reduce both their absorption by various plants that is named bioavailability and leachability. As a result, sites that are contaminated with different pollutants could be improved via modifying the native soil with compost. Similar binding effect lets compost be used as a filter for storm water treatment. Furthermore, it has been reported that compost caused to minimize leaching of pesticides in soil systems.

\subsection{Horticulture and agriculture}

Compost is used in horticulture in many different contexts. Compost can be mixed with sand, clay, aged sawdust, and other materials in raised-bed gardening in order to create an enriched mix for landscape beds or raised-bed gardens. In this case, compost should be about $30 \%$ of the total mix. To avoid nutrient and oxygen competition with plants, high-quality compost should be used.

Similar to bedding mixes, using of compost up to $30 \%$ based on total mix, depending on maturity and salinity, may be a useful ingredient in potting media in a container garden.

It could be used as a substitute for peat moss, but it must be used in limited amounts due to low porosity and water-holding capacity of peat. Compost has a nutrient content lower than the necessity for supplemental chemical fertilizers, although this must be determined in each case.

Areas that have been excavated areas around the foundation of new buildings are backfilled after construction has been completed, but these planting zones may contain rubble, residues of toxic chemicals, and other undesirable substances. In order to improve the soil in these zones and provide a healthier start for the foundation plantings, it is a good idea to remove the backfill and replace it with a mix of soil and compost.

If the product has course textures and is mature, then two or more inches of compost can be used alone or together with conventional mulch products to keep root zones cool, conserve moisture, and act as a slow-release fertilizer. For a weed barrier, compost can be used at double or triple the amount and be placed on top of a thick layer of newspapers, to replace geomembrane weed barriers. This, however, only holds true for composts that are free of weeds.

For trees and shrubs, mixes of old compost with the native soils can be used as backfill. Immature composts may cause settling and young root disturbance since they are deprived of oxygen. To create new turf areas such as lawns and recreation areas, compost can be applied before seeding or sodding and work into the soil. Compost can be used seasonally as covering and may also be raked into the soil. Some turf farms also use compost to prevent topsoil loss by growing grass in a couple of inches of the material. 
Finally, for use in fields, in order to grow corn, wheat, soybeans, and some other crops, compost can be spread on top of the soil by using spreaders pulled behind a tractor or a spreader trucks. The obtained layer after spreading is very thin, about $6 \mathrm{~mm}$ which is worked usually into the soil before planting process. When attempting to rebuild poor soils or control erosion, application rates as $25 \mathrm{~mm}$ or more are usual.

\subsection{Erosion control}

Topsoil loss is a serious ecological issue. A relatively new technology in this realm is the application of compost to control sediment runoff and fight erosion. It has recently been adopted by local authorities, developers, farmers, and other major disturbers of soil as another tool to reduce topsoil loss.

A compost blanket is a layer of compost spread over a disturbed area of soil. While having a high water-holding capacity, compost can remain on the surface to temper the impact of rainfall. Even insignificant amounts can be helpful, but typical recommendations require a 5 $\mathrm{cm}$ (2 in.) layer to insure adequate surface coverage. Direct planting into the blanket is also possible.

Compost berms and socks are used alone or together with compost blankets to alleviate the impact of high-volume water discharges. Compost berms are more aesthetically satisfactory than silt fences and remove the need to do away with the berm when the project is complete. After passing the time, compost biodegrades simply and returns to earth. A mesh tube that is stuffed with compost is named a compost sock. The compost socks show better response to heavy equipments and can be anchored, removed, and reused easily. When a sock based on biodegradable fiber is used, it may be left in place to biodegrade; however, since this is not in confidence with the idea of the sock, it is not common.

Other important applications of compost are as follows: Planting media for artificial or constructed wetlands, Cap for a landfill cell when used closely to encourage vegetation and erosion reduction, and erosion control of possibly alleviating damages and restore beauty and functionality to riparian zones in the future.

\section{Biodegradation $[1,6,16]$}

Degradation is an irreversible process that leads to great changes of the material structure, usually characterized by a loss of properties and/or fragmentation. Degradation is under the effect of environmental conditions over a certain period of time and consists of one or more steps. Properties such as integrity, molecular weight or structure, and mechanical strength decreases during biodegradation.

According to Dr. Rolf-Joachim Muller's definition [25], biodegradable plastics refer to plastics and non-water-soluble polymer-based materials that degrade via an attack by microorganisms. It is believed that the biodegradation of plastics is usually a heterogeneous process. 
Due to the size and the lack of water solubility of polymeric molecules, microorganisms cannot transport the polymeric material into the cells directly like in most biochemical processes; rather, they must first excrete extracellular enzymes that depolymerize the polymeric chains outside the cells (Fig. 12).

Therefore, if the molar mass of the polymers can be sufficiently reduced to generate watersoluble intermediates, these can be transported into the microorganisms and fed into the appropriate metabolic pathway(s). As a result, the end products of these metabolic processes include water, carbon dioxide, and methane (in the case of anaerobic degradation), together with a new biomass. The extracellular enzymes are too large to penetrate deeply into the polymer material and so act only on the polymer surface. Consequently, the biodegradation of plastics is usually a surface erosion process. Although the enzyme-catalyzed chain length reduction of polymers is in many cases the primary process of biodegradation, nonbiotic chemical and physical processes can also act on the polymer, either in parallel or as a first stage solely on the polymer. These nonbiotic effects include chemical hydrolysis, thermal polymer degradation, and oxidation or scission of the polymer chains by irradiation (photo degradation).

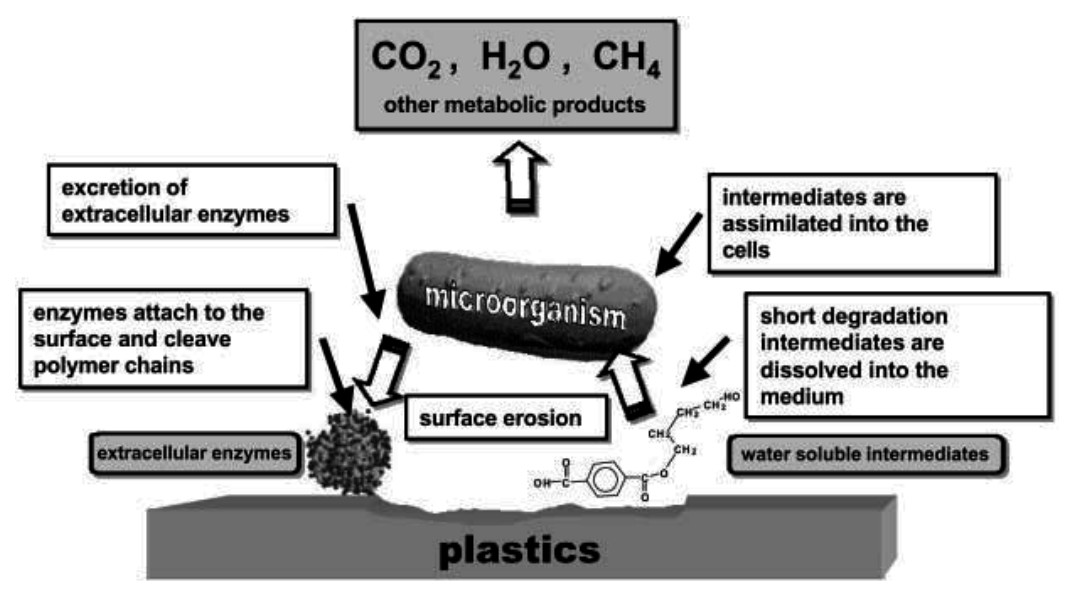

Figure 12. General mechanism of plastics biodegradation [28]

\subsection{Biodegradable}

According to ASTM D883-99, degradation results from the action of naturally occurring microorganisms such as bacteria, fungi, and algae (according to ASTM D883-99). One of the necessary steps in the testing strategy for materials is testing the biodegradability to define ultimate compostability and a suitable indicator of final compostability. Of course, biodegradability is not the same as compatibility. For instance, a potato or a fruit is fully biodegradable but will not compost as such in a composting environment. In a particular context, even geographical or legal context may affect on the definition of compostable, to make fully a biodegradable product "non-compostable." 


\subsection{Compostable}

A number of standardization committees such as ISO, DIN, ASTM, CEN, and UNI have been working assiduity on compostability testing as well as acceptance criteria or rules for several years. Therefore, the general principles and guidelines regarding testing and basic characteristics have been defined which are universally accepted; however, discussion still continues for particular aspects.

According to ISO and ASTM standards, biological degradation during composting caused to produce $\mathrm{CO}_{2}$, water, inorganic compounds as well as biomass at a rate consistent with other known materials that are compostable and do not leave visually toxic or distinguishable residues.

To claim compostability, it should have been proved that packaging can be disintegrated and biodegraded in a composting system (can be shown by standard test methods). Also its biodegradation must complete during the end use of the compost.

The compost should be meeting the relevant quality criteria that include amount of heavy metal, no obviously distinguishable residues, and finally no ecotoxicity.

Environmentally degradable polymers or EDPs can be described as follows:

- Polymeric materials that maintain the same formulation during use as conventional polymers

- Polymeric materials that degrade to lower-molecular-weight compounds after use by a combination of the above biological, chemical, and physical incitement or other stimulations in the environment

- Polymeric materials that degrade ultimately to $\mathrm{H}_{2} \mathrm{O}$ and $\mathrm{CO}_{2}$

\subsection{Different levels of degradation}

When transferring from a polymeric device insertion to a living organism, regardless of the type, there are different levels of degradation. The various levels, such as isolated organism or the environment itself, are schematized in Fig. 13.

As shown in Fig. 13, it is observed that dissolution and fragmentation processes do not relate to macromolecule scission.

Actually, they show the disappearance of the visible device and hence leave biostable macromolecular compounds as residues. The fragments or the dissolved macromolecules will be retained in the human body, unless they are rejected through boils and abscess or by filtration if molar masses are less than the filtration threshold (10, $000 \mathrm{D}$ to $40,000 \mathrm{D}$, depending on the compound).

In the environmental conditions, dissolved macromolecules or the fragments can be stored as organic sand or reached to running or underground water after dissolution. 


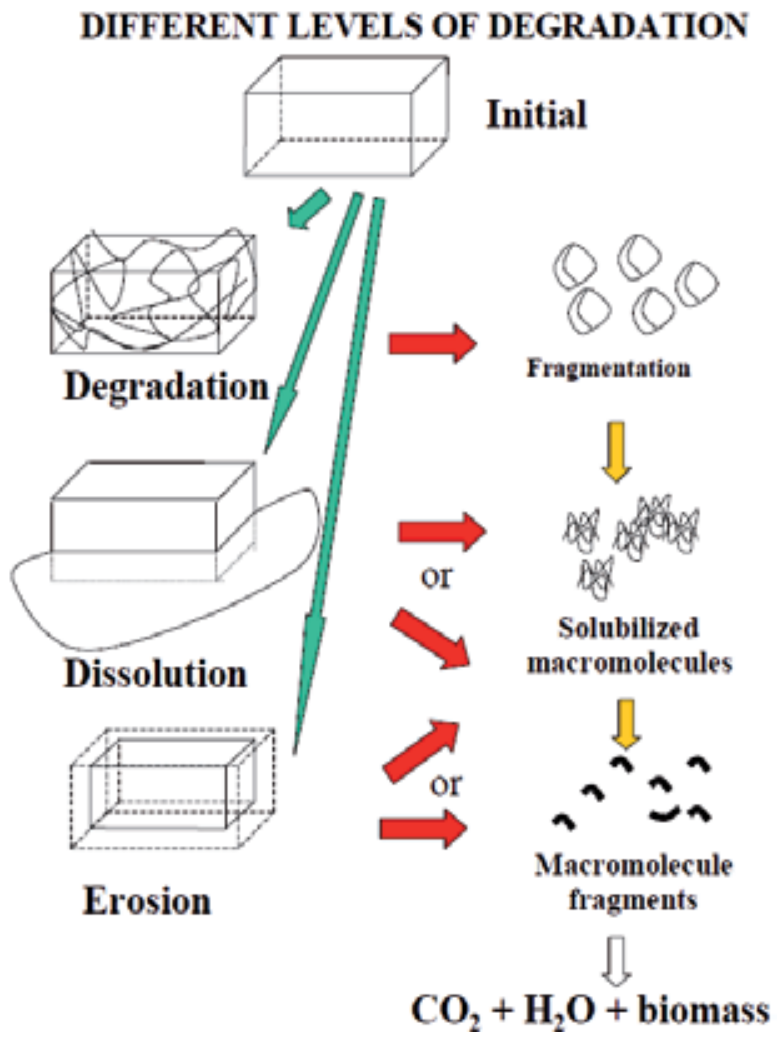

Figure 13. The various levels of degradation for a polymer device

Another stage is the process of macromolecule breakdown to some biostable small molecules is achieved. In this stage, toxic compounds might be generated, and therefore only biostable biocompatible by-products are the acceptable degradation process products.

The concept of biocompatibility is very important and is acknowledged in medicine and pharmacology. As far as the outdoor environment is concerned, it is not defined in a similar way. The final stage of degradation is multiple, meaning that it consists of mineralization and also biomass formation with residual material.

As a result, the scheme describes the need for specific terms to distinguish these different stages and also distinguish the particularities of the different sections of human activity that are important. Another basic discussion has to be made to identify the possible routes leading from the device to the ultimate stage, which is named mineralization biomass formation.

The two main routes to degrade a polymeric device up to mineralization and biomass formation are possible that are shown in Fig. 14.

The left-handside route related the attack of the device or compound that is followed by an enzymatic process of the degradation products through biochemistry. In this route, the presence of proper enzymes and thus of specific cells under viable conditions (such as 


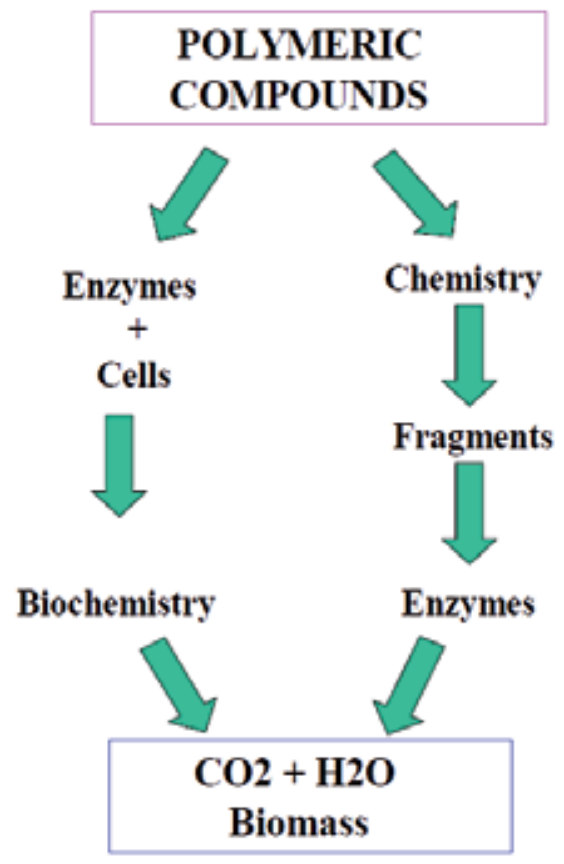

Figure 14. The two general routes leading to ultimate degradation and bio-assimilation [27]

atmosphere, water, nutrients, etc.) is needed. No life-allowing conditions means that there is not any degradation happening.

The right-hand-side route has a different way in which breakdown of the device and macromolecule depends on some chemical processes, and the elimination of the generated small molecules proceeds dominantly through biochemical pathways. In this type, the reagents (light, water, heat, etc.) are needed to trigger the degradation. In fact, no-triggering phenomenon means that there isn't any degradation happening [16].

\section{The composting process and methods [26-29]}

As nature's way of recycling, composting is the process of transforming organic material into solid-like product that is called humus. This process breaks down the organic materials by using microorganisms such as bacteria and fungi. Having a continuous supply of food (organics), water, and oxygen, the best gen is critical to obtain the best results. In addition, the other important factor to make the process work is managing the composting material's temperature.

Making compost is viable from the most organic by-products [18]. Feedstocks such as poultry, hog, and cattle manures, food processing wastes, sewage sludge, municipal leaves, brush and grass clipping, and sawdust are the most common [19]. 
The main composted waste types are:

- Green waste: park and garden waste

- Biowaste: food waste

- Biodegradable waste stream from manufacturing (food processing wastes, wood wastes)

- Sewage sludge

- Municipal solid waste

- Slurries and manure from husbandry

During composting process, organic matter has broken down by microorganisms consequently carbon dioxide, heat, water and compost are produced:

$$
\text { Organic matter }+ \text { microorganisms }+\mathrm{O}_{2}(\text { air }) \rightarrow \mathrm{H}_{2} \mathrm{O}+\mathrm{CO}_{2}+\text { Compost }+ \text { heat }
$$

Although nature compost is the end product of the stabilization stage, fresh compost is an intermediate product of the thermophilic stage.

The raw materials and the factors that affect the progress of the process are the main factors that affect compost characteristics.

Depending on the quality produced and product quality, composts have various applications. For instance, high-quality compost is being used in horticulture, agriculture, landscaping, and home gardening. The medium quality is used in erosion control and roadside landscaping.

Even low-quality compost in land reclamation projects can be used as a landfill coverer. There are three basic types of centralized composting processes:

1. In-vessel method: in this process, the organic material is composted inside a silo, a drum, an agitated bed in covered or open channel, in a batch container or other structure. The process conditions are clearly monitored and controlled; also the material is aerated and mechanically agitated.

2. Aerated static pile method: in this method compostable materials form into large piles, which are aerated by drawing the air through the pile or forcing air out through it. In this method, pile is not turned.

3. Windrow method: In this method, compostable material is formed into elongated piles, known as windrows. The windrows are turned on a regular basis mechanically. Therefore important composting systems are titles as follows [21]:

\section{- Low-tech}

- Windrow

\section{- Mid-tech}

- Aerated static pile 
- Aerated compost bins

\section{- High-tech (in-vessel)}

- Rotary drum composters

- Box/tunnel composting systems

- Mechanical compost bins

In high-tech "in-vessel "composting systems, enclosed rigid structures or vessels are used to contain the material undergoing biological processing [22]. For monitoring of the process, process control systems are used to evaluate biological activity by using probes that measure the air temperature and the concentration of $\mathrm{O}_{2}$ and/or $\mathrm{CO}_{2}$. Precise determination of the status of the degradation process is possible via monitoring the concentration of evolved gases.

In most plants, an air treatment unit for limiting of the emission of particulate and gaseous pollutants into the atmosphere is also included.

In-vessel systems divide into two main categories: vertical and horizontal bioreactors. Vertical reactor has cylindrical structure or container and composed of concrete or steel, having a volume of about 100 to more than $2,000 \mathrm{~m}^{3}$ [30]. The material is loaded at the top and is extracted from the bottom continuously. Forcing air from the bottom of the reactor by means of a centrifugal blower is carried out, countercurrent to the flow of the composting material and caused to a suitable aeration. Vertical systems have been almost replaced by horizontal bioreactors. In horizontal systems, forced aeration is used to maintain the biomass at the necessary aerobic conditions, usually combined with mechanical turning. Continuous or discontinuous working cycle can be used. Composting needs special conditions, particularly of temperature, moisture, $\mathrm{pH}$, aeration, and carbon-to-nitrogen $(\mathrm{C} / \mathrm{N})$ ratio, related to optimum biological activity in the various stages of the process [17].

Degradation of the waste in compost carried out in three phases [17, 23]:

1. Mesophilic phase

2. Thermophilic phase

3. Cooling and maturation phase

The mesophilic phase, according to the ASTM standard [3], is the phase of composting that occurs from 20 to 45 ; the thermophilic phase is the phase in the composting process that occurs from 45 to 75 which associated with certain colonies of microorganisms that have a high rate of decomposition.

\subsection{The first mesophilic phase [23]}

In the first stage of composting, mesophilic bacteria and fungi degrade degradable compounds of organic matter, such as monosaccharide, starch, and lipids easily due to their solubility. Organic acids are produced by bacteria, and the $\mathrm{pH}$ decreases to 5-5.5. 
As heat is released from exothermal degradation reactions, the temperature starts to rise spontaneously. Also, the degradation of proteins leads to release of ammonia, and the $\mathrm{pH}$ rises from 8 to 9 rapidly. A few hours to a few days is needed to end this phase.

\subsection{Thermophilic phase [23]}

The thermophilic phase starts when the temperature reaches about $40{ }^{\circ} \mathrm{C}$. The degradation rate of the waste increases as thermophilic bacteria and fungi take over. If the temperature reaches over $55-60{ }^{\circ} \mathrm{C}$, microbial activity and diversity greatly decrease. The $\mathrm{pH}$ stabilizes to a neutral level after peak heating. This phase can last from a few days to several months.

\subsection{Cooling and maturation phase [23]}

When the easily degradable carbon sources have been consumed, the compost starts to cool. After cooling, stable compost is obtained. Then, mesophilic bacteria and fungi reappear, and finally the maturation phase follows. However, most of the species are different from the species of the first mesophilic phase. Actinomycetes often grow during this phase extensively, and a wide range of macroorganisms and some protists are usually present. The biological processes are now slow, but the compost is further converted to humus (humified) and becomes mature.

The required time for the phases depends on the composition of the organic matter as well as the efficiency of the process, which can be determined based on oxygen consumption during the process.

\section{Compostable polymers}

"Compostable polymers" were first introduced commercially in the 1980s and were also named "biodegradable polymers." These materials that are the first-generation biodegradable products were made from a conventional polymer, usually polyolefin (e.g., polyethylene) mixed with starch or other organic substances. When starch was eaten by microorganisms, the products were broken down, leaving small fragments of polyolefins. In 1994, Narayan wrote: "The U.S. biodegradables industry fumbled at the beginning by introducing starch filled (6-15\%) polyolefins as true biodegradable materials"'[28].

These were only biodisintegradable at the best conditions and not completely biodegradable.

According to ISO/DIS 17088 and ASTM D 6400 standards, definitions of compost and compostability are as follows:

Compost: Organic soil conditioner obtained by biodegradation of a mixture consisting principally of vegetable residues, occasionally with other organic material and having a limited mineral content 
Composting: The autothermic and thermophilic biological decomposition of biowaste (organic waste) in the presence of oxygen and under controlled conditions by the action of microorganisms and microorganisms in order to produce compost

Compostable polymer: A polymer that undergoes degradation by biological processes during composting to yield $\mathrm{CO}_{2}$, water, inorganic compounds, and biomass at a rate consistent with other known compostable materials and leaves no visible, distinguishable, or toxic residue

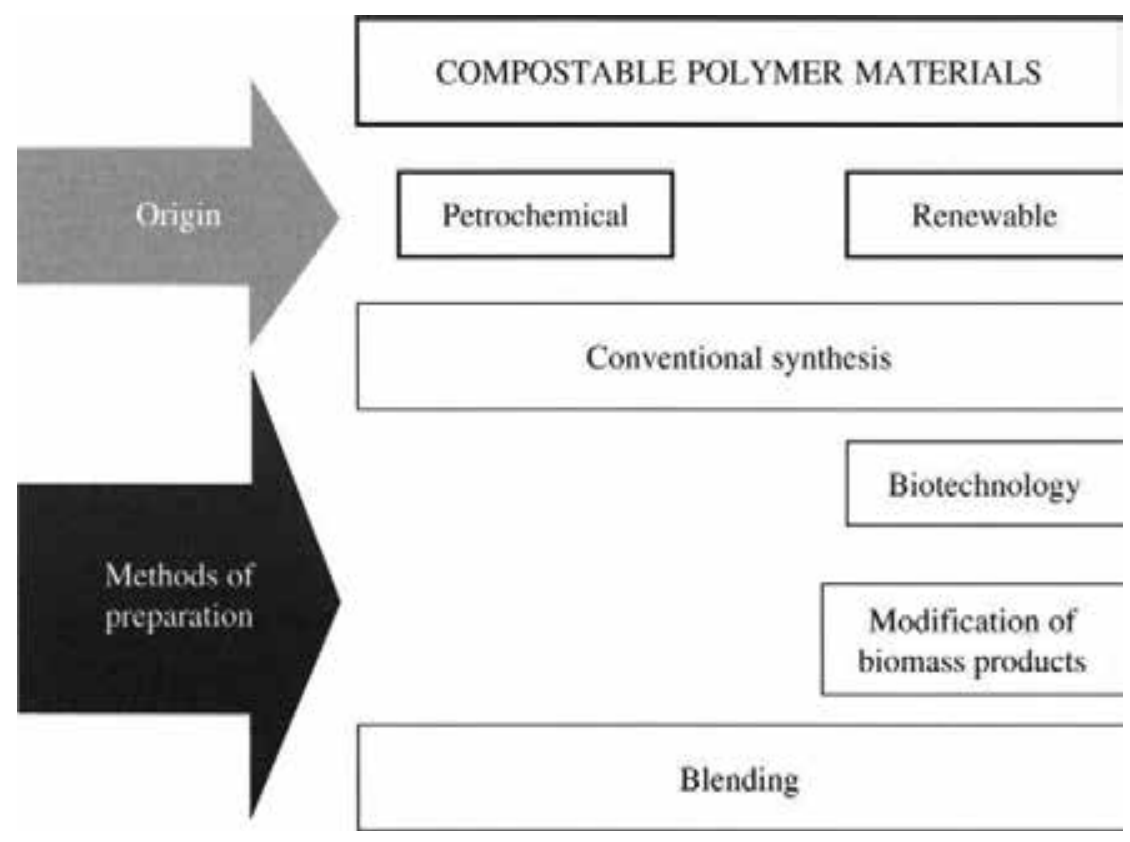

Figure 15. Classification of compostable polymers

Disintegration: The physical breakdown of a material into very small fragments. Put briefly, the requirements a material must satisfy to be termed "compostable" include mineralization (i.e., biodegradation to carbon dioxide, water, and biomass), disintegration into a composting system, and completion of its biodegradation during the end use of the compost, which, moreover, must meet relevant quality criteria, e.g., no ecotoxicity. The satisfaction of requirements should be proven by standardized test methods. These requirements and test methods are described in Section 7.

\subsection{Classification of compostable polymers}

Compostable polymers can be divided according to the source of origin or preparation method (Fig. 15).

On the basis of origin, compostable polymers are derived from renewable and petrochemical resources. 


\subsubsection{Biodegradable polymers from renewable resources include:}

1. Polylactide (PLA)

2. Polyhydroxyalkanoates: poly(3-hydroxybutyrate) (PHB)

3. Thermoplastic starch (TPS)

4. Cellulose

5. Chitosan

6. Proteins

There are three principal ways to produce polymers from renewable resources, i.e., bio-based polymers:

1. To make use of natural polymers which may be modified but remain intact to a large extent (e.g., starch polymers)

2. To produce bio-based monomers by fermentation which are then polymerized (e.g., polylactic acid)

3. To produce bio-based polymers directly in microorganisms or in genetically modified crops (polyhydroxyalkanoates)

In general, on the basis of methods of preparation, compostable polymer materials can be prepared via:

1. Conventional synthesis:

Examples: PCL, poly (e-caprolactone) - copolyesters

- Polymerization from renewable monomer feedstocks:

Examples: polylactic acid

2. Biotechnological route (extraction, fermentation)

Examples: poly(hydroxybutyrate-co-hydroxyvalerate) - PHBV

3. Preparation directly from biomass

Examples: plants - starch

\section{Blending}

Examples: Starch-polycaprolactone blends

A method based on blending of biodegradable polymers is very often used in order to improve the properties of compostable polymer materials or to decrease their cost. The various polymers used are both renewable polymers in an extruder in the presence of water or plasticizer [31]. 


\subsubsection{Biodegradable polymers from petrochemical sources include:}

1. Aliphatic polyesters and copolyesters (e.g., polybutylene succinate, PBS; polybutylene succinate adipate, PBSA).

2. Aromatic copolyesters (e.g., polybutylene adipate, PBAT)

3. Poly $\varepsilon$-caprolactone - PCL

4. Polyesteramides - PEA

5. Polyvinyl alcohol - PVA

\subsubsection{Blends}

The blending of biodegradable polymers is one of the strategies adopted in producing compostable polymer materials. Blending is a common practice in polymer science to improve unsatisfactory physical properties of the existing polymer or to decrease cost. By varying the composition and processing of blends, it is possible to manipulate properties. The leading compostable blends are starch-based materials. The aim is to combine the low cost of starch with higher-cost polymers having better physical properties. An example of such material is Mater-Bi manufactured by Novamont [46]. Mater-Bi is prepared by blending starch with other biodegradable polymers in an extruder in the presence of water or plasticizer. Some of Commercially available blends are presented in Table 2 .

\begin{tabular}{llll} 
Tradename & Supplier & Origin & Website \\
\hline Mater-Bi & Novamont & Italy & www.materbi.com \\
Ecostar & National Starch & USA & www.nationalstarch.com \\
Ecofoam & National Starch & USA & www.nationalstarch.com \\
Biograde (cellulose blends) & FKuR & Germany & www.fkur.de \\
Bioflex (PLA blends) & FKuR & Germany & www.fkur.de \\
Fasal (celluse based) & Austel + IFA & Austria & www.austel.at \\
Cereplast & Cereplast, Inc. & USA & www.cereplast.com
\end{tabular}

Table 2. Commercially available blends

\section{Biocompostables}

Compared to other available options, biocompostable products are an eco-friendly alternative, which can help reduce social and economic inequalities, decrease the impact of our consumption on the environment, and provide opportunities for creating a better and sustainable planet. In line with this goal, many technical attempts have been made to find a substitute plastic for packaging, compostable polymers, tissue engineering, etc. Several biopolymers have been exploited to develop materials for eco-friendly food packaging. However, there is 
a limitation on the use of biopolymers due to its usually poor mechanical and barrier properties, which may be improved by adding reinforcing compounds or fillers in order to form composites.

Most reinforced materials result in poor matrix-filler interactions, which usually improve with decreasing filler dimensions. The use of fillers with at least one nanoscale dimension (nanoparticles) produces nanocomposites. By using a variety of building blocks with dimensions in the nanosize region, designing and creating new materials with unprecedented flexibility and improvements in their physical properties is possible.

The ideal biopolymer is of renewable biological origin and biodegradable at the end of its life. Biopolymers include polysaccharides such as cellulose and starch, carbohydrate polymers produced by bacteria and fungi, and animal protein-based biopolymers such as wool, silk, gelatin, and collagen. On the other hand, poly(vinyl alcohol) (PVA), poly(caprolactone) (PCL), and poly(butylene succinate) (PBS) are examples of polymers that have synthetic origin but are biodegradable. Recently, natural renewable products made from starches extracted from corn, potato, tapioca, or other plants and vegetable matter are combined with biodegradable polymers to create products that are compostable or biodegradable and can assist in reducing the carbon footprint impact on the environment. Some product sources can come from recycled fiber from sugarcane, bamboo, wheat, rice, and even switch-grass to be formed into everyday used compostable.

\subsection{Nanocomposites for food packaging applications}

Most materials that are being used for food packaging are nondegradable and therefore create environmental problems. Several biopolymers have been taken advantage of to develop materials for eco-friendly food packaging. There have been limitations on the use of biopolymers due to their poor mechanical and barrier properties. This may be modified by adding some reinforcing compounds, forming composites.

Most reinforced materials present poor matrix-filler interactions, which usually improve with decreasing filler dimensions. To produce nanocomposites, the use of fillers with at least one nanoscale dimension (nanoparticles) is a common method.

Nanoparticles have proportionally larger surface area than their microscale counterparts, which favors the filler-matrix interactions and the performance of the resulting material. Furthermore, nanoparticles can have other functions when added to a polymer, such as increasing of tensile modulus, antimicrobial activity, enzyme immobilization, biosensing, etc. An outline of the main kinds of nanoparticles which have been studied for use in food packaging systems is given, as well as their effects and application. Besides nanoreinforcements, nanoparticles can have other functions when added to a polymer, such as enzyme immobilization, antimicrobial activity, biosensing, etc.

Some of the nanoparticles are:

- Clays and silicates

- Cellulose-based nanoreinforcements 
- Carbon nanotubes

- Silica $\left(\mathrm{SiO}_{2}\right)$

- Starch nanocrystals

- Chitin/chitosan nanoparticles

The layered silicates which are commonly used in nanocomposites consist of two-dimensional layers that are $1 \mathrm{~nm}$ thick and several microns long depending on the used particular silicate. The presence of these types of reinforcing agents in polymer formulations increases the tortuosity of the diffusive path for a permeant molecule (Fig. 16) and provides good barrier properties [24].

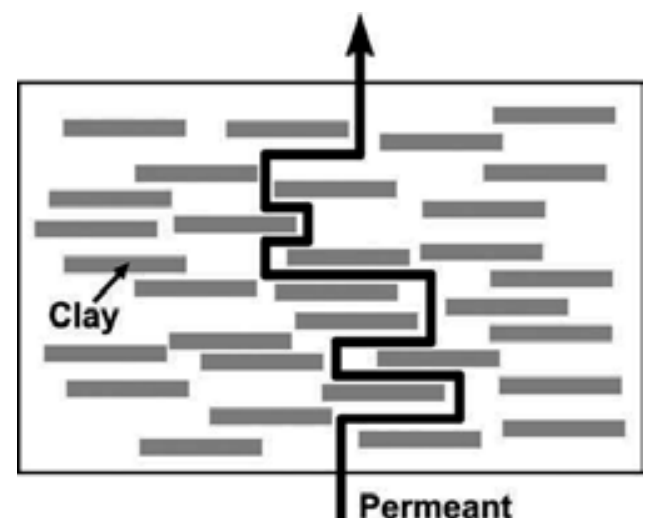

Figure 16. Tortuous path of a permeant in a clay nanocomposite [32]

Biodegradable all-cellulosic composite nonwoven materials composed of cotton and kenaf or cotton and bagasse have been developed by Zhang [33].

Composting causes significant reduction in the use of chemical fertilizer, plant diseases, water consumption, erosion, etc. It also increases soil quality, production yield, and product quality.

Some technologies exist, but investment cost may be a problem and preselecting is necessary. The composting method depends on waste composition.

\section{Testing methods for evaluation of biodegradation}

To determine biological action on man-made materials for various classes, test methods have been available for many years. Recently, the evaluation of the degradability of chemicals in the environment, specifically in wastewater, as one important aspect of the ecological impact of a compound has become significant when attempting to bring new chemical products to the marketplace. For this means, many standardized tests have been prepared for different environments, using different analytical methods [34]. An overview of existing international 
standards in this area is provided in Table 3. In principle, tests can be subdivided into three categories: field tests, simulation tests, and laboratory tests. Fossil fuels will finish; therefore we require new resources for energy and polymers and effective waste management strategies (according to AS ISO 14855).

Table 3. Standard test methods for biocorrosion phenomena on plastics

\begin{tabular}{|c|c|}
\hline ASTM G21-96 & Standard practice for determining resistance of synthetic polymer materials to fungi \\
\hline ASTM G29-96 & Standard practice for determining algal resistance of plastic films \\
\hline $\begin{array}{l}\text { DIN IEC } 60068- \\
2-10-1991\end{array}$ & $\begin{array}{l}\text { Elektrotechnik; Grundlegende Umweltprüfverfahren; Prüfung J und Leitfaden: } \\
\text { Schimmelwachstum; (Identisch mit IEC 60068-2-10: 1988) }\end{array}$ \\
\hline $\begin{array}{l}\text { EN ISO 846- } \\
1997\end{array}$ & Plastics - Evaluation of the action of microorganisms \\
\hline $\begin{array}{l}\text { IEC } 60068-2-10- \\
1988\end{array}$ & Elektrotechnik; Grundlegende Umweltprüfverfahren; Prüfung J: Schimmelwachstum \\
\hline ISO 846-1997 & $\begin{array}{l}\text { Plastics: Determination of behaviour under the action of fungi and bacteria. Evaluation } \\
\text { by visual examination or measurement of changes in mass or physical properties }\end{array}$ \\
\hline
\end{tabular}

Table 3. Standard test methods for biocorrosion phenomena on plastics

\subsection{General principles in testing biodegradable plastics}

Testing degradation phenomena of plastics in the environment has an overall problem regarding the type of tests to be implemented and the results that can be obtained. The guiding principle is that tests can be subdivided into three categories: field tests, simulation tests, and laboratory tests (Fig. 17).

While field tests, such as burying plastics samples in soil, placing them in lakes or rivers, or performing a full-scale composting process with the biodegradable plastic, represent the ideal practical environmental conditions, several serious disadvantages exist regarding these types of tests.

Environmental conditions such as temperature, $\mathrm{pH}$, or humidity cannot be controlled very well. Also, the analytical opportunities to monitor the degradation process are limited. In most cases, evaluating visible changes on the polymer specimen or perhaps determining disintegration by measuring weight loss is the only solution.

However, if the material breaks into small fragments that must be quantitatively recovered from the compost, soil, or water, the latter approach can lead to a problem. The analysis of residues and intermediates is complicated by the unspecified and complex environment. The pure physical disintegration of a plastic is not known as biodegradation; therefore, these tests alone can never prove whether a material is biodegradable or not. Various simulation tests, as an alternative to field tests, have been used to measure the biodegradation of plastics in the laboratory. 

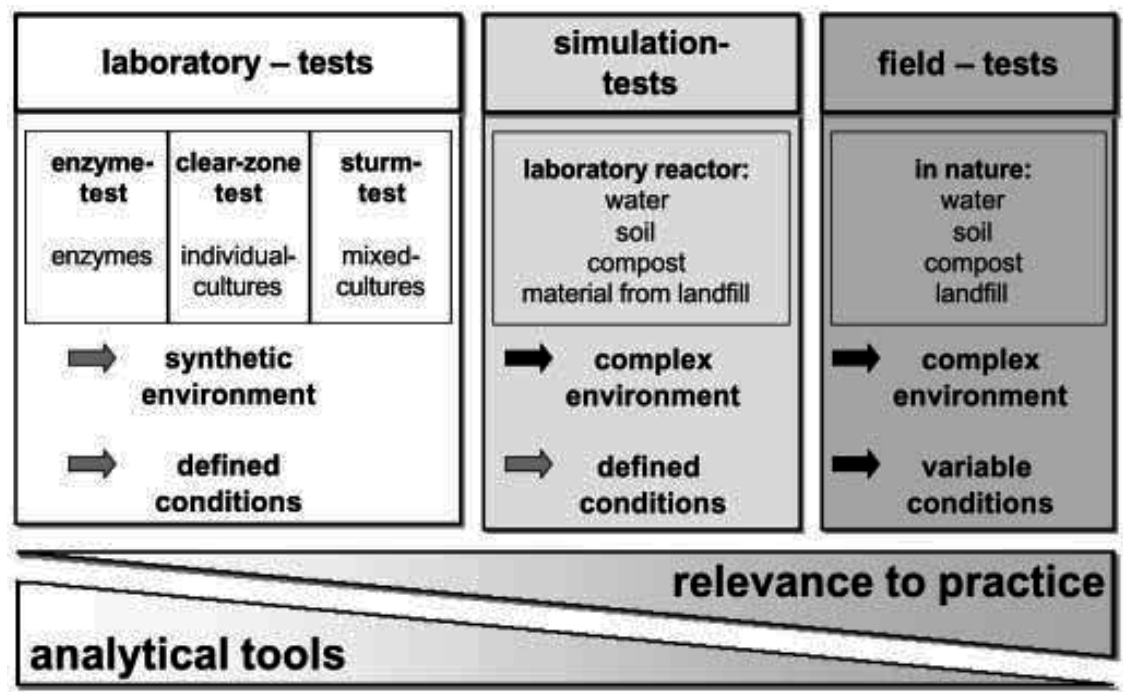

Figure 17. Schematic overview on tests for biodegradable plastics

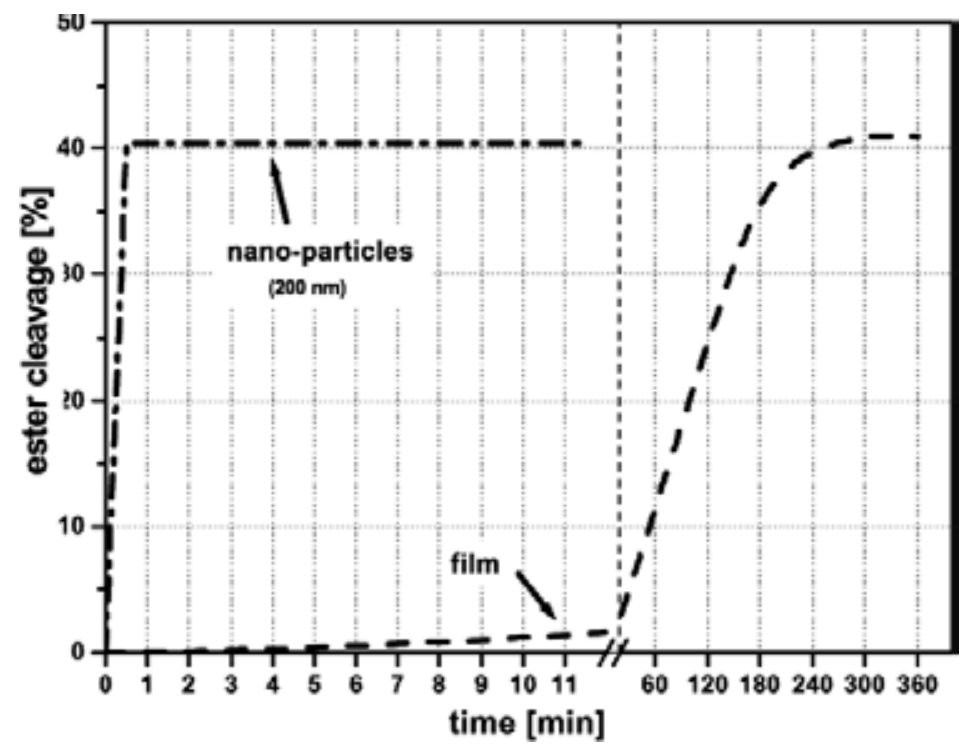

Figure 18. Comparison of the enzymatic degradation of the polyester poly(tetramethylene adipate). With a lipase from pseudomonas sp.

In this case, the degradation might take place in compost, seawater, or soil placed in a controlled reactor in a laboratory. However, the environment is still close to the field test situation; the external parameters such as temperature or $\mathrm{pH}$ or humidity, etc., can be controlled and adjusted; also the analytical tools available are better than would be used for some 
important tests such as field tests, for example, for analysis of residues and intermediates and determination of $\mathrm{O}_{2}$ consumption or $\mathrm{CO}_{2}$ evolution.

Important tests include the soil burial test [35], controlled composting test [36-38], test simulating landfills [25,39], and aqueous aquarium tests [40].

Occasionally, nutrients are added to increase the microbial activity and accelerate degradation that results in reduction of the time taken to conduct the tests.

Tests which are the most reproducible biodegradation tests are the laboratory tests, in which defined media are used and immunized with a mixed microbial population (from waste water) or individual microbial strains that may have been screened especially for a special polymer.

In the abovementioned tests, which may be optimized for the particularly used microorganisms' activity, polymers often show higher degradation rate than natural conditions.

During studying the basic mechanisms of polymer biodegradation, higher degradation rate can be considered as an advantage itself, but in laboratory tests, it is only possible to obtain limited conclusions on the absolute degradation rate of plastics in a natural environment. However, these tests are used to a great extent for many systematic investigations. Attempting to use more controlled and reproducible degradation tests involves using of systems where only those extracellular enzymes are present. These enzymes are used to depolymerize a particular group of polymers. This method, compared to weight loss measurements, cannot be used to prove biodegradation in terms of metabolism by a microorganism, but the system is valuable when used a lipase from Pseudomonas sp. for a polymer film and polymer nanoparticles at $40{ }^{\circ} \mathrm{C}$ and $\mathrm{pH}$ 7. Figure 18 shows an enzymatic degradation of a polyester poly(tetramethylene adipate) with a lipase. In the mentioned test, degradation is expressed as percentage of cleaved ester bonds. The highest ester cleavage of about $40 \%$ results from the dissolution of low-molecular-weight ester groups that are not accessible to attack by the lipase $[16,41]$.

\subsection{Aerobic biodegradation testing}

This test method estimates the compostability of a plastic sample by measuring the amount of carbon dioxide developed over time and the degree of disintegration of the plastic at the outcome.

Samples and mature compost are mixed and tested for a period of six months (according to AS ISO 14855).

According to test method, the compost-sample mix is contained in $3 \mathrm{~L}$ glass jars that are called bioreactors and heated up to $58 \pm 2{ }^{\circ} \mathrm{C}$ inside a water bath. The mentioned bioreactors which are aerated continuously and have their contents mixed routinely are hydrated to maintain a favorable composting environment. All samples are assessed in triplicate against cellulose powder. For passing the biodegradation test, the sample must produce enough $\mathrm{CO}_{2}$ to theoretically degrade by more than $90 \% \mathrm{w} / \mathrm{w}$ in total (or percentage degradation normalized relative to the degradation of the positive reference) in a period of six months. Figure 19 shows apparatus for aerobic biodegradation testing. 


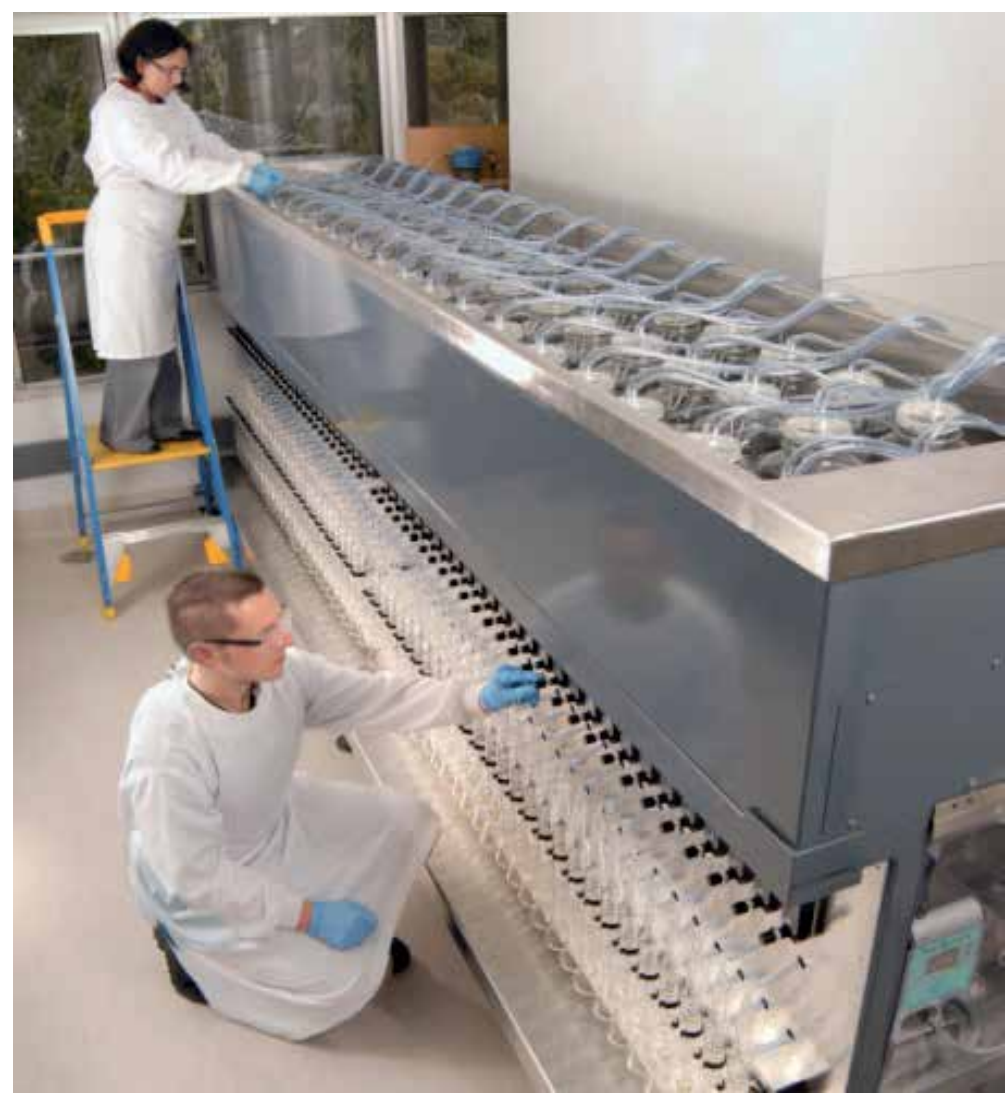

Figure 19. Aerobic biodegradation testing

\subsubsection{Disintegration testing}

The disintegration test is a pilot-scale aerobic composting test. In this test, an industrial composting process is simulated in a 200 Liter insulated composting bin. The compost is consisted of organic waste that should cause self-heating during its juvenile stages which is similar to full-scale composting process. Temperature of the compost, composition of exhaust gas, and $\mathrm{pH}$ and moisture are monitored routinely until the test is terminated at the end of 12 weeks. The obtained results must satisfy the validation requirements mentioned in a standard test method. Plastic fragmentation in an aerobic composting environment according to AS ISO is shown in Figure 20.

The bin's contents are turned manually at certain time intervals to maintain a uniform test environment. The test specimens can be visually evaluated during the test. At the end of 12 weeks, the remaining specimen fragments are retrieved, sized, and weighed, relative to the initial sample weight. By the test, degree of disintegration achieved can be determined. To pass disintegration testing, the sample must disintegrate or physically break down to a fragment size less than $2 \mathrm{~mm}$, more than $90 \% \mathrm{w} / \mathrm{w}$ after 12 weeks. All samples are tested in duplicate. 


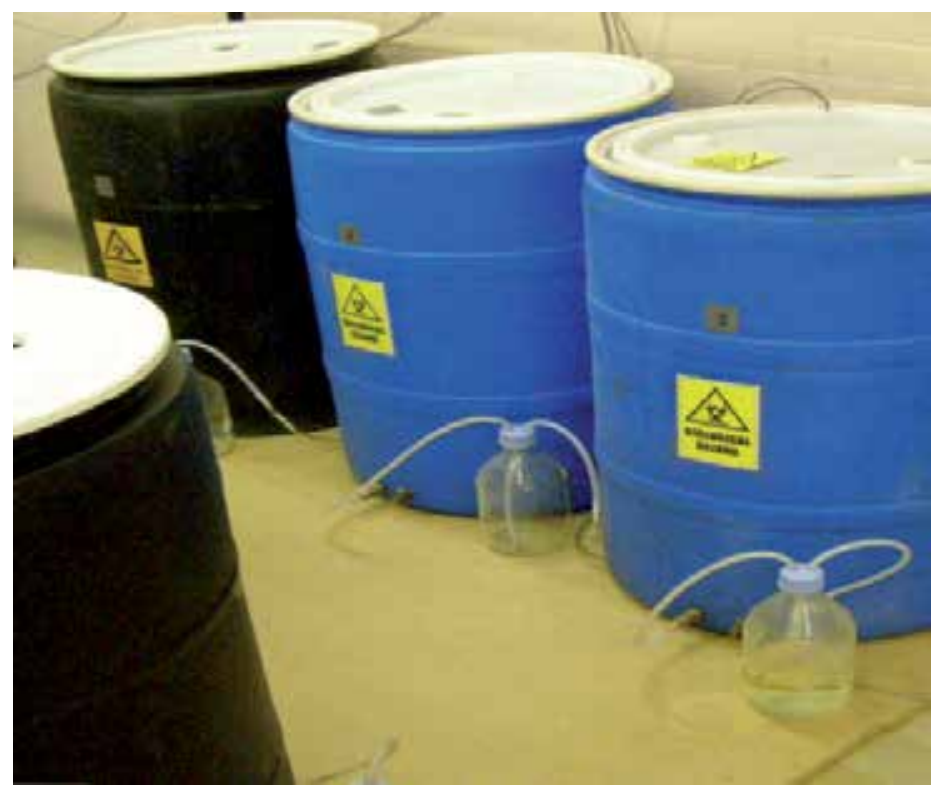

Figure 20. Disintegration barrels used to assess plastic fragmentation in an aerobic composting environment according to AS ISO
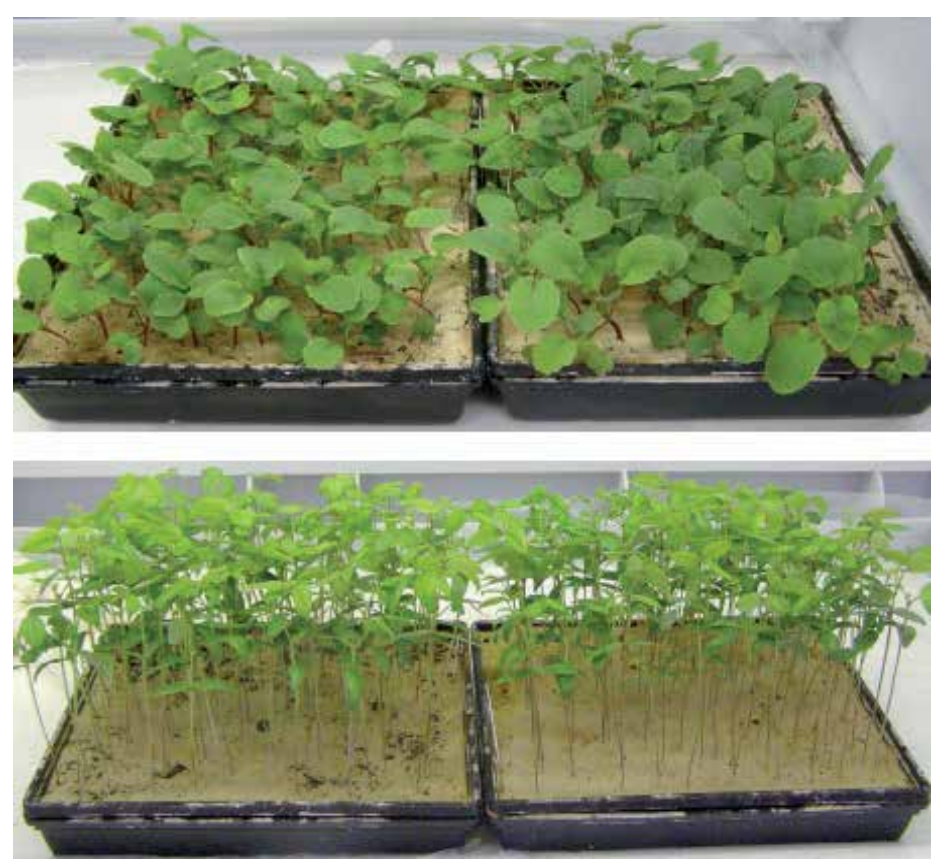

Figure 21. Typical growth seen in radish, seedlings bean during 14-day higher plant 


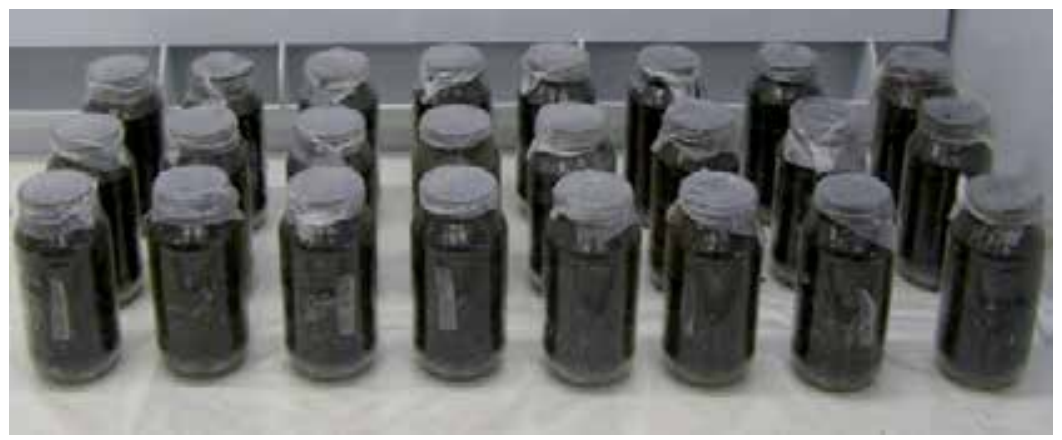

Figure 22. Photo of an earthworm ecotoxicity test setup ecotoxicity testing mung

\section{Regulation and voluntary standards}

In the USA, two guidelines named EPA Class A and B were developed to manage the processing and beneficial reuse of sludge or mud, also called biosolids, following the US EPA ban of ocean dumping. Now, in 26 American states, composts are required to be processed to control for vector and pathogen according to these federal protocols, even though the application to non-sludge materials has not been tested scientifically. As an example, green waste composts at higher rates than sludge compost were used. UK guidelines regarding compost quality also exist which is common in Canadian, Australian, and the various European states. Some compost manufacturers participate in a testing program in the USA called the US Composting Council (USCC) that is offered by a private lobbying organization. In order to promote composting of disposable diapers, the USCC was established in 1991 by Procter \& Gamble, following state forces to ban diapers in landfills, which caused a national uproar. Since composting diapers was not proven scientifically to be possible, ultimately the idea was not considered as a good idea.Therefore, composting emphasized to recycle organic wastes that were previously destined for landfills. In America, there are no legal quality standards, but a seal called "Seal of Testing Assurance" (also called "STA") has been sold by the USCC. By paying a high cost, the applicant may use the USCC logo on products, agreeing to volunteer to customers a current laboratory analysis that includes parameters such as respiration rate, nutrients, $\mathrm{pH}$, salt content, and limited other indicators. However that the STA program is not ISO approved, and STA is a financially beneficial activity for the private USCC, which is an organization that discloses its books earned and benefits \$65, 000 from STA fees in 2009. Existence some argue about the STA program means that EPA or USDA does not regulate composts. Tables 4 and 5 show titles of some important standards and definitions used in correlation with biodegradable plastics, respectively.

Coexistence of both biotic and nonbiotic processes, polymer degradation mechanism could also be referred to environmental degradation not only to environmental factors influence the polymer to be degraded, but they also have a influence on the activity of the different microorganisms and microbial population. Factors such as humidity, temperature, salinity, $\mathrm{pH}$, the 
absence or presence of oxygen, and supply of different nutrients are important effects on the microbial degradation of polymers and should be kept in mind when the biodegradability of plastics is tested. A standard evaluation of biodegradable polymers should always be based on definitions and what biodegradation with regard to polymers actually means. International and national standardization organizations have published several different definitions.

\begin{tabular}{|c|c|c|}
\hline Organization & Number & Title of the standard \\
\hline ASTM & D5209-92 & $\begin{array}{l}\text { Standard test method for determining the aerobic biodegradation } \\
\text { of plastic materials in the presence of municipal sewage sludge }\end{array}$ \\
\hline ASTM & D5210-92 & $\begin{array}{l}\text { Standard test method for determining the anaerobic } \\
\text { biodegradation of plastic materials in the presence of municipal } \\
\text { sewage sludge }\end{array}$ \\
\hline ASTM & D5247-92 & $\begin{array}{l}\text { Standard test method for determining the aerobic biodegradability } \\
\text { of degradable plastics by specific microorganisms }\end{array}$ \\
\hline ASTM & D5271-93 & $\begin{array}{l}\text { Standard test method for determining the aerobic biodegradation } \\
\text { of plastic materials in an activated-sludge-wastewater-treatment } \\
\text { system }\end{array}$ \\
\hline ASTM & $\begin{array}{l}D 5338- \\
98 \mathrm{e} 1\end{array}$ & $\begin{array}{l}\text { Standard test method for determining aerobic biodegradation of } \\
\text { plastic materials under controlled composting conditions }\end{array}$ \\
\hline ASTM & D5511-94 & $\begin{array}{l}\text { Standard test method for determining anaerobic biodegradation of } \\
\text { plastic materials under high solids anaerobic-digestion conditions }\end{array}$ \\
\hline ASTM & D5525-94a & $\begin{array}{l}\text { Standard practice for exposing plastics to a simulated active } \\
\text { landfill environment }\end{array}$ \\
\hline ASTM & D5526-94 & $\begin{array}{l}\text { Standard test method for determining anaerobic biodegradation of } \\
\text { plastic materials under accelerated landfill conditions }\end{array}$ \\
\hline ASTM & D5951-96 & $\begin{array}{l}\text { Standard practice for preparing residual solids obtained after } \\
\text { biodegradability standard methods for plastics in solid waste for } \\
\text { toxicity and compost quality testing }\end{array}$ \\
\hline ASTM & D6002-96 & $\begin{array}{l}\text { Standard guide for assessing the compostability of } \\
\text { environmentally degradable plastics }\end{array}$ \\
\hline ASTM & D6003-96 & $\begin{array}{l}\text { Standard test method for determining weight loss from plastic } \\
\text { materials exposed to simulated municipal solid waste (MSW) } \\
\text { aerobic compost environment }\end{array}$ \\
\hline ASTM & D6094-97 & $\begin{array}{l}\text { Standard guide to assess the compostability of environmentally } \\
\text { degradable non woven fabrics }\end{array}$ \\
\hline ASTM & D6340-98 & $\begin{array}{l}\text { Standard test method for determining aerobic biodegradation of } \\
\text { radiolabeled plastic materials in a aqueous or compost } \\
\text { environment }\end{array}$ \\
\hline ASTM & D6400-99 & Standard specification for compostable plastics \\
\hline ISO & $\begin{array}{l}\text { 14851: } \\
1999\end{array}$ & $\begin{array}{l}\text { Determination of the Ultimate Aerobic Biodegradability of Plastic } \\
\text { Materials in an Aqueous Medium - Method by measuring the } \\
\text { Oxygen Demand in a Closed Respirometer }\end{array}$ \\
\hline ISO & $\begin{array}{l}\text { 14852: } \\
1999\end{array}$ & $\begin{array}{l}\text { Determination of the Ultimate Aerobic Biodegradability of plastic } \\
\text { materials in an Aqueous Medium - Method by Analysis of evolved } \\
\text { Carbon Dioxide }\end{array}$ \\
\hline ISO & $\begin{array}{l}\text { 14855: } \\
1999\end{array}$ & $\begin{array}{l}\text { Determination of the Ultimate Aerobic Biodegradability and } \\
\text { Disintegration of plastic materials Under Controlled Composting } \\
\text { Conditions - Method by Analysis of evolved Carbon Dioxide }\end{array}$ \\
\hline CEN & EN 13432 & $\begin{array}{l}\text { Requirements for packaging recoverable through composting and } \\
\text { biodegradation -Test scheme and evaluation criteria for the final } \\
\text { acceptance of packaging }\end{array}$ \\
\hline
\end{tabular}

Table 4. Titles of some important standards 
DIN

FNK 103.2

ASTM sub-committee D20-96

Japanese Biodegradable Plastics Society

ISO $472 \quad$ Biodegradable plastics ${ }^{1)}$

Biodegradable plastics ${ }^{1)}$

A plastic material is called biodegradable if all its organic compounds undergo a complete biodegradation process. Environmental conditions and rates of biodegradation are to be determined by standardized test methods.

\section{Biodegradation $^{3)}$}

Biodegradation is a process, caused by biological activity, which leads under change of the chemical structure to naturally occurring metabolic products.

\section{Biodegradable plastics ${ }^{1)}$}

A degradable plastic in which the degradation results from the action of naturally occurring microorganisms such as bacteria, fungi and algae.

Biodegradable plastics ${ }^{1)}$

Polymeric materials which are changed into lower molecular weight compounds where at least one step in the degradation process is though metabolism in the presence of naturally occurring organisms.

A plastic designed to undergo a significant change in its chemical structure under specific environmental conditions resulting in a loss of some properties that may vary as measured by standard test methods appropriate to the plastic and the application in a period of time that determines its classification. The change in the chemical structure results from the action of naturally occurring microorganisms.

CEN Biodegradable plastics ${ }^{1)}$

A degradable material in which the degradation results from the action of microorganisms and ultimately the material is converted to water, carbon dioxide and/or methane and a new cell biomass.

Biodegradation $^{2)}$

Biodegradation is a degradation caused by biological activity, especially by enzymatic action, leading to a significant change in the chemical structure of a material Inherent biodegradability²)

The potential of a material to be biodegraded, established under laboratory conditions. Ultimate biodegradability ${ }^{2}$

The breakdown of an organic chemical compound by microorganisms in the presence of oxygen to biodegradability carbon dioxide, water and mineral salts of any other elements present (mineralization) and new biomass or in the absence of oxygen to carbon dioxide, methane, mineral salts and new biomass.

Compostability $\left.{ }^{2}\right)$

Compostability is a property of a packaging to be biodegraded in a composting process. To claim compostability it must have been demonstrated that a packaging can be

biodegraded in a composting system as can be shown by standard methods. The endproduct must meet the relevant compost quality criteria.

1) Pagga (1998);2) Calmon-Decriaud et al. (1998);3) DIN V 94900 (1998)

Table 5. Definitions used in correlation with biodegradable plastics 


\subsection{Testing methods}

In order to determine biological action on man-made materials, test methods have been available for quite a long time for different classes of materials. Recently, the evaluation of the degradability of chemicals in the environment, specifically in waste water, as an important aspect of the ecological impact of a compound has become very significant when efforts are being made to present to the marketplace a new chemical product. As a result, numerous standard tests for different environments have been developed using various analytical methods [34]. Table 6 shows an overview of some international standards in this area. In order to evaluate the influence of microorganisms on polymer, test methods have been initiated even before biodegradable plastics were first developed. While conventional plastics are relatively resistant against environmental influences, at some point, microorganisms can attack the plastics to a certain extent and create unwanted changes in the material properties, e.g., in the color or in mechanical properties such as flexibility or mechanical strength [35].

\begin{tabular}{|c|c|}
\hline ASTM G21-96 & Standard practice for determining resistance of synthetic polymer materials to fungi \\
\hline ASTM G29-96 & Standard practice for determining algal resistance of plastic films \\
\hline $\begin{array}{l}\text { DIN IEC } 60068- \\
2-10-1991\end{array}$ & $\begin{array}{l}\text { Elektrotechnik; Grundlegende Umweltprüfverfahren; Prüfung J und Leitfaden: } \\
\text { Schimmelwachstum; (Identisch mit IEC 60068-2-10: 1988) }\end{array}$ \\
\hline $\begin{array}{l}\text { EN ISO 846- } \\
1997\end{array}$ & Plastics - Evaluation of the action of microorganisms \\
\hline $\begin{array}{l}\text { IEC } 60068-2-10- \\
1988\end{array}$ & Elektrotechnik; Grundlegende Umweltprüfverfahren; Prüfung J: Schimmelwachstum \\
\hline ISO $846-1997$ & $\begin{array}{l}\text { Plastics: Determination of behaviour under the action of fungi and bacteria. Evaluation } \\
\text { by visual examination or measurement of changes in mass or physical properties }\end{array}$ \\
\hline
\end{tabular}

Table 6. Standard test methods for biocorrosion phenomena on plastics

While this wide range of degradation tests was already available, it was necessary to develop special test methods when working with biodegradable plastics.

As it could be understood from the listed standards in Table 6, special aspects of plastics materials could not be considered. Regarding the biocorrosion phenomena, the subject of whether or not that a plastic is degraded is not the concern, but it is important that whether minor chemical changes in the polymers (e.g., extraction of plasticizer, oxidation, etc.) caused to changes in the material properties. Evaluation of low-molecular-weight substances was developed specifically for biodegradable plastics during the past decade or so (Itvaara and Vikman, 1996). However, they have been tried to adapt to specific environments in which biodegradable plastics might be degraded. Furthermore, these methods consider the fact that plastics have a complex structure and are degraded by a heterogeneous surface mechanism mainly. Table 7 shows standard test methods used in evaluation of chemicals biodegradability. 


\begin{tabular}{|c|c|}
\hline \multicolumn{2}{|c|}{ OECD Guidelines (OECD, 1993) } \\
\hline 301 & Ready Biodegradability \\
\hline 301 A-1992 & DOC Die-Away Test \\
\hline 301 B-1992 & $\mathrm{CO}_{2}$ Evolution Test \\
\hline $301 \mathrm{C}-1992$ & Modified MITI Test \\
\hline $301 \mathrm{D}-1992$ & Closed Bottle Test \\
\hline $301 \mathrm{E}-1992$ & Modified OECD Screening Test \\
\hline $301 \mathrm{~F}-1992$ & Manometric Respirometry Test \\
\hline 302 & Inherent Biodegradability \\
\hline$\overline{302}$ A-1981 & Modified SCAS Test \\
\hline 302 B-1992 & Zahn-Wellens Test \\
\hline 302 C-1981 & Modified MITI Test \\
\hline 302 D B draft (2002) & Inherent biodegradability-concave test \\
\hline 303 & Simulation Test \\
\hline 303 A-2001 & Aerobic Sewage Treatment: Activated Sludge Units \\
\hline 304 & Biodegradation in Soil \\
\hline$\overline{304}$ A-1981 & Inherent Biodegradability in Soil \\
\hline $306-1992$ & Biodegradability in Seawater \\
\hline 307 B draft (2000) & Aerobic and anaerobic transformation in soil \\
\hline 308 B draft (2000) & Aerobic and anaerobic transformation in aquatic sediment systems \\
\hline 309 B draft (2001) & Aerobic mineralisation in surface water-simulation biodegradation test \\
\hline 301 B draft (2002) & Ready biodegradability $\mathrm{B} \mathrm{CO}_{2}$ in sealed vessels (Headspace test) \\
\hline 311 B draft (2002) & Ready anaerobic biodegradability: Gas production from diluted anaerobic sewage sludge \\
\hline ISO 7827-1994 & $\begin{array}{l}\text { Water quality - Evaluation in an aqueous medium of the "ultimate" aerobic } \\
\text { biodegradability of organic compounds - Method by analysis of dissolved organic } \\
\text { carbon (DOC) }\end{array}$ \\
\hline ISO 9439-1999 & $\begin{array}{l}\text { Water quality - Evaluation in an aqueous medium of the "ultimate" aerobic } \\
\text { biodegradability of organic compounds - Method by analysis of released carbon } \\
\text { dioxide }\end{array}$ \\
\hline ISO 9408-1999 & $\begin{array}{l}\text { Water quality - Evaluation in an aqueous medium of the "ultimate" aerobic } \\
\text { biodegradability of organic compounds - Method by determining the oxygen } \\
\text { demand in a closed respirometer }\end{array}$ \\
\hline ISO 9887-1992 & $\begin{array}{l}\text { Water quality - Evaluation of the aerobic biodegradability of organic compounds in } \\
\text { an aqueous medium - Semi-continuous activated sludge method (SCAS) }\end{array}$ \\
\hline ISO 9888 в 1999 & $\begin{array}{l}\text { Water quality - Evaluation of the aerobic biodegradability of organic compounds in } \\
\text { an aqueous medium - Static test (Zahn-Wellens method) }\end{array}$ \\
\hline ISO $10634-1995$ & $\begin{array}{l}\text { Water quality - Guidance for the preparation and treatment of poorly water-soluble } \\
\text { organic compounds for the subsequent evaluation of their biodegradability in an }\end{array}$ \\
\hline & an aqueous medium -Static test (Zahn- Wellens method) \\
\hline ISO $10707-1994$ & $\begin{array}{l}\text { Water quality - Evaluation in an aqueous medium of the ultimate aerobic } \\
\text { biodegradability of organic compounds - Method by analysis of biochemical oxygen } \\
\text { demand (closed bottle test) }\end{array}$ \\
\hline ISO $10708-1997$ & $\begin{array}{l}\text { Water quality - Evaluation in an aqueous medium of the ultimate aerobic } \\
\text { biodegradability of organic compounds - Method by determining the biochemical } \\
\text { oxygen demand in a two-phase closed - bottle test }\end{array}$ \\
\hline ISO $11733-1995$ & $\begin{array}{l}\text { Water quality - Evaluation of the elimination and the biodegradability of organic } \\
\text { compounds in an aqueous medium. Activated sludge simulation test }\end{array}$ \\
\hline ISO $11734-1995$ & $\begin{array}{l}\text { Water quality - Evaluation of the ultimate anaerobic biodegradability of organic } \\
\text { compounds in digested sludge. Method by measurement of the biogas production }\end{array}$ \\
\hline
\end{tabular}


ISO/FDIS 14592-1 Water quality - Evaluation of the aerobic biodegradability of organic compounds at low concentrations - Part 1: Shake-flask batch test with surface water or surface water/sediment suspension

ISO/DIS 14592-2 Water quality - Evaluation of the aerobic biodegradability of organic compounds at low concentrations - Part 2: Continuous flow river model with attached biomass

ISO 14593-1999 Water quality - Evaluation of ultimate aerobic biodegradability of organic compounds in aqueous medium - Method by analysis of inorganic carbon in sealed vessels $\left(\mathrm{CO}_{2}\right.$ headspace test)

ISO/TR 15462-1997 Water quality - Selection of tests for biodegradability

ISO 16221 B 2001 Water quality - Guidance for determination of biodegradability in the marine environment

EN ISO 7827-1995 Water quality - Evaluation in an aqueous medium of the "ultimate" aerobic biodegradability of organic compounds - Method by analysis of dissolved organic carbon (DOC)

EN ISO 9439-2000 Water quality - Evaluation of ultimate aerobic biodegradability of organic compounds in aqueous medium - Carbon dioxide evolution test

EN ISO 9408-1999 Water quality - Evaluation of ultimate aerobic biodegradability of organic compounds in aqueous medium by determination of oxygen demand in a closed respirometer

EN ISO 9887-1994 Water quality - Evaluation of the aerobic biodegradability of organic compounds in an aqueous medium - Semi-continuous activated sluge method (SCAS)

EN ISO 9888-1999 Water quality - Evaluation of ultimate aerobic biodegradability of organic compounds in aqueous medium - Static test (Zahn-Wellens method)

EN ISO 10634-1995 Water quality - Guidance for the preparation and treatment of poorly water-soluble organic compounds for the subsequent evaluation of their biodegradability in an aqueous medium

EN ISO 10707-1997 Water quality - Evaluation in an aqueous medium of the "ultimate" aerobic biodegradability of organic compounds - Method by analysis of biochemical oxygen demand (closed bottle test)

EN ISO 11733-1998 Water quality - Evaluation of the elimination and biodegradability of organic compounds in an aqueous medium - Activated sludge simulation test

EN ISO 11734-1998 Water quality - Evaluation of the "ultimate"; anaerobic biodegradability of organic compounds in digested sludge - Method by measurement of the biogas production

Inhibition tests

ISO 8192 B 1986

ISO 9509 B 1989

Water quality - Test for inhibition of oxygen consumption by activated sludge Water quality - Method for assessing the inhibition of nitrification of activated sludge microorganisms by chemicals and waste waters

ISO 10712 B 1995 Water quality - Pseudomonas putida growth inhibition test (Pseudomonas cell multiplication inhibition test)

ISO 11348 Part 1, 2, 3 Water quality - Determination of the inhibitory effect of water samples and the light - $1998 \quad$ emission of Vibrio fischeri (Luminescent bacteria test)

EN ISO 8192 - 1995 Water quality - Test for inhibition of oxygen consumption by activated sludge

EN ISO 9509 - 1995 Water quality - Method for assessing the inhibition of nitrification of activated sludge microorganisms by chemicals and waste water

EN ISO 10712 - 1996 Water quality - Pseudomonas putida growth inhibition test (Pseudomonas cell multiplication inhibition test)

EN ISO 11348 Teil 1, Water quality - Determination of the inhibitory effect of water samples on the light 2, 3- 1998 emission of Vibrio fischeri (Luminescent bacteria test)

Table 7. Standard test methods for biodegradability of chemicals

\section{Conclusion}

Various contaminants into natural environments that have resulted in instability, disorder, harm, or discomfort to an ecosystem is known as pollution and includes different forms such 
as air, soil, water, sound, etc. Reducing the amount of solid waste in landfills and the addition of nutrient-rich organic matter are the help that composting gives to the Earth. Polymers, composites and nanocomposites made of major chemicals that are highly toxic and pose a serious threat to all living species on the planet Earth. The earth cannot digest these materials and leads to serious damage to the environment during their production and disposal process.

Composting of composites and nanocomposites based on bio-based polymers used in various applications is an important solution to reduce the amount of solid waste in landfills or any other polluted area.

Which way must be chosen to save our planet: the management of packaging and packaging waste's, use of combustible packaging waste in order to generate energy by completely burning the substance or changing them to compost?

Composts improve soil quality, assist plant growth, increase water holding capacity, store carbon in the soil, and reduce the need for chemical fertilizer and pesticides. "Compostable polymer" undergoes degradation by biological processes during composting to yield $\mathrm{CO}_{2}$, water, inorganic compounds, and biomass at a rate consistent with other known compostable materials and leaves no visible, distinguishable, or toxic residue.

Nanoparticles can have other functions when added to a polymer, such as increasing of tensile modulus, antimicrobial activity, enzyme immobilization, biosensing, etc. An outline of the main kinds of nanoparticles which have been studied for use in food packaging systems is given, as well as their effects and application.

Testing degradation phenomena of compostable polymers and nanocomposites in the environment has an overall problem regarding the type of tests to be implemented and the results that can be obtained. The guiding principle is that tests can be subdivided into three categories: field tests, simulation tests, and laboratory tests. Important tests include the soil burial test, controlled composting test, test simulating landfills, and aqueous aquarium tests.

There are some regulation and voluntary standards such as EPA Class A and B tests in USA, UK guidelines regarding compost quality also exist which is common in European Union, Canadian, Australian in the world.

"Let us save our environment from polymer pollution to make it a better environment for the future" To do so, compostable polymers and nanocomposites are a big chance for planet Earth.

\section{Author details}

Gity Mir Mohamad Sadeghi ${ }^{1^{*}}$ and Sayaf Mahsa ${ }^{2}$

*Address all correspondence to: gsadeghi@aut.ac.ir

1 Dep. of Polymer Engineering \& Color Technology, Amirkabir University of Technology, Tehran, I.R., Iran

2 Dep. of Chemical Engineering Isfahan University of Technology, Isfahan, I.R., Iran 


\section{References}

[1] http://www.earthtimes.org/encyclopaedia/environmental-issues/pollutio

[2] http://www.pardos-marketing.com/hot04.htm

[3] An analysis of European plastics production, demand and waste data for 2011. Available from: http://www.plasticseurope.org, Plastics Europe Market Research Group (PEMRG)

[4] Plastic waste: ecological and human health impacts. Available from: http://ec.europa.eu/environment/integration/research/newsalert/pdf/IR1_en.pdf

[5] Mud gal, S., Lyons, L., Bain, J. et al. (2010) Plastic waste in the environment. Final Report for European Commission DG Environment, Bio Intelligence Service. Available from: www.ec.europa.eu/environment/waste/studies/pdf/plastics.pdf

[6] Plastics wastes. Available from: http://marketpublishers.com/report

[7] Garbage patches. Available from: http://marinedebris.noaa.gov/info

[8] Science for environment policy: In-Dept report, Nov. 2011.

[9] Shamsi R et al, 2009; Mohammadi et al, 2010 \& Mir Mohamad Sadeghi G. et al, 2011.

[10] Zenda, K, Funazukur T, Depolymerization of poly (ethylene terephthalate) in dilute aqueous ammonia solution under hydrothermal conditions. J Chem Technol Biotechnol 2008, 83, 10, 1381-1386.

[11] Compostable polymer materials, ISBN: 978-0-08-045371-2, Ewa rudnik.

[12] Michael Evans's bio. Available from: http://www.banginfo.in/Environment/Plasticpollution.html

[13] Workshop: Promotion of Sustainable Plastics, 29-30 November 2005, San Jos6, Costa Rica.

[14] Shamsi R, Mir Mohamad Sadeghi G, Afshar F, Abdouss M. Polym Int. 2009, 58, $22-$ 30. Doi: 10.1002/pi.2488.

[15] link.springer.com/article/10.1007/s10965-007-9131-9.

[16] Environmentally degradable plastics, Leonadoda Vinci Program: www.ics.trieste.it, Stanislav Miertus.

[17] Jain A, Soni RK, Spectroscopic investigation of end products obtained by ammonolysis of poly ethylene terephthalate waste in the presence of zinc acetate as a catalyst. J Polym Res 2007. http://link.springer.com/article/10.1007/s10965-007-9131-9.

[18] Cooperband L, The Art and Science of Composting, Uni. Wisconsin-Madison, Center for Integrated Agricultural Systems, 2002. 
[19] Eder P, Case study-compost in End of Waste Project, Inst. Prospective Technological Studies, DG Joint Research.

[20] Institute, September 2006. Available from: http://www.jrc.ec.europa.eu

[21] Sharma VK, Canditelli M, Fortuna E, Cornacchia G, Processing of urban and agroindustrial residues by aerobic.

[22] Composting: review. Energy Conv. Mangmt 1997, 38, 453.

[23] Coker C.: Composting industrial and commercial organics, 20 April 2000, www.owr.ehnr.state.nc.us/compost

[24] Henriette M.C. de Azeredo, Nanocomposites for food packaging applications. Food Res Int 2009, 42, 1240-1253. Doi: 10.1016/j.foodres.2009.03.019.

[25] Biodegradability of polymers: Regulations and methods for testing, Dr. rolf-Joachim Muller, 366-388.

[26] Biodegradable materials based on polymers, and corresponding multiphase systems for biomedical applications. Available from: www.biodeg.net

[27] Composting benefits. Available from: http://eartheasy.com/grow_compost.html

[28] Rudnik E, Compostable polymer materials. Handb of Biiopolym Biodegradable Plast, 2013, 189-211.

[29] Rudnik E, Compostable Polymer Materials. Compositing methods and legislation, 2008.

[30] Handbook of Biopolymers and Biodegradable Plastics, A volume in Plast. Design Lib., ISBN: 978-1-4557-2834-3.

[31] Tizazu Mekonnen, Paolo Mussone, Hamdy Khalil, David Bressler, Progress in biobased plastics and plasticizing modifications. J Mater Chem A 2013, 1, 13379 13398.Tizazu Mekonnen, Paolo Mussone, Hamdy Khalil and David Bressler Doi: 10.1039/C3TA12555F.

[32] Henriette MC de Azeredo, Nanocomposites for food packaging applications. 2009, $42,9,1240-1253$.

[33] Investigation of Biodegradable Nonwoven Composites Based on Cotton, Bagasse and Other Annual Plants, Louisiana state university, Zhang Phd. Thesis, 2004.

[34] Pagga U, Testing biodegradability with standardized methods. Chemosphere 1997, 35, 12, 2953-2972.

[35] Pantke M, Seal KJ, An inter laboratory Investigation into the biodeterioration of plastics, with special reference to polyurethans, part 2, Soil Burial Experiments. Mater Org 1990, 25, 2. 
[36] Pagga U, Beimborn DB, Boelens J, De Wilde B, Determination of the aerobic biodegradability of polymeric material in a laboratory controlled by composting test. Chemosphere 1995, 31, 4475-4487.

[37] Degli-Innocenti F, Tosin M, Bastioli C, Evaluation of the biodegradation of starch and cellulose under controlled composting conditions. J Env Polym Degrad 1998, 6, 4:197.

[38] Degli-Innocenti F, Tosin M, Bastioli C, Evaluation of the biodegradation of starch and cellulose under controlled composting conditions. J Env Polym Degrad 1998, 6, 4:197-202.

[39] Gu JD, Eberiel D, McCarthy SP, Gross RA, Degradation and mineralization of cellulose acetate in simulated thermophilic compost environments. J Env Polym Degrad 1993, 1:281-291.

[40] Püchner P, Müller WR, Bartke D, Assessing the biodegradation potential of polymers in screening and long term test systems. J Env Polym Degrad 1995, 3:133-143.

[41] Yoichi Ando, Biodegradability of poly(tetramethylene succinate-co-tetramethylene adipate): I. Enzymatic hydrolysis. Polym Degrad Stab 1998, 61, 1:129-137. 
Chapter 5

\title{
Potential for Introduction of Preservative Treated Wood in Wood Waste Recycling Streams and its Prevention
}

\author{
Jeffrey J. Morrell \\ Additional information is available at the end of the chapter \\ http://dx.doi.org/10.5772/59327
}

\section{Introduction}

The public desire to reduce, reuse and recycle has led to substantial investments in recycling programs. Metals, paper, plastics and a host of other materials are now recycled, thereby conserving precious landfill space. One particularly important waste diversion is in the area of wood and garden waste [1]. These materials tend to be bulky and, more importantly, contribute to the production of methane as they degrade under anaerobic conditions in the landfill. Many communities now divert this material to be composted, separated and burned for energy production or, if the resource is sufficiently free of contaminants, even used to produce composite wood products. Composting has become especially attractive because this material can be combined with more putrescible wastes such as food compost to produce a very rich composted material.

One aspect of wood recycling operations that is often overlooked is the presence of contaminants in the chipped mixture. Metal fasteners can be removed using magnets, but many other materials wind up in this mixture. One of the more important potential contaminants is preservative treated wood [2,3]. Preservative treated wood is typically impregnated with combinations of heavy metals to provide resistance to biological attack. For decades, the most commonly used preservative for residential applications was chromated copper arsenate (CCA). CCA is no longer used for residual applications, but the replacement systems are primarily copper based including alkaline copper quaternary compound (ACQ) or alkaline copper azole (CA). The U.S. Environmental Protection Agency generally recommends that, wherever possible, treated wood be reused in a similar application. Once this is no longer possible, the wood should be disposed of in a licensed municipal solid waste facility with the appropriate liners and leachate management technology. The EPA specifically prohibits the burning of treated wood except in specially licensed facilities. The most common use of 
combustion for disposal of treated wood is with creosote, although it is technically possible to combust other treated wood products. These activities are generally associated with industrial products such as railroad ties or utility poles.

While industrial products are an important component of the potential treated wood disposal stream, the users of these products are generally aware of the requirements for disposal. However, a large amount of preservative treated wood is employed in residential applications for decking, fencing, and a host of other uses. These products have varying service lives and eventually find their way into the waste stream. As with other treated wood products, the EPA recommends reuse following by landfill disposal for these products at the end of their service lives; however, there are several factors that can make this difficult. First, treated wood in many parts of the country tends to fade and weather as it is exposed to ultraviolet light. In many cases, it is virtually impossible to visually distinguish between treated and non-treated wood once it has weathered. In addition, many homeowners do not know that treated wood needs to be disposed of in a landfill and therefore tend to place this material into their yard recycling container where they already place other woody debris. Finally, there is no specific collection pathway for treated wood products, making them difficult to assemble as a single material.

\section{Level of contamination in recycled wood}

The potential for contamination of wood recycling streams was brought to light over a decade ago in Florida. Energy recovery facilities that used mixtures of bagasse and waste wood obtained from construction and demolition landfills as fuel sources discovered that their resulting ash contained very high levels of copper, chromium and arsenic. Further investigation revealed that high percentages of wood entering construction and demolition debris (C\&D) facilities were treated with CCA. However, the wood had weathered to the extent that it was no longer possible to visually detect this material. The Florida situation is unique in a number of ways. The higher risk of decay in this state means that treated wood represents a much higher percentage of the total volume of wood used. In addition, these more severe exposure conditions lead to a shorter overall service life for a given product. The severe UV exposure conditions typically found in Florida tend to reduce the surface appearance of the material, leading to premature removal of wood that is structurally sound, but has a poor appearance. Florida also has a very limited landfill capacity and, at the time had a number of non-lined C\&D facilities. This led to large amounts of materials entering combustion facilities. The occurrence of elevated metal levels stimulated a large research effort at the University of Miami and University of Florida to determine the levels of treated wood entering the recycling stream, and, once it became evident that a substantial volume of treated wood was present, how to rapidly detect it.

Copper based systems are currently the most commonly used wood preservatives, but older wood can also contain chromium and arsenic. The EPA labels associated with these chemicals specifically indicate that disposal of products treated with wood preservatives should be in a lined landfill; however, it can sometimes be difficult to determine if wood that has been 
subjected to extensive ultraviolet light contains preservative treatment. As a result, there is a risk that treated wood can enter the recycling stream. In the case of woody debris used for biofuels, the presence of metal based preservative can result in air-emissions as well as elevated metal levels in the resulting ash. Inadvertent inclusion of treated wood in composting operations could result in elevated metal levels in the subsequent compost. While this is unlikely to pose a risk to plants, it could lead to difficulties if the materials are marketed as being organic.

In either case, quantifying the amounts of treated wood entering a waste stream can help producers determine the level of risk so that they can develop appropriate mitigation measures. This risk is likely to differ regionally because of the differing degrees to which treated wood is employed and the length of time it remains in service. The Pacific Northwest is an excellent area in which to determine treated wood incidence in recycling streams because it has well developed recycling programs and the treated wood has distinctive features that make it easier to detect. In this chapter, we will discuss surveys of treated wood incidence in a wood recycling center over a 10 year period and then discuss possible methods for limiting the incidence of such materials [12].

Surveys were conducted at a recycling facility located near Corvallis, Oregon [4]. The facility is a regional composting and recycling facility that processes over 28,000 metric tons of material per year. The facility receives regular yard waste that includes branches, grass, brush, and seasonal influxes such as leaves and Christmas trees. The facility also accepts wood waste from various sources. These materials were formerly chipped separately with the yard debris being composted and the wood debris going to various facilities for combustion for either steam or electricity. This situation has recently changed as a result of the introduction of generation of food waste composting coupled with changes in wood demand in the surrounding area. The food composting operation has resulted in an increase demand for woody debris as a media for the composting, while lower natural gas prices have sharply curtailed the use of woody biomass for energy production. As a result, nearly all wood entering the facility now ends up in the compost mixture.

Most materials arrive at the facility by commercial haulers, but nearby residents can also drop off materials for a fee. Loads can be inspected at the gate house, but it is not feasible to inspect every load. As a result, it is possible for contaminants to enter the recycling stream. Wood entering the facility is segregated into a separate pile for chipping. Chipping occurs as equipment becomes available and the resulting wood chips are stored until needed for constructing a compost pile. Once the wood is chipped, it is virtually impossible to detect the presence of treated wood.

Detecting treated wood prior to chipping is relatively simple. The wood is normally piled in such a way that the vast majority of the pile is accessible. Treated wood in the Pacific Northwest is much easier to detect because it is generally stained with a brown pigment to makes it appear like western redcedar. In addition, a large percentage of the material is incised. This process drives metal teeth into the wood to improve the depth of preservative treatment. Incision marks are easily seen, even in older wood, making detection of treated wood in a pile relatively simple (Figure 1). 


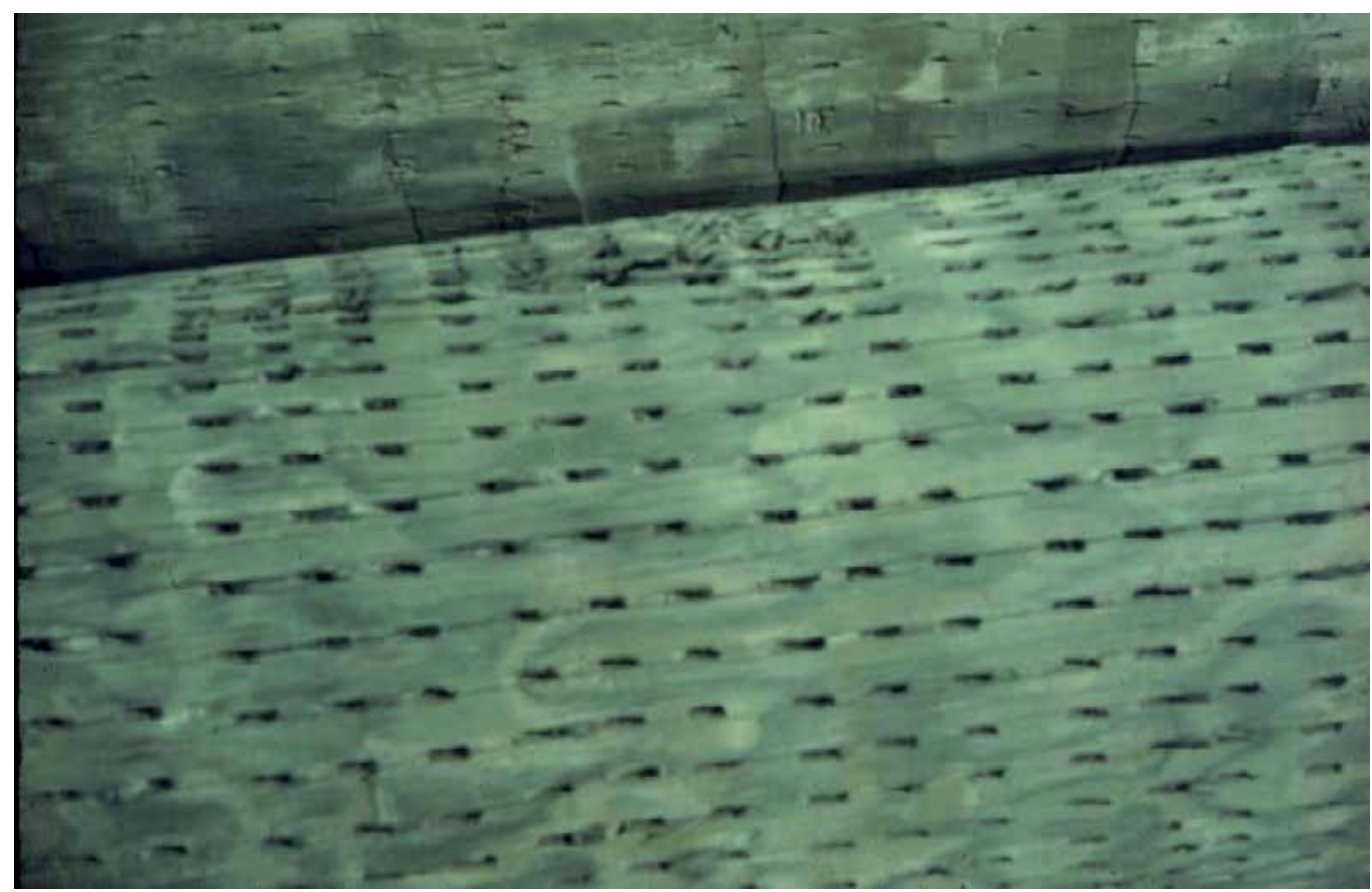

Figure 1. Example of wood with incisions that make it relatively easy to detect preservative treated wood in recycling facilities in the Western U.S.

The amount of treated wood has been visually assessed 168 times over the 12 year period [10]. At each time point, the size of the entire pile was estimated. The presence of treated wood of a given dimension in the pile was then visually determined (for example 4 by 4 inches, 2 by 4 inches, etc.) and the length was estimated to the nearest $300 \mathrm{~mm}$. As mentioned, treated wood is readily detected in this part of the United States because of the distinctive brown stain and/ or the presence of incisions. Depending on pile size, visual detection of treated wood is possible 1 to $3 \mathrm{~m}$ inward from the outside of the pile. In addition, we estimated the relative proportions of yard debris, pallets, panels, and demolition debris. This latter categorization only began after we had performed for the first 40 observations.

Ideally, wood mass would be used to estimated treated wood proportions, however, this was not possible because of safety issues related to the placement of the materials in a pile. Instead, the lineal footage of each piece of dimension material detected was used to determine overall volume of wood using actual dimensions. Lumber for residential applications was primarily treated with chromated copper arsenate (CCA) until 2003 when this material was withdrawn from the market. Alkaline copper quaternary (ACQ) compound or copper azole (CA) largely replaced CCA for this application [5]. It is not possible to visually distinguish wood treated with these three chemicals because of the brown pigments. The use of a copper indicator also would not help since all three systems contain copper as the primary biocide. For the purpose of determining chemical loading, we assumed that all of the wood had been treated to the American Wood Protection Association Standards ground contact retention for treatment of 
lumber with any of the water borne materials $\left(6.4 \mathrm{~kg} / \mathrm{m}^{3}\right.$ for ACQ or CCA $)$ and that the entire cross section had been treated to that level. Average wood densities were then used to calculate the total amount of metal present in the material [6,7]. This is an extremely conservative approach because wood in this region is difficult to penetrate with preservatives. As a result, somewhere between 40 and $60 \%$ of the cross section is actually preservative treated and not all wood is treated to the higher retention level. However, since we could not visually assess treatment depth or retention, we used the conservative approach. As a result, the estimates of total chemical in the wood were intentionally high.

Pallets, yard debris, and demolition debriswere the most abundant materials detected in piles at the site (Figure 2). The average volume of material present at any given inspection was 338.8 $\mathrm{m}^{3}$. Pallets were the most abundant manufactured material at the site (39 of 128 times), while yard debris, which include branches and leaves was the most common 68 times [10]. A variety of other materials were also present including panel trim scraps and shingles, but these represented minor volumes compared to the two most common materials. For example, Christmas trees were seasonally abundant, but represented an overall low percentage of the total mass delivered to the site.

\section{Frequency of dominant material}

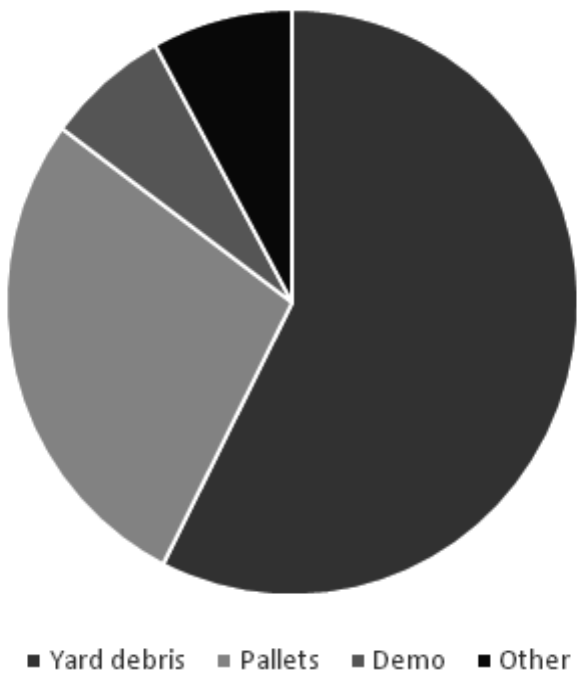

Figure 2. Frequency of a given woody material being the dominant substrate present at the recycling center (from 10)

Treated wood was present in 155 out of 168 inspections or $92.3 \%$ of the samples (Figure 3). The percentages of treated wood were generally low in the samples, ranging from $<0.01 \%$ to $2.0 \%$ of the estimated volume (Figure 4). Levels at or above $1 \%$ were only detected 3 times over the 12 year period. The average volume of treated wood present was $0.15 \%$ over the 12 years. Treated wood levels were $>0.2 \%$ of the volume in $20.5 \%$ of the inspections, while they were between 0.1 and $0.2 \%$ of the volumes in another $16.1 \%$ of the inspections. Treated wood 


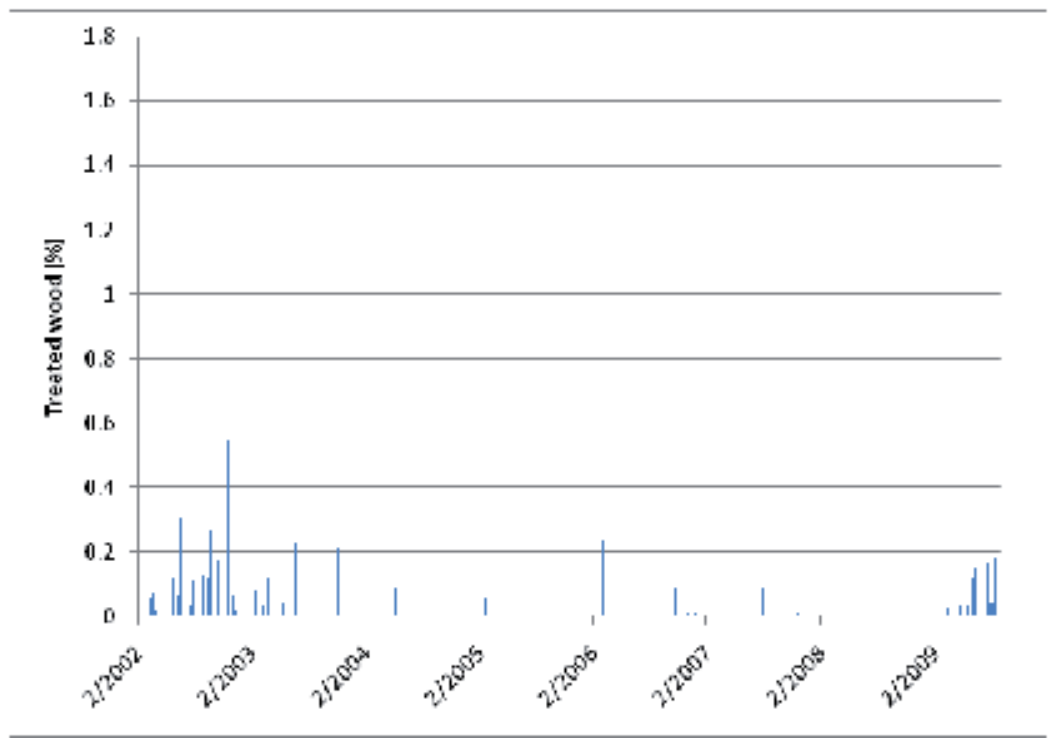

Figure 3. Percentages of treated wood detected in a recycling facility located in Western Oregon as determined by period visual surveys over a 12 year period.

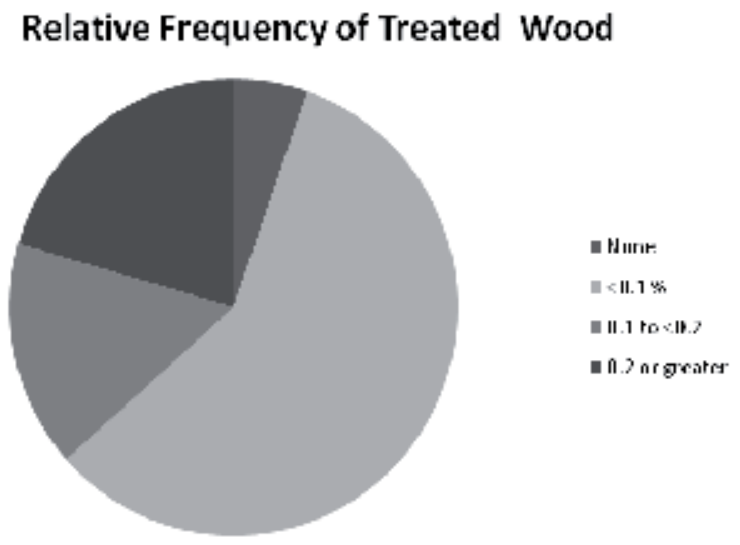

Figure 4. Frequency of different levels of treated wood in a wood recycling center in Western Oregon assessed over a 10 year period. Values are based upon 112 surveys (from 10).

represented less than $0.1 \%$ of the volume in a majority of inspections $(63.4 \%)$, indicating that this material was a relatively small proportion of the recycling stream.

\section{Implications of treated wood contamination}

These data provide an example of the potential for inadvertent presence of treated wood in the recycling stream and a relatively simple method for assessing the extent. However, it is 
important to recognize that every site is different. In some cases, the overall volumes of wood in a facility are too great for this approach or the materials are processed directly and not available for inspection. In addition, the proportions of treated wood at this site were relatively low and the treated products were relatively easily detected. Never the less, it is important to develop reliable estimates of the levels of treated wood entering recycling streams. In the cases of materials that are combusted for energy production, excess amounts of treated wood in the feedstock can lead to releases of arsene gases and produce residual ash with excessively high metal contents that can pose a disposal hazard. This becomes quite important in some facilities. For example, previous studies of wood recycling facilities have shown that $5.9 \%$ of volume at a C\&D facility in Florida was treated wood [8], while $2.5 \%$ of the wood entering the waste stream in Virginia was treated [9]. The risk can be examined by considering the potential inputs of metals into ash resulting from combustion of the materials. If we used the Oregon facility data indicating that if an average of $0.15 \%$ of the incoming wood was CCA treated, then As, $\mathrm{Cr}$ and $\mathrm{Cu}$ levels would be 2380,2640 and $1580 \mathrm{ppm}$ in the resulting ash [10]. Cu levels would be much higher if the wood was treated with either alkaline copper azole or alkaline copper quat but no arsenic or chromium would be present. It is important to realize that material from this particular facility was used to supplement other fuel supplies at local wood processing facilities. As a result there is likely to be considerable dilution with non-treated wood so that the resulting ash would not pose a disposal issue. However, the results do illustrate the potential for creating metal contaminated ashes in areas where large amounts of treated wood are employed. For example, if the treated wood levels present in the C \& D facility in Florida were used, then As, $\mathrm{Cr}$ and $\mathrm{Cu}$ levels in the resulting ash would be 92820, 102,960, and 61620 ppm, respectively, and ash disposal would pose a major challenge. It is important to remember that metals do not disappear from compost. Thus, these same metal input levels would be present in any compost. The Oregon facility received 1318.2 metric tons of wood waste in 2013 along with other materials. If we use the $0.15 \%$ treated wood composition figure, this material would result in an input of $28.2 \mathrm{~kg}$ of CCA. CCA Type C is composed of $47.5 \%$ chromic acid, $18.5 \%$ copper oxide and $34 \%$ arsenic pentoxide [5]. These elements are expressed on an oxide basis. If we convert the total CCA input to elemental metals, the treated wood would input $6.97 \mathrm{~kg}$ of $\mathrm{Cr}, 4.50 \mathrm{~kg}$ of copper and $4.61 \mathrm{~kg}$ of arsenic into the system. The facility produced over $58,707,273 \mathrm{~kg}$ of compost (wet weight) from all of the inputs. If we use a $50 \%$ moisture content for the compost, then the metal inputs would represent potential increases of 0.119 ppm, $0.077 \mathrm{ppm}$, and $0.079 \mathrm{ppm}$ for $\mathrm{Cr}, \mathrm{Cu}$ and As, respectively. Obviously, the potential impacts of such small inputs would be lost within the inherent variability of other material inputs such as the components of the food compost (for example, some seafoods contain elevated levels of arsenic). The results illustrate the minimal impact of treated wood on either combustion or composting of the incoming material at the Oregon site. A comparative operation in Florida where the treated wood input was estimated to be 39 times higher would increase metal levels in the resulting compost by 4.6, 3.0 and 3.1 ppm respectively. There are limited publically available data on metal levels in compost from facilities such as these, but a survey of Florida composting operations suggests that these inputs would not markedly alter the metal levels in the compost [11]. Some Florida soils have extremely low metal levels and these concentrations would certainly have the potential to increase overall soil metal levels if 
compost were repeatedly used on the same site; however, these inputs would likely be balanced by plant uptakes. It is important to note that these levels would still be well below those found in soils from most other locations in North America.

\section{Preventing contamination of recycled wood}

The volumes of treated wood entering the facility we surveyed were 1.9 to $4 \%$ of those found at other sites. Furthermore, the levels have actually declined slightly over the past decade.The reasons for the decline are unclear since the facility made no specific effort to exclude materials. While attempts should be made to divert as much of this material as possible from the recycling stream and into a lined landfill, it is obvious that there is a far greater need to accomplish this at the other sites.

Diverting this material; however, is problematic because most of those disposing treated wood materials are homeowners or small contractors who have little basic knowledge about wood treatments. While end-tags on most treated lumber do warn against burning the product, few read these tags and most of the tags are no longer on the wood at the end of its service life. Thus, recycling facilities need to consider alternative methods. Detection at the recycling center would be ideal because it would eliminate the need for consumers to be aware of proper disposal. However, this approach requires that the material be processed so that every piece of wood can be examined. In the case of the Oregon facility, the chipper is mobile and has a relatively short conveyor system that would make it difficult to assess every piece of wood. Even when assessment is possible, problems arise because of the difficulty in sorting individual samples. A number of approaches have been examined for detecting wood treated with waterborne preservatives which would most likely be present in a recycling stream. As mentioned earlier, metal treated wood in many locations tends to weather to a greyish colour that makes it virtually indistinguishable from weathered non-treated wood. Thus, visual detection is likely to be very inaccurate except where other factors, such as the use of dyes or incising in the western U.S. make the wood more recognizable. Nearly all of these systems are copper-based and there are several very sensitive indicators that might be useful. These indicators would have to be sprayed on all of the wood pieces in order to be used. That would require sizable quantities of indicator and some time for the reaction to become evident. This would make it difficult to apply in an industrial environment. There are similar indicators capable of detecting arsenic but these systems would suffer from the same problems. These indicators would also not be suitable for newer materials entering the waste stream, since arsenic based systems were phased out of the residential market in 2003 and will therefore represent an ever-decreasing percentage of the treated material of potential concern.

Heavy metals can also be detected using x-ray technologies, notably x-ray fluorescent spectroscopy $(\mathrm{XRF})$. XRF is widely used in quality control programs for assessing the amounts of copper, zinc, arsenic and chromium in preservative treated wood. It is fairly sensitive to low levels of metal and preliminary studies indicate that the method even detected residual metals in wood through surface coatings $[12,13]$; however, it does use ionizing radiation and most 
current systems use x-ray tubes that may be somewhat fragile for operations within an industrial environment with a great deal of contamination. These are, however, technical issues that could be overcome if there were sufficient levels of treated wood in a waste stream. At present, routine $x$-ray screening for the presence of treated wood is probably not feasible or economical given the low value of the resulting compost or biomass chips.

An emerging technology for sorting treated wood is laser induced breakdown spectroscopy (LIBS), which uses a laser beam to degrade a segment of the wood surface to produce plasma. The wavelength of the emission from this plasma flash can be characterized spectroscopically to detect the presence of specific elements of interest. This system can also detect coatings, including those with lead based paints, and, if additional pulses are used, can remove the surface coating to detect a preservative underneath [12]. However, each additional laser pulse adds to the time required to assess each sample, thereby slowing production. The system is also sensitive to moisture, which requires additional laser pulses. This technology, while promising, would require additional research to more fully develop it for this application and is probably not feasible given the relatively low value of the resulting products.

While these technologies have the potential to remove treated wood from the recycling stream, they are less efficient because they operate at the end of the disposal path and must, therefore process large quantities of material that do not contain any treatment. Most of these techniques require additional employees or a substantial investment in sophisticated equipment. This renders such approaches inherently inefficient and costly. It is not clear that such approaches would be necessary in cases where the levels of treated wood present are low.

A far better approach to minimizing the presence of treated wood in the recycling stream would be prevention. It is not practical for haulers to remove treated wood during collection. Most haulers have nearly fully automated collection, making it extremely difficult and unsafe to attempt to remove specific contaminants during collection. However, it is possible to begin an education process for homeowners and contractors to make them more aware of the proper disposal of treated wood. For example, many haulers send notices to customers, either in conjunction with their monthly bills or as separate newsletters. These could provide venues for a gradual education of the customer base concerning disposal of treated wood. Publically operated haulers can use their local government newsletters for the same purpose. Most consumers are willing to take positive steps for the environment, provided they are not too onerous. Placing waste in different containers should fit within this arena. Informing customers about the reasons for these efforts may require a bit of education about what treated wood is and why it does not belong in the recycling bin. This would need to be coupled with regular reminders and education as the customer base changes. It may also be useful to educate contractors about proper disposal of decking removed during renovations and to prepare any information in multiple languages in recognition that many employees do not speak English as their first language.

At the same time, where facilities allow customers to drop off materials, creating signage about sorting treated wood could help better inform facility users. In addition, creating a space where customers can drop off material inadvertently mixed into their waste will reduce the need 
to"sneak" materials. While these efforts are unlikely to eliminate treated wood from the recycling stream, they can reduce the incidence to the point where it does not pose a risk to the final product.

One longer term concern about the incidence of treated wood in the recycling stream will be the gradual introduction of non-metal based systems, particularly for above ground application such as decking. These so-called "organic" preservatives are just emerging in the market and require much more sophisticated instrumentation to detect in treated wood. Most cannot be detected visually or through the use of chemical indicators. In some cases, traces of metals or boron to overcome the problem of using indicators to detect these components; however, it is unclear whether these materials will remain for long periods in the treated products. On the positive side, many of these preservative systems are more rapidly degraded in soil and should not pose a risk of long term accumulation. Some of these systems can also be burned provided the proper temperatures are maintained to ensure complete thermal destruction.

\section{Conclusions}

Treated wood appears to be a consistent presence in the recycled wood stream. Ideally, systems would be developed to sort and exclude this material; however, the low value of the resulting wood makes it difficult to justify the costs for sophisticated instrumentation required to accurately distinguish between treated and non-treated wood. The relatively small amounts present at some facilities also make it difficult to justify major capital expenses to remove a minor contaminant. Continuing customer education appears to have the greatest potential for reducing the amounts of treated wood entering the waste stream and can be accomplished with minimal cost.

\section{Author details}

Jeffrey J. Morrell

Address all correspondence to: jeff.morrell@oregonstate.edu

Department of Wood Science \& Engineering, Oregon State University, Corvallis, OR, USA

\section{References}

[1] Falk, B. 1997. Wood recycling: opportunities for the woodwaste resource. Forest Products Journal 47(6):17-22. 
[2] Reinhart, D., A. Behzadan, and M.S. Toth. 2011. Construction and demolition debris recovery and recycling. Final Report 61038054, Hinkley Center for Solid and Hazardous Waste Management, Gainesville Florida. 57 p.

[3] Townsend, T. 1998. Characterization of recovered screened material form a C\&D recycling facility in Florida. Final Report 98-13, Hinkley Center for Solid and Hazardous Waste Management, Gainesville Florida. 47 p.

[4] Anonymous. 2014. Coffin Butte Landfill and Pacific Region Compost: Annual Report 2013. Republic Services, Corvallis, OR.

[5] American Wood Protection Association. 2012a. Standard U1-08. Use Category System: User Specification for Treated Wood. AWPA Annual Book of Standards, AWPA, Birmingham, Alabama.

[6] American Wood Protection Association. 2012b. Standard A12. Wood densities for preservative calculations by standards. In: AWPA Annual Book of Standards. AWPA, Birmingham, Alabama.

[7] Panshin, A.J. and C. deZeeuw. 1980. Textbook of Wood Technology. McGraw-Hill Book Co. New York, NY. 705 p.

[8] Solo -Gabriele, H., T. Townsend, and D. Hahn. 2003. Sorting technologies for CCAtreated wood waste. In: Proceedings Managing the Treated wood Resource. American Wood Preservers Association Boston, MA.

[9] Alderman, D.R., Jr. and R.L. Smith. 2000. Solid wood received and marketed by Virginia landfill facilities. Forest Products Journal 50(6):39-44.

[10] Morrell, J.J. 2010. Occurrence of preservative-treated wood in a wood recovery center in Western Oregon. Forest Products Journal 60(1):23-26.

[11] Ma, L. and U. Saha. 2009. Chemical characterization of yard waste in Florida. Final Report, Hinkley Center for Solid and Hazardous Waste Management, Gainesville Florida. 56 p.

[12] Solo-Gabriele, H., A. Omae, T. Townsend, and D.Hahn. 2006. Identification of wood treated with waterborne metal-based preservatives. Chapter 18. In: Environmental impacts of treated wood. T.G. Townsend and H. Solo-Gabriele, Ed.) Taylor and Francis, CRC Press, Boca Raaton, FL. Pages 329-347.

[13] Solo-Gabriele, H., T. Townsend, J. Penmha, T. Tolayman, and V. Calitu. 1999. Disposal-end management of treated wood. In: American Wood Preservers' Association Proceedings 95:65-74. 


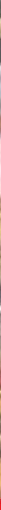

\section{Edited by Dimitris S. Achilias}

Reducing the amount of solid wastes in landfills is one of the main targets in nowadays wastes treatment. To this direction, there is a great need in finding of smart recycling techniques which should, as is possible, to be environmentally friendly. The intention of this book is to present some recent methods for the recycling of several materials, including plastics and wood, as well as to show the importance of composting of polymers. It targets professionals, recycling companies, researchers, academics and graduate students in the fields of waste management and polymer recycling in addition to chemical engineering, mechanical engineering, chemistry and physics. This book comprises 5 chapters covering areas such as, recycling of polystyrene, polyesters, PC, WEEE and wood waste, together with compostable polymers and nanocomposites. 